\title{
Reconnaissance of Land-Use Sources of Pesticides in Drinking Water, McKenzie River, Oregon
}

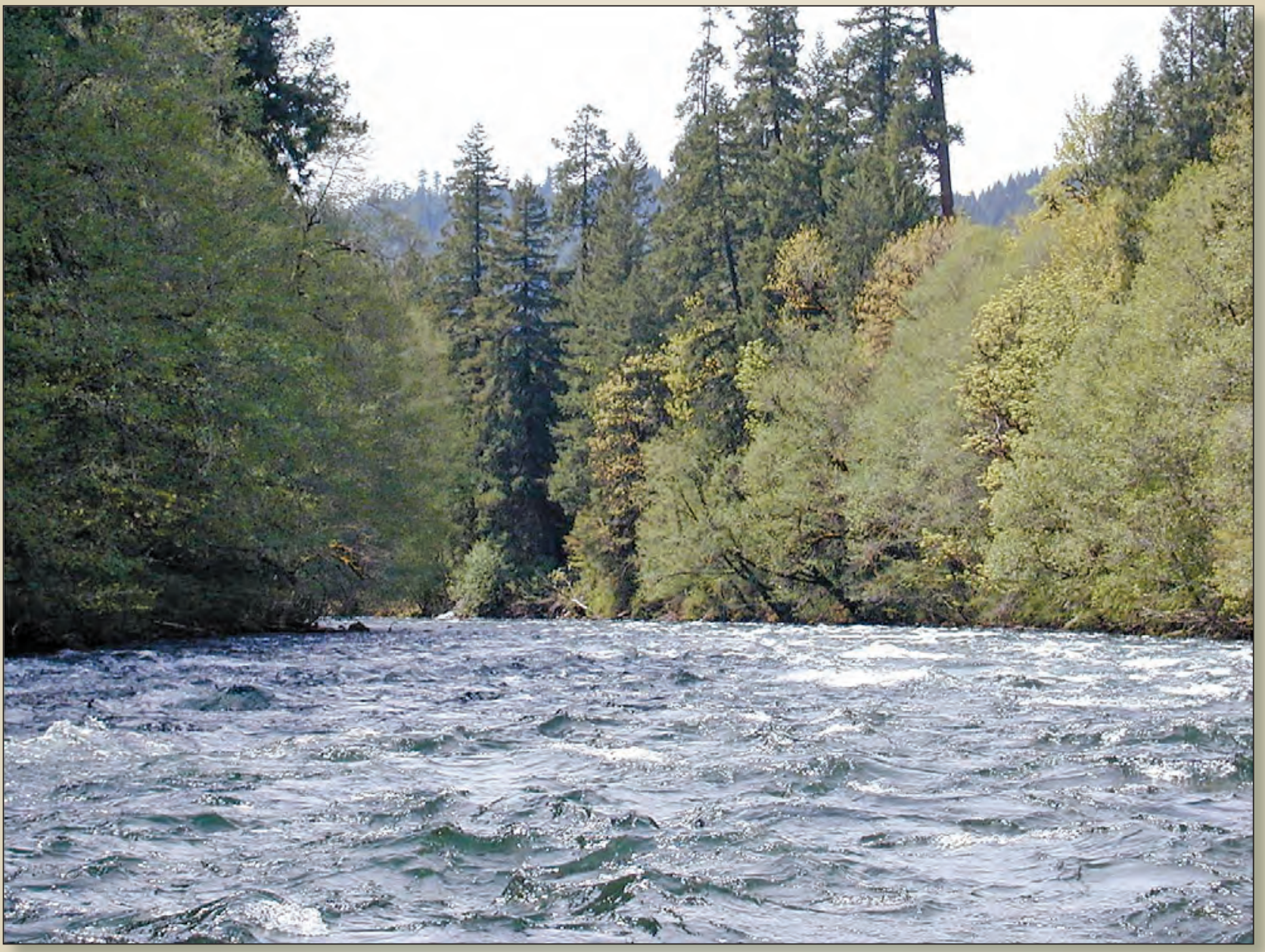

Scientific Investigations Report 2012-5091 



\section{Reconnaissance of Land-Use Sources of Pesticides in Drinking Water, McKenzie River, Oregon}

By Valerie J. Kelly and Chauncey W. Anderson, U.S. Geological Survey, and Karl Morgenstern, Eugene Water and Electric Board

Prepared in cooperation with Eugene Water and Electric Board

Scientific Investigations Report 2012-5091 


\title{
U.S. Department of the Interior \\ KEN SALAZAR, Secretary \\ U.S. Geological Survey \\ Marcia K. McNutt, Director
}

\author{
U.S. Geological Survey, Reston, Virginia: 2012
}

For more information on the USGS - the Federal source for science about the Earth, its natural and living resources, natural hazards, and the environment, visit http://www.usgs.gov or call 1-888-ASK-USGS.

For an overview of USGS information products, including maps, imagery, and publications, visit http://www.usgs.gov/pubprod

To order this and other USGS information products, visit http://store.usgs.gov

Any use of trade, product, or firm names is for descriptive purposes only and does not imply endorsement by the U.S. Government.

Although this report is in the public domain, permission must be secured from the individual copyright owners to reproduce any copyrighted materials contained within this report.

Suggested citation:

Kelly, V.J., Anderson, C.W., and Morgenstern, Karl, 2012, Reconnaissance of land-use sources of pesticides in drinking water, McKenzie River, Oregon: U.S. Geological Survey Scientific Investigations Report 2012-5091, 46 p. 


\section{Contents}

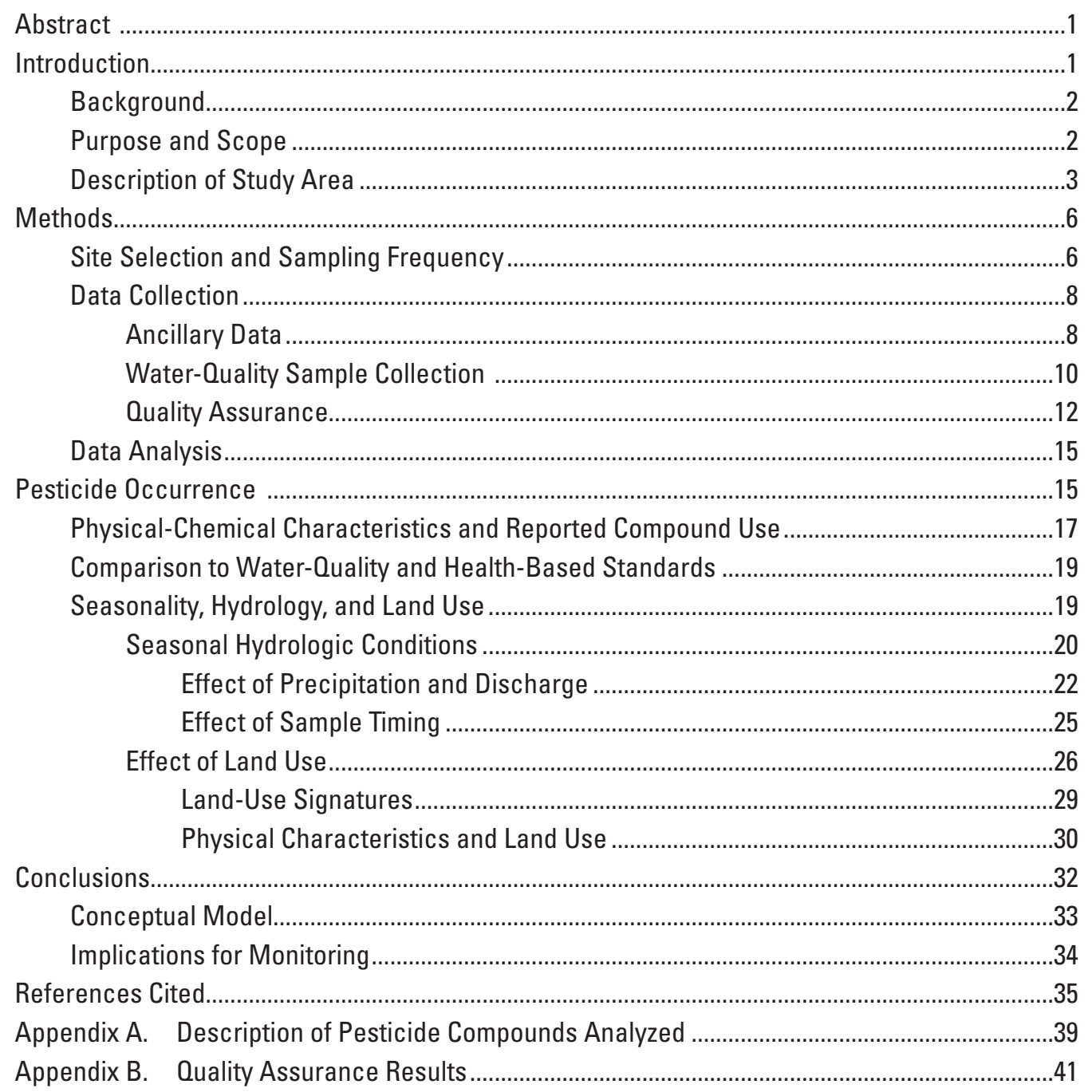




\section{Figures}

Figure 1. Map of study area, including sampling sites and precipitation gages,

McKenzie River basin, Oregon

Figure 2. Graph showing daily streamflow for the McKenzie River above Hayden Bridge and at outlet of Clear Lake, McKenzie River basin, Oregon, 2007-10

Figure 3. Graph showing mean monthly precipitation in the middle and lower McKenzie River basin, Oregon, 1961-90.

Figure 4. Graph showing streamflow stage and sample aliquot collection at Cogswell Creek, McKenzie River basin, Oregon, fall 2005.

Figure 5. Graph showing pesticide concentrations detected during seasonal surveys in the McKenzie River basin, Oregon, 2002-10

Figure 6. Graphs showing daily precipitation and sample collection, McKenzie River basin, 2002-10

Figure 7. Graphs showing pesticide concentrations by major land-use category, McKenzie River basin, Oregon

Figure 8. Graph showing total concentrations for detected pesticide compounds by season and land use, McKenzie River basin, Oregon

Figure 9. Graphs showing physical characteristics for pesticide compounds detected at specific sample sites, McKenzie River basin, Oregon

\section{Tables}

Table 1. Precipitation gages and stations sampled for pesticides in the McKenzie River basin, Oregon, 2002-10

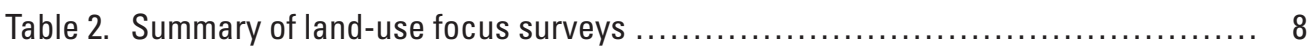

Table 3. Guidelines for interpretation of Benchmark Quotients ...................... 9

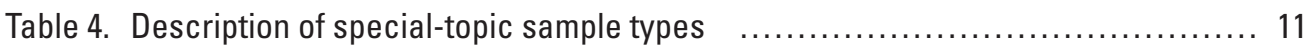

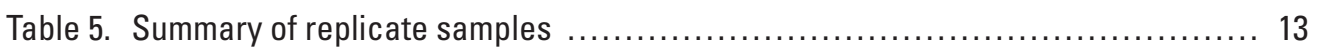

Table 6. Maximum concentration and detection frequency for all compounds detected ... 16

Table 7. Physical-chemical characteristics and categories of land use for detected compounds and compounds reported to be used but never detected ............ 18

Table 8. Benchmark quotients for compounds detected at source water for the Eugene Water and Electric Board drinking water facility ............................ 20

Table 9. Number of analyte/pesticide detections for different land use sites by season $\ldots 20$

Table 10. Correlation results for analysis of total concentration and number of pesticides detected (as proportion of analyses conducted) with precipitation sums from 7 days prior to sample collection ......................................... 22

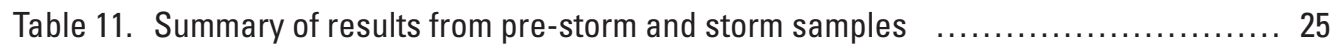

Table 12. Summary of results from sampling over different regions of the storm hydrograph

Table 13. Detected compounds at Cedar and Camp Creeks, McKenzie River basin, Oregon 


\section{Conversion Factors, Datum, and Abbreviations}

Inch/Pound to SI

\begin{tabular}{lcl}
\hline \multicolumn{1}{c}{ Multiply } & \multicolumn{1}{c}{ By } & \multicolumn{1}{c}{ To obtain } \\
\hline & Length & \\
\hline foot $(\mathrm{ft})$ & 0.3048 & meter $(\mathrm{m})$ \\
mile $(\mathrm{mi})$ & 1.609 & kilometer $(\mathrm{km})$ \\
yard $(\mathrm{yd})$ & 0.9144 & meter $(\mathrm{m})$ \\
\hline & Flow rate & \\
\hline cubic foot per second $\left(\mathrm{ft}^{3} / \mathrm{s}\right)$ & 0.02832 & cubic meter per second $\left(\mathrm{m}^{3} / \mathrm{s}\right)$ \\
\hline
\end{tabular}

Vertical coordinate information is referenced to the North American Vertical Datum of 1988 (NAVD 88).

Horizontal coordinate information is referenced to the North American Datum of 1983 (NAD 83).

Altitude, as used in this report, refers to distance above the vertical datum.

Concentrations of chemical constituents in water are given either in milligrams per liter ( $\mathrm{mg} / \mathrm{L}$ ) or micrograms per liter $(\mu \mathrm{g} / \mathrm{L})$.

Abbreviations

EWEB Eugene Water and Electric Board

GIS Geographic information systems

HBSL Health-based screening levels

HPLC High performance liquid chromatography

LRL Labortory reporting level

LT-MDL Long-term detection limit

MCL Maximum contaminent levels

NWQL National Water Quality Laboratory

PAN Pesticide Action Network

RAWS Remote automated weather station

USEPA U.S. Environmental Protection Agency

USGS U.S. Geological Survey 
This page intentionally left blank. 


\title{
Reconnaissance of Land-Use Sources of Pesticides in Drinking Water, McKenzie River Basin, Oregon
}

\author{
By Valerie J. Kelly and Chauncey W. Anderson, U.S. Geological Survey, and Karl Morgenstern, Eugene Water \\ and Electric Board
}

\section{Abstract}

The Eugene Water and Electric Board (EWEB) provides water and electricity to the City of Eugene, Oregon, from the McKenzie River. In the spring of 2002, EWEB initiated a pesticide monitoring program in cooperation with the U.S. Geological Survey as part of their Drinking Water Source Protection Plan. Approximately twice yearly pesticide samples were collected from 2002 to 2010 at a suite of sampling sites representing varying land uses in the lower McKenzie River basin. A total of 117 ambient samples were collected from 28 tributary and mainstem sites, including those dominated by forestry, urban, and agricultural activities, as well as the mouths of major tributaries characterized by a mixture of upstream land use. Constituents tested included 175 compounds in filtered water ( 72 herbicides, 43 insecticides, 10 fungicides, and 36 of their degradation products, as well as 14 pharmaceutical compounds). No attempt was made to sample different site types equivalently; sampling was instead designed primarily to characterize representative storm events during spring and fall runoff conditions in order to assess or confirm the perceived importance of the different site types as sources for pesticides. Sampling was especially limited for agricultural sites, which were only sampled during two spring storm surveys.

A total of 43 compounds were detected at least once, with many of these detected only at low concentrations (<0.1 micrograms per liter). Nine compounds were detected at the drinking- water intake, and most of these were reported as estimates less than the laboratory reporting level. Humanhealth benchmark concentrations were consistently several orders of magnitude higher than detected concentrations at the intake, indicating that pesticide concentrations present a negligible threat to human health.

The largest number of pesticide detections occurred during spring storm surveys and primarily were associated with urban stormwater drains. Urban sites also were associated with the highest concentrations, occasionally exceeding 1 microgram per liter. Many of the compounds detected at urban sites were relatively hydrophobic (do not mix easily with water), persistent, and suspected of endocrine disruption. In contrast, forestry compounds were rarely detectable in the McKenzie River, even though forest land predominates in the basin and forestry pesticide use was detected in small tributaries draining forested lands following application. Agricultural pesticide runoff was not well characterized by the limited data available, although a large number of compounds was estimated to be used in the basin and concentrations were moderately high in the few samples collected from small tributaries draining agricultural lands.

Results from this analysis indicate that urban pesticide use is potentially an important source for pesticides of concern for drinking water, not limited exclusively to storm conditions. Forestry pesticide use is not considered a likely threat to drinking water quality at the present time (2012). A more complete understanding of agricultural chemicals in runoff in the McKenzie River basin requires further investigation.

In addition to evaluating the data collected in this study, a conceptual model describing pesticide contamination in the McKenzie River basin is provided, based on current scientific understanding that is consistent with the data analysis presented in this report. This model is intended to provide a foundation for future monitoring in the basin.

\section{Introduction}

Nearly 20,000 to more than 40,000 pounds of active ingredient pesticides, including insecticides, herbicides, rodenticides, and fungicides, were reportedly used in Oregon during 2007 and 2008 to control a wide variety of insects, weeds, rodents, and fungi (Oregon Department of Agriculture, 2008, 2009). These compounds included approximately 550-570 different active ingredients. Most pesticides were reportedly used on agricultural crops, with other major use categories including urban and residential applications on home gardens, lawns, golf courses, and commercial landscaping, as well as site preparation following logging, and along roads and other rights-of-way. The movement of water is an important mechanism for the transport of pesticides from where they are applied to other components of the environment (Larson and others, 1997). Consequently, this kind of extensive pesticide use increases the potential for contamination of hydrologic systems, especially surface water. 
Monitoring of pesticides by the U.S. Geological Survey (USGS) throughout the conterminous United States has found widespread occurrence of pesticides in streams and rivers, particularly in developed areas, but also in predominantly undeveloped drainage basins (Larson and others, 1997; Gilliom and others, 2006). Pesticide studies by the USGS and others in Oregon have focused primarily on the Willamette Valley and show that a large number of pesticide compounds occur in streams and are most pronounced during periods of high runoff during spring and fall (Anderson and others, 1996, 1997; Rinella and Janet, 1997; Wood, 2001; Field and others, 2003; Rupp and others, 2006). The fate of these chemicals is largely controlled by prevailing environmental conditions that govern water transport, particularly precipitation that leads to runoff following application, and the physical properties of the individual compound that influence its persistence or how it partitions between different environmental media, such as water and sediment (Mackay and others, 1997). Other factors related to pesticide transport that are not dealt with in this study include the chemical formulation and method of application. Additionally, most pesticide products contain adjuvants or ingredients that are considered to be inert, acting only to increase the effectiveness of the active ingredient. Even though some of these compounds may have health consequences (Gilliom and others, 2006), they were not included in this analysis and will not be addressed in this report.

Many pesticide compounds and their degradation products are known to have adverse effects on human health and aquatic life. These compounds and products are of particular concern when they impact sources of drinking water, because many organic compounds are unaffected by conventional drinking-water treatment (Coupe and Blomquist, 2004; Stackelberg and others, 2004). Given sufficient understanding of pesticide occurrence patterns, drinking-water treatment can be augmented when necessary by advanced treatment, such as activated carbon to remove dissolved organic chemicals. Alternatively, management strategies can be targeted toward decreasing pesticide loading from specific land-use applications that have been determined to degrade the quality of public drinking water. This study provides a foundation for these kinds of source protection activities by characterizing the occurrence of pesticides and other organic compounds in the McKenzie River, a tributary to the Willamette River in the southern Willamette Valley that serves as the sole source of drinking water for the City of Eugene, Oregon. This assessment is complementary to, and not a substitute for, required monitoring of drinking-water quality by Federal, State, and local programs that focus on post-treatment compliance monitoring.

\section{Background}

The Eugene Water and Electric Board (EWEB) is the municipal utility that provides water and electricity to the City of Eugene, Oregon, from the McKenzie River. The McKenzie River has a history of providing drinking water of excellent quality (Alsea Geospatial and others, 2000). To better understand the potential threats to the high quality of water in the McKenzie River, EWEB developed and approved a Drinking Water Source Protection Plan in 2000 (Blair, 2000). This plan was implemented in 2001, and a comprehensive monitoring plan was developed to identify contaminant sources that could adversely affect water quality in the McKenzie River. In 2002, EWEB entered into an agreement with the USGS to design and initiate the pesticide component of their monitoring plan. Beginning in spring 2002 and continuing through spring 2010, approximately twice yearly pesticide samples have been collected in a reconnaissance or exploratory mode, primarily under spring and autumn storm runoff conditions at a suite of sampling sites representing varying land uses in the lower McKenzie River basin. This report describes the results of this reconnaissance study and focuses on relating detected pesticide concentrations to seasonal and dominant land-use characteristics in the basin.

\section{Purpose and Scope}

The purpose of this report is to identify land-use sources of pesticides in the McKenzie River basin to support source reduction efforts made by EWEB to protect drinking water quality. The approach includes the following objectives: (1) to describe the occurrence of pesticides in the McKenzie River at the EWEB drinking-water intake, as well as in selected small streams and stormwater conveyances that reflect specific categories of land use; (2) to identify the seasonal and climatological factors that are associated with those patterns; and (3) to characterize the relationship between observed pesticide patterns and land use. A particular emphasis is placed on determining if any tributaries or specific land use present a greater threat to drinking water quality in order to more effectively focus future monitoring activity as well as guide the development of management strategies to reduce pesticide runoff. Physical and chemical characteristics of compounds are evaluated to provide insight into compound persistence and likely modes of transport. Concentrations of detected compounds are compared to the U.S. Environmental Protection Agency (USEPA) Maximum Contaminant Levels (MCLs) or USGS Health-Based Screening Levels (HBSLs) to assess known or suspected threats to human health from drinking water. This report also assesses the potential threat of endocrine disruption from detected compounds. Results are synthesized with current findings from other studies 
to generate a conceptual model of pesticide transport in the basin, which essentially represents a set of hypotheses to be evaluated with future data collection. The report concludes with a description of a possible direction for further monitoring that can effectively verify and refine the conceptual model.

The analyses in this report include data from 16 different sampling events conducted during 2002-10, encompassing a total of 117 ambient samples collected from 28 tributary and mainstem sites. Although the study area for EWEB's drinking water source protection plan includes the entire McKenzie River basin upstream of the treatment facility, data collection for this project focused on sites downstream of Blue River. Sampling sites were selected to represent specific land-use categories, including forestry, urban, and agricultural activities, as well as the mouths of major tributaries characterized by a mixture of upstream land use. Constituents included a suite of 175 compounds in filtered water, including 72 herbicides, 43 insecticides, 10 fungicides, and 36 of their degradation products, as well as 14 pharmaceutical compounds. The term "pesticide" is used generically in this report to refer to any of the herbicide, insecticide, fungicide, or metabolite compounds.

\section{Description of Study Area}

The McKenzie River is located in western Oregon and has a drainage basin of approximately $1,300 \mathrm{mi}^{2}$ that is bounded on the west by the southern Willamette Valley and on the east by the Cascade Range (fig. 1). The river originates at the crest of the Cascades and flows south and west for about $90 \mathrm{mi}$ to the confluence with the Willamette River near Eugene and Springfield, Oregon. The headwaters are located in the High Cascades physiographic province, which largely comprises young and highly porous volcanic material and represents approximately 24 percent of the basin (Tague and Grant, 2004). Downstream of the confluence with Blue River, the McKenzie River flows into the Western Cascades physiographic province (about 58 percent of the basin), which is much less permeable than the High Cascades (Tague and Grant, 2004). This region is characterized by steeply dissecting streams and relatively narrow canyons (Risley and others, 2010). In the lower McKenzie River basin, the river drains Quaternary alluvium (about 18 percent of the basin) where the river widens, and agriculturally productive soils are found along the valley bottom (Sherrod and Smith, 2000).

Hydrologic characteristics vary across these geologic provinces so that they represent distinct regions of potential contaminant sources in the McKenzie River basin. The upper McKenzie River is fed by many large springs discharging large quantities of groundwater fed by snowmelt, and consequently a large volume of steady, year-round baseflow is discharged from the High Cascades region at high altitudes. Streamflow farther downstream is dominated by runoff from local precipitation events. Daily streamflow for the McKenzie River at the outlet of Clear Lake (located outside the study area at river mile 92.4) shows little variability throughout the year, while flows for the McKenzie River above Hayden Bridge (site 5) reflect runoff from winter storms as well as snowmelt in late spring (fig. 2).

Climate in the McKenzie River basin is wet and cool during the winter, and dry and warm during the summer. Mean annual precipitation (1961-90) in the study area ranges from about $50 \mathrm{in}$. near the river mouth to $65 \mathrm{in}$. at high altitudes, about 90 percent of which occurs between October and May (fig. 3) (Western Regional Climate Center, 2010). Local topography generates considerable microclimatic variability within individual storms so that rainfall often falls inconsistently over the area.

Land use in the basin is predominantly forest (about 92 percent). Land ownership is a mixture of private, State, and Federal. Rural and urban residential and industrial neighborhoods are a comparatively small component of drainage basin area (about 4 percent), although these neighborhoods are of concern because they predominate in the lower basin and their associated runoff discharges to the river close to the EWEB intake. Similarly, agricultural activity is of concern because it primarily occurs in the lower basin close to the river and the EWEB intake, even though agricultural lands also represent a small proportion of the drainage basin area (about 2 percent). Pasture and hay for livestock constitute most agricultural production; other crops include filberts, Christmas trees, grass seed, and blueberries (Morgenstern, 2006).

Natural flow patterns in the McKenzie River are influenced to varying degrees by the presence of five dams in the upper basin (outside the study area), as well as another dam and two canal diversions in the middle basin that are operated primarily for hydropower production. Reservoirs in the upper basin include the Carmen Reservoir complex, a hydroelectric project whose outflow is re-regulated by the Trail Bridge Reservoir to mimic inflow patterns. These are run-of-the-river reservoirs with short residence times, and they do not have a significant effect on streamflow patterns. Two Army Corps of Engineers flood control reservoirs (Cougar and Blue River Reservoirs) are located farther downstream, and their combined effect is to decrease peak flows from snowmelt in the spring and augment low flows in summer and fall (Risley and others, 2010). In the middle McKenzie River basin, two canals divert water into small EWEB reservoirs for power generation (Blair, 2000; Risley and others, 2010). 

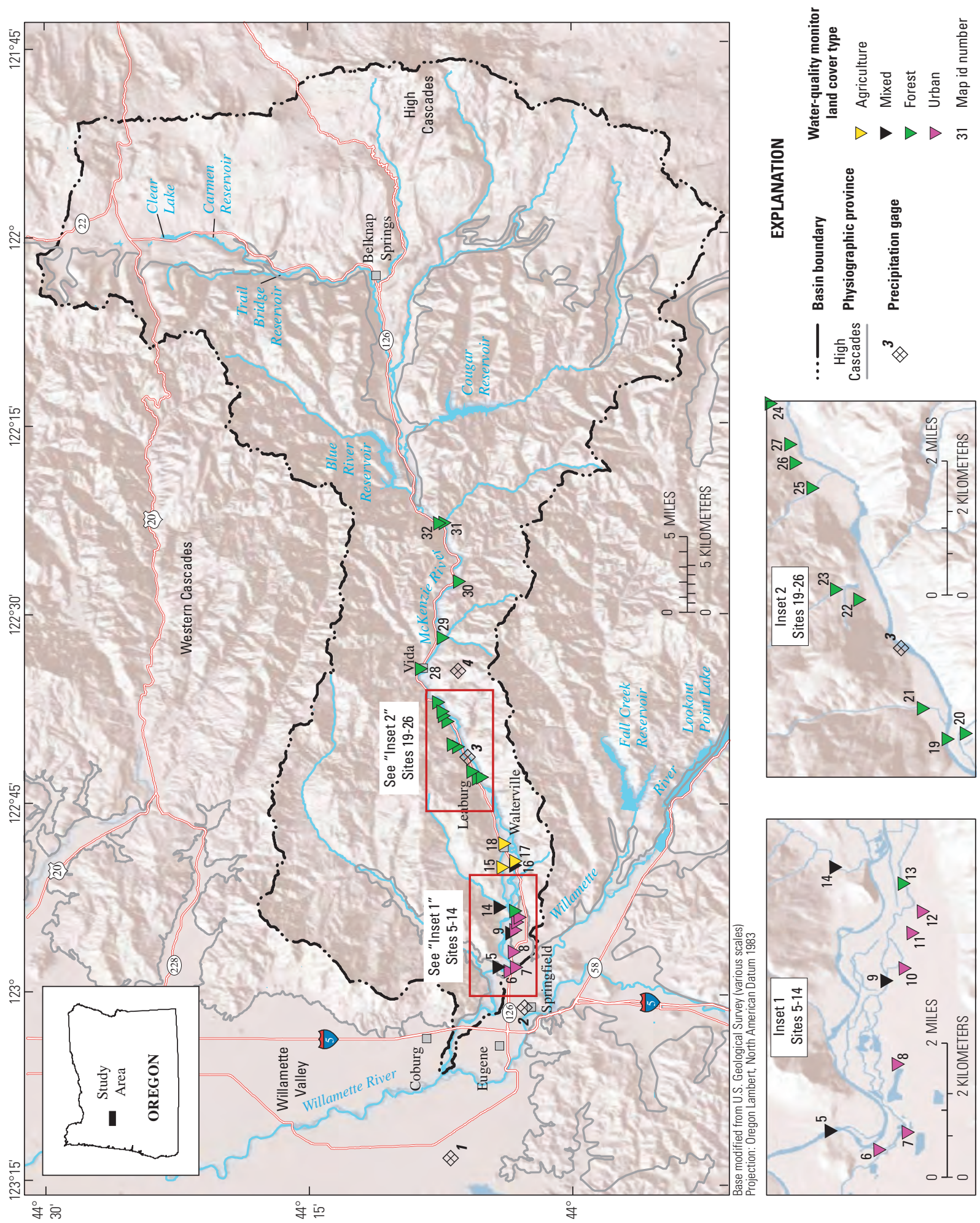

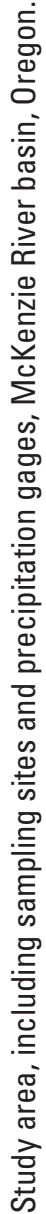

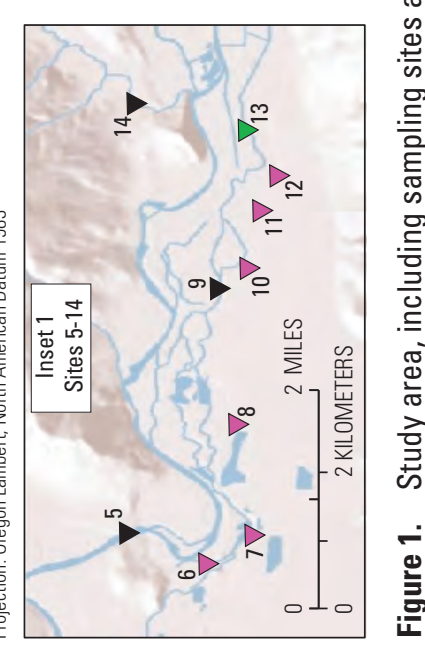




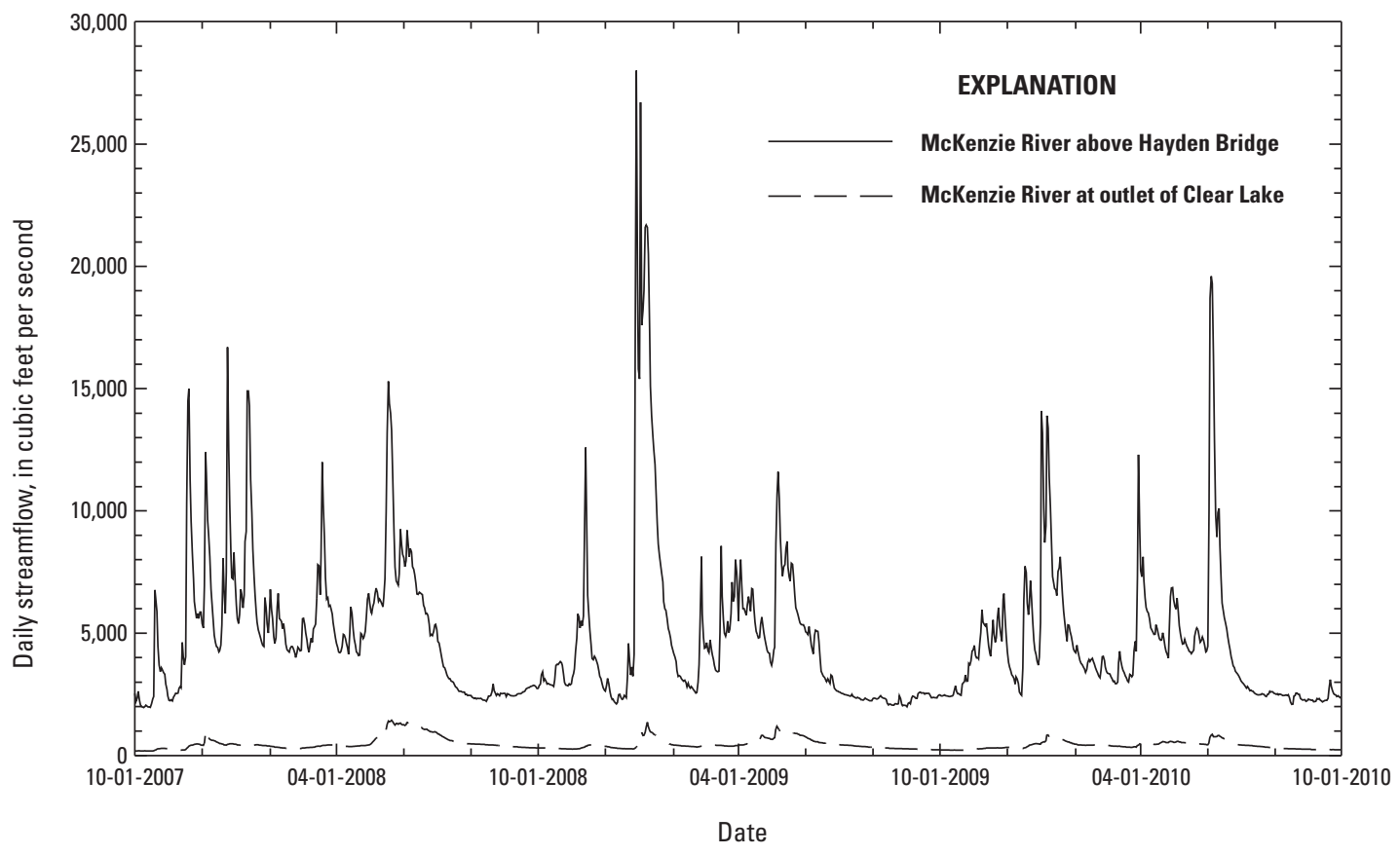

Figure 2. Daily streamflow for the McKenzie River above Hayden Bridge and at outlet of Clear Lake, McKenzie River basin, Oregon, 2007-10.

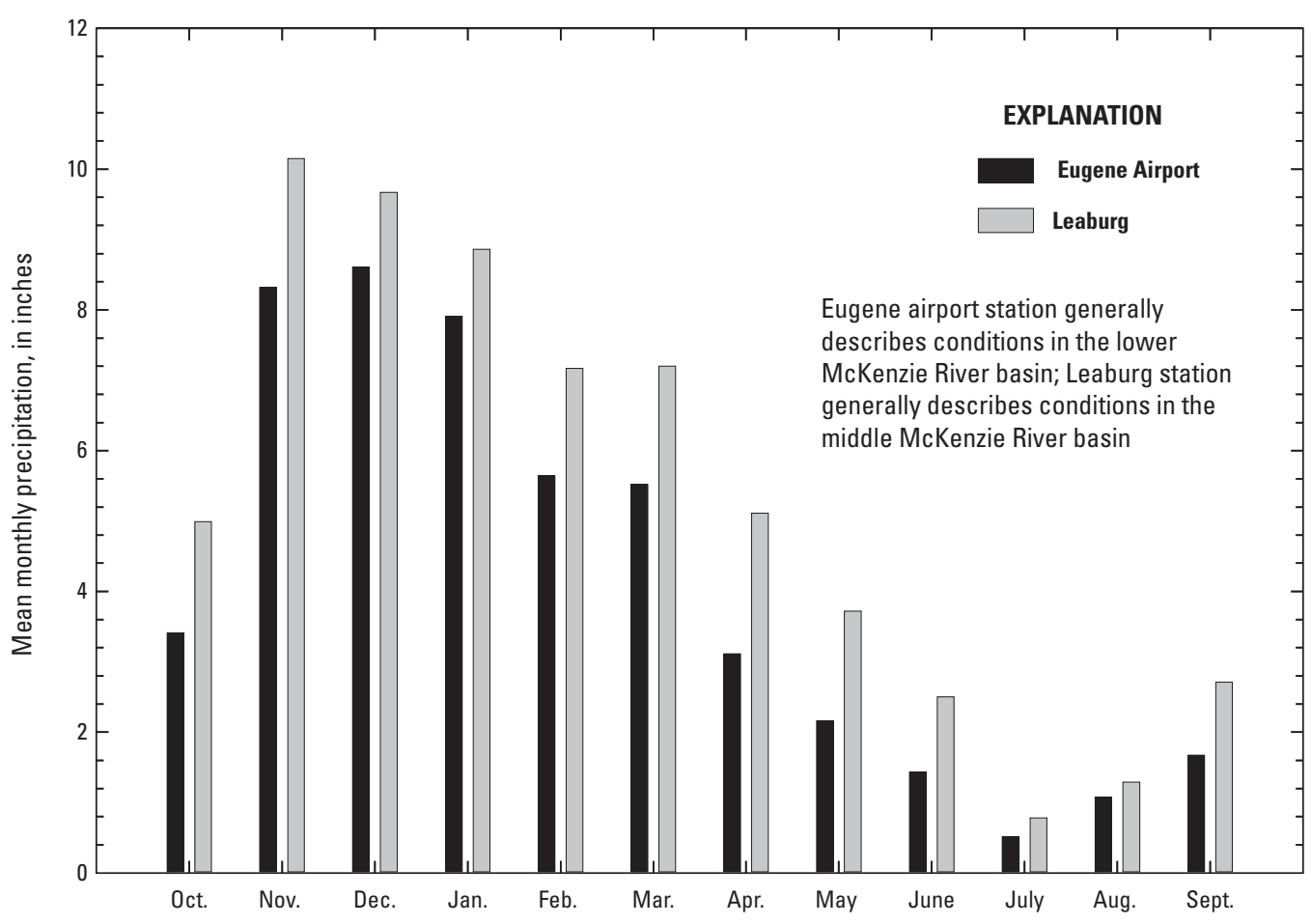

Figure 3. Mean monthly precipitation in the middle and lower McKenzie River basin, Oregon, $1961-90$. 
Reconnaissance of Land-Use Sources of Pesticides in Drinking Water, McKenzie River Basin, Oregon

The first canal near the unincorporated community of Leaburg diverts part of the mainstem river at Leaburg Dam for $5 \mathrm{mi}$ before it is returned to the river through a hydroelectric facility. Farther downstream, the second canal diverts water near the unincorporated community of Walterville for $4 \mathrm{mi}$, where it is again returned to the river for power generation.

In the lower McKenzie River basin, the stream network incorporates the stormwater drainage system of the City of Springfield, which includes five stormwater outfalls that drain either exclusively or occasionally into the McKenzie River. Three of these (at 72nd, 69th, and 64th Streets) empty into Cedar Creek, a major tributary in the lower basin, and collectively represent most of the storm water from the eastern portion of Springfield. A fourth outfall (at 52nd Street) drains into Keizer Slough, which is a slow-moving side channel that discharges to the McKenzie River about 0.25 mi upstream of the EWEB intake upstream of Hayden Bridge. The fifth outfall (at 42nd Street) drains primarily into another series of sloughs and canals that empty into the Willamette River most of the year; during heavy rain, however, it overflows into Keizer Slough.

\section{Methods}

\section{Site Selection and Sampling Frequency}

Based on observed patterns of pesticide occurrence from other Oregon studies (Anderson and others, 1996, 1997; Rinella and Janet, 1997; Wood, 2001; Waite and others, 2006), pesticide surveys were conducted approximately twice yearly during storm runoff in fall and spring, beginning in the fall 2002 through spring 2010. Twenty-four sites that represent one predominant upstream land-use type as determined by EWEB personnel (urban, agricultural, or forestry) were selected from among a total of 28 sites in the mainstem McKenzie River and its tributaries downstream of inflow from the Blue River (table 1). Four additional mixed land-use sites include the mainstem McKenzie River sites at the Hendricks Park boat ramp and above Hayden Bridge (the intake of raw water to the drinking water treatment facility), and sites near the mouths of major tributaries Camp Creek and Cedar Creek that flow into the mainstem of the river in the lower basin. The Hendricks Park site is downstream of EWEB's Walterville Power Canal diversion. Land use in the vicinity includes residential homes along the river, the small community of Walterville, agricultural crops in the valley, and commercial forestlands in the surrounding hills. As such, the Hendricks Park site is representative of the influence of both forestry and agricultural land-use activities, with less impact from urban areas that are more pronounced downstream. The site on Camp Creek represents a small watershed that also is predominantly a mixture of forested and agricultural land use. Sampling sites on Cedar Creek at Springfield and the McKenzie River above Hayden Bridge incorporate a larger amount of urban area and thereby represent a mix of all land-use categories.

No attempt was made to sample different site types equivalently; rather, sampling was designed primarily to characterize representative storm events during spring and fall runoff conditions in order to assess or confirm the perceived importance of the different site types as sources for pesticides. Sites were selected for sampling in a non-fixed design that included both explicitly stormwater/urban and forestry surveys, as well as other surveys focused on a mix of land-use types (table 2). Additionally, winter storm conditions were sampled in 2003 and 2009, and baseline or non-storm samples were collected in spring and summer 2009, and in spring 2010, to investigate the importance of non-runoff periods for pesticide occurrence.

The mixed sites formed the backbone of the sampling strategy, and were sampled most consistently throughout the study period because they represented the largest potential loading to the drinking water source. Because urbanization was perceived as an important degrading influence on drinking water quality, the first five storm surveys in 2002-05 focused primarily on urban sites in addition to the mixed sites. To evaluate the potential influence of forestry management, these urban surveys were followed by two storm surveys in the fall of 2005 and 2006 that focused primarily on forestry sites. Sampling intensity was subsequently reduced to focus only on the mixed sites in 2008, partly as a result of poor runoff conditions, and then expanded to include urban sites in fall 2009, and a comprehensive suite of agricultural, forestry, urban, and mixed sites in the spring of 2009 and 2010. Despite the irregular sampling frequency, the number of non-replicate samples collected to characterize each land use was roughly equivalent for forestry sites $(\mathrm{n}=33)$ and urban sites $(\mathrm{n}=35)$, with slightly more samples associated with mixed sites $(n=45)$; agricultural sites were relatively undersampled $(n=5)$. More forestry samples were collected in the fall $(n=22)$ than in the spring $(\mathrm{n}=10)$, although samples were more evenly distributed for urban sites ( $\mathrm{n}=16$ for fall, $\mathrm{n}=11$ for spring) and mixed sites ( $\mathrm{n}=18$ for fall, $\mathrm{n}=15$ for spring). Agricultural sites were only sampled in the spring. Winter storm samples included forestry $(n=1)$, mixed $(n=5)$, and urban $(n=6)$ sites, and non-storm samples were collected at urban $(\mathrm{n}=1)$ and mixed $(\mathrm{n}=7)$ sites.

As a consequence of the reconnaissance nature of the sampling, and the unpredictable nature of storm sampling in general, there are large differences in the number of samples collected among the sampled sites (table 1). The EWEB intake at the McKenzie River above Hayden Bridge (site 5) was sampled the most frequently. Cedar Creek at Springfield (site 9) and Camp Creek (site 14) also were sampled more frequently because they represent the largest tributaries in 
Table 1. Precipitation gages and stations sampled for pesticides in the McKenzie River basin, Oregon, 2002-10.

[Map No.: Location is shown in figure 1]

\begin{tabular}{|c|c|c|c|c|}
\hline $\begin{array}{l}\text { Map } \\
\text { No. }\end{array}$ & Station or site No. & Site name & $\begin{array}{l}\text { Dominant } \\
\text { land use }\end{array}$ & $\begin{array}{c}\text { Number of } \\
\text { samples }\end{array}$ \\
\hline \multicolumn{5}{|c|}{ Precipitation gages } \\
\hline 1 & NA & Eugene airport & NA & \\
\hline 2 & NA & Springfield City Hall & NA & \\
\hline 3 & NA & Leaburg & NA & \\
\hline 4 & NA & Trout Creek & NA & \\
\hline \multicolumn{5}{|c|}{ Sampling stations } \\
\hline 5 & 14164900 & McKenzie River above Hayden Bridge, at Springfield & Mixed & 14 \\
\hline 6 & 440339122580800 & Keizer Slough at SUB Bridge, Springfield & Urban & 7 \\
\hline 7 & 440317122574900 & 42nd Stormwater culvert at Weyco, Springfield & Urban & 5 \\
\hline 8 & 440325122563600 & 52nd Stormwater channel at Highway 126, Springfield & Urban & 6 \\
\hline 9 & 14164700 & Cedar Creek at Springfield & Mixed & 11 \\
\hline 10 & 440320122545300 & 64th Stormwater pipe at TMS, Springfield & Urban & 4 \\
\hline 11 & 440314122541500 & 69th Stormwater channel at Thurston Road, Springfield & Urban & 6 \\
\hline 12 & 440306122535200 & 72nd Stormwater culvert atThurston Road, Springfield & Urban & 4 \\
\hline 13 & 440321122532200 & Cedar Creek at Billings Lane Bridge, Springfield & Forestry & 5 \\
\hline 14 & 14164550 & Camp Creek at Camp Creek Road Bridge, Springfield & Mixed & 10 \\
\hline 15 & 440405122495600 & Unnamed tributary to Walterville Canal at Camp Creek Road & Agriculture & 1 \\
\hline 16 & 440322122494600 & McKenzie River at Hendricks Park Boat Ramp, Springfield & Mixed & 5 \\
\hline 17 & 440321122492600 & Unnamed creek near Walterville at Hendricks Park & Agriculture & 1 \\
\hline 18 & 440359122480300 & Unnamed tributary to McKenzie River near Walterville culvert & Agriculture & 1 \\
\hline 19 & 440530122425500 & McKenzie River at Holden Creek Road Bridge, near Leaburg & Forest & 2 \\
\hline 20 & 440516122424900 & Haagen Creek at Deerhorn Road Bridge, near Deerhorn & Forest & 1 \\
\hline 21 & 440549122422200 & Holden Creek at McKenzie Highway, near Leaburg & Forest & 4 \\
\hline 22 & 440638122402500 & EWEB Power Canal downstream of Johnson Creek, near Leaburg & Forest & 2 \\
\hline 23 & 440656122401400 & Johnson Creek at EWEB Power Canal, near Leaburg & Forest & 3 \\
\hline 24 & 440746122365400 & EWEB Power Canal at Mountain View Lane Bridge, near Leaburg & Forest & 2 \\
\hline 25 & 440714122382500 & Cogswell Creek at EWEB Power Canal, near Leaburg & Forest & 2 \\
\hline 26 & 440727122375800 & Ward Creek at Canal Lane, near Leaburg & Forest & 2 \\
\hline 27 & 440731122373800 & Montgomery Creek at McKenzie Highway, near Leaburg & Forest & 2 \\
\hline 28 & 14163000 & Gate Creek at Vida & Forest & 1 \\
\hline 29 & 440731122314800 & Marten Creek at Goodpasture Road Bridge, near Leaburg & Forest & 2 \\
\hline 30 & 440635122272100 & Deer Creek at Goodpasture Road Bridge, near Leaburg & Forest & 1 \\
\hline 31 & 440724122224300 & Quartz Creek at mouth, near Finn Rock & Forest & 1 \\
\hline 32 & 14162400 & McKenzie River at Finn Rock & Forest & 1 \\
\hline
\end{tabular}

the lower basin. Urban surveys show a good mix of coverage throughout the year, with each site sampled from four to eight times. Forestry sampling was more inconsistent because sites were selected based on forestry spray information, which reflected irregular and intermittent application patterns among the different tributaries. This meant that each individual forestry site generally was sampled only once or twice, after being identified as a target for spraying upstream. Spring forestry surveys were not conducted consistently because of the difficulty in capturing runoff events in the spring following application. Finally, agricultural surveys were not conducted until near the end of the reconnaissance period because site selection was complicated by logistics and lack of access to private lands. 
Table 2. Summary of land-use focus surveys.

[Sites referenced by map No. from table 1]

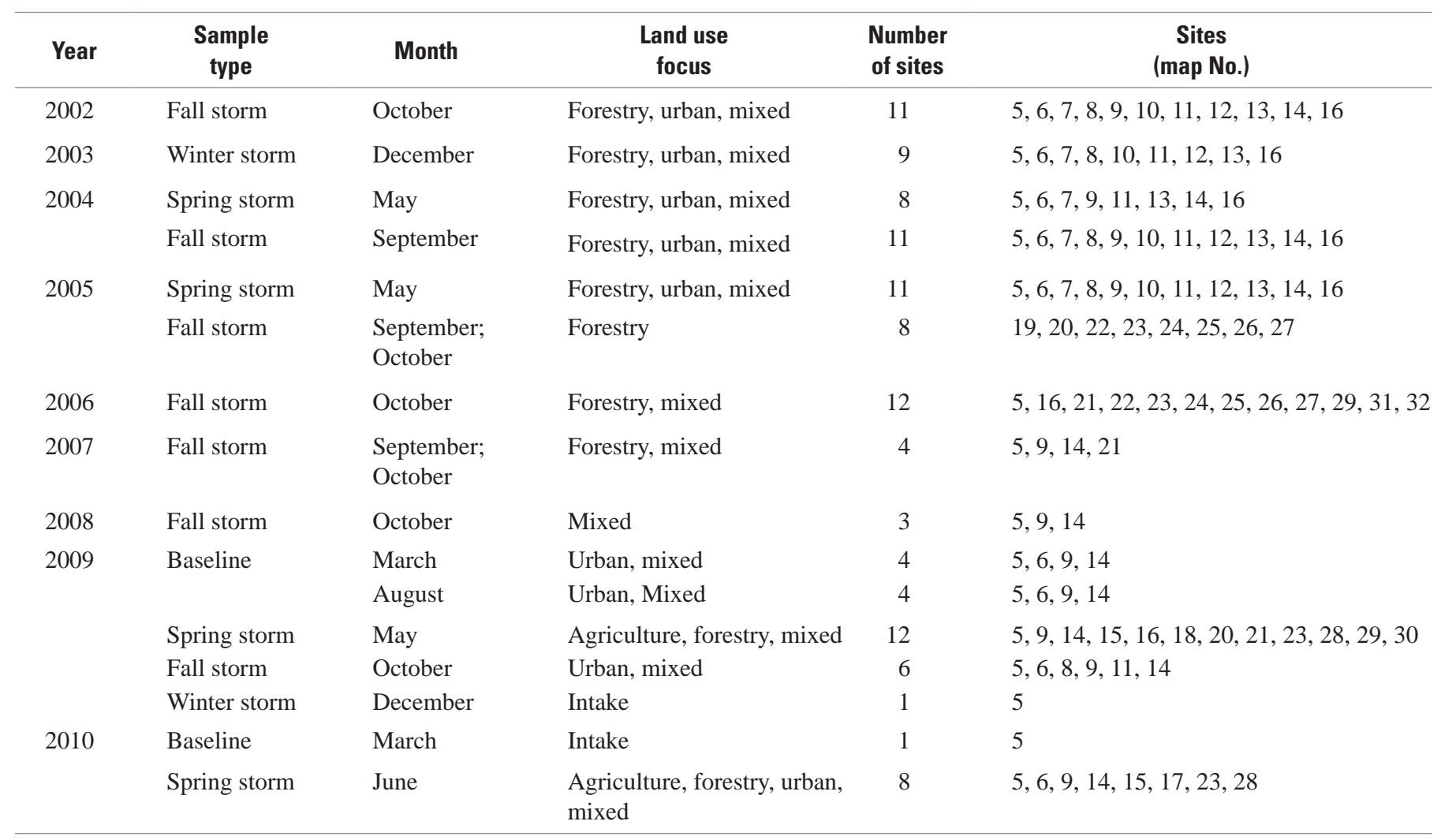

\section{Data Collection}

\section{Ancillary Data}

Data evaluated in this analysis include not only pesticide concentrations, but also various ancillary data that were collected to provide context for understanding the patterns of pesticide occurrence. These include land-use data, precipitation data, discharge data, data describing physical and chemical characteristics of the compound, health-based screening criteria, and potential for endocrine disruption for detected pesticide compounds. Additionally, reported or estimated pesticide-use data were acquired to evaluate the detection of compounds relative to their presumed use.

All drainage basin delineations and land-use analyses were conducted by the Lane Council of Governments (LCOG) for EWEB. Land-use data were associated with target drainage basins by intersecting Geographic Information System (GIS) layers with zoning, land use, and land-cover data (David Richey, LCOG, written comm., November 18, 2010). Zoning and land-use data were from 2010 and land-cover data were from the 2001 National Land Cover Database (Homer and others, 2004). Each of these data sources were summarized by forestry, agricultural, and urban/residential categories, and mean values for selected drainage basins across the range of data sources are presented in this report.

Hourly precipitation data acquired for two precipitation gages provide complementary perspectives on precipitation patterns for the study area (fig. 1). The first gage, generally representative of precipitation patterns in the lower to middle region of the study area, is located near the mouth at Springfield City Hall (altitude $456 \mathrm{ft}$ ) (site 2, fig. 1) and is maintained by Lane Regional Air Protection Agency. The second is located near the upper end of the study area at Trout Creek (altitude 2,400 ft) (site 4, fig. 1), and is a Remote Automated Weather Station (RAWS) operated by the Western Regional Climate Center. This gage generally describes precipitation patterns in the middle to upper regions of the study area.

Continuous instantaneous discharge data, collected and published according to standard USGS procedures (Turnipseed and Sauer, 2010), were evaluated for Cedar Creek at Springfield (site 9, table 1). Water velocity also was measured for selected samples over the course of storm sampling 
by $\mathrm{HACH}^{\mathrm{TM}}$ velocity sensors associated with automatic samplers deployed in stormwater drains. The water velocity data were converted to instantaneous discharge data using standard area-velocity equations based on channel dimensions (Turnipseed and Sauer, 2010). This information provides qualitative estimates for station hydrographs (for example, to describe the timing of peak flows) prior to and during sample collection. Although these data also were collected at other sites, evaluation of instantaneous discharge data in this report is limited to data from stormwater drains and USGS data collected at Cedar Creek at Springfield.

Estimates for selected physical-chemical characteristics for detected pesticide compounds were assembled from literature sources (Vogue and others, 1994; Mackay and others, 1997; Gilliom and others, 2006) in order to provide insight into the expected behavior and mode of transport for these compounds. Important factors related to pesticide transport in runoff include the tendency of the specific compound to partition into water or to be associated with soil particles, as measured by the sorption coefficient (Koc), as well as its persistence in its original chemical form, as measured by the soil half-life $\left(\mathrm{T}_{1 / 2}\right)$ (Gustafson, 1989). Koc describes the potential for sorption of the compound from the dissolved phase to the solid phase, with low Koc associated with small sorption potential. Koc is inversely related to solubility in water, so that transport of compounds with low Koc will be largely determined by the flow of water because these compounds primarily are associated with the dissolved phase. In contrast, compounds with high Koc that are strongly associated with soil/suspended sediment particles exhibit different transport behavior, tending to settle out in slow-moving regions of the hydrologic system. Compounds with low Koc are described as hydrophilic while those with high Koc are described as hydrophobic. Although Koc provides a measure of a compound's mobility in runoff, $\mathrm{T}_{1 / 2}$ is important because it represents how quickly degradation occurs in soil prior to runoff. $\mathrm{T}_{1 / 2}$ is the length of time required for one-half of the amount of compound to degrade in the soil, so that each half-life that passes continues to reduce the amount present by one-half. In general terms, pesticides may be considered to be non-persistent if their half-life is less than or equal to 30 days, moderately persistent if their half-life is 31-99 days, and persistent if their half-life is greater than 100 days (Vogue and others, 1994). Values presented for Koc and $\mathrm{T}_{1 / 2}$ in this report cannot be considered as absolute, because these attributes vary depending on many factors, but are nonetheless considered useful for comparing relative differences among different compounds.

To assess the potential threat to drinking-water quality, observed concentrations at the EWEB drinking-water intake were compared to the USEPA MCLs for compounds subject to established drinking-water standards. For unregulated compounds for which standards have not been established, concentrations were compared to HBSLs compiled by the
USGS (Toccalino and others, 2003; Toccalino, 2007). HBSLs represent benchmark concentrations from various sources that may be of concern for human health where the HBSLs are exceeded. HBSL guidelines are not legally enforceable regulatory standards, although they are based on the standard USEPA cancer classifications, toxicity data, and procedures for establishing drinking-water guidelines. Accordingly, they are consistent with USEPA methods for establishing Lifetime Health Advisory and Risk-Specific Dose values. They provide important context for identifying pesticides that may represent a potential concern, although they do not provide information on specific effects on human health.

In order to compare the relative toxicity for each detected compound, measured concentrations were normalized by the appropriate drinking water MCL or HBSL concentration to calculate a Benchmark Quotient (the ratio of the measured concentration to the benchmark concentration). Caution must be used in evaluating these metrics because they are relevant only in terms of concentrations that represent long-term exposure to contaminants in drinking water (generally defined as drinking $2 \mathrm{~L}$ daily for 70 years). Concentrations measured in samples from storm runoff do not meet this definition, especially concentrations in storm runoff samples associated with tributaries that are not used for drinking water, or where insufficient data are available to determine a reliable mean concentration over the full range of storm conditions. Nonetheless, these criteria provide a way to identify contaminants, sources, or conditions that may warrant additional monitoring or source reduction efforts where storm concentrations approach the benchmark. The recommended guidelines for interpretation of the Benchmark Quotients are described in table 3 (Toccalino, 2007).

Table 3. Guidelines for interpretation of Benchmark Quotients.

[Abbreviations: $\geq$, equal to or greater than; $\leq$, equal to or less than; >, greater than]

\begin{tabular}{cc}
\hline $\begin{array}{c}\text { Benchmark } \\
\text { quotient, } \\
\text { in water }\end{array}$ & \multicolumn{1}{c}{ Interpretation } \\
\hline$\geq 0.1$ & $\begin{array}{c}\text { Compound indicates a need for additional } \\
\text { monitoring to provide early indication of } \\
\text { concentration approaching benchmark } \\
\text { concentration, but does not necessarily } \\
\text { indicate adverse human health effects. } \\
\end{array}$ \\
& $\begin{array}{c}\text { Adverse human health effects are unlikely to } \\
\text { be caused by this compound alone, even in } \\
\text { water ingested over a lifetime. } \\
\text { A potential human-health concern in water } \\
\text { ingested without treatment over a lifetime; } \\
\text { potential adverse effects may be reduced } \\
\text { by treatment. }\end{array}$ \\
\hline
\end{tabular}


Further assessment of potential threats to human health was provided by the evaluation of detected compounds as potential endocrine disrupting compounds. Endocrine disrupting compounds interfere with the function of estrogen, androgen, and thyroid hormones in humans and animals. Because exposure to these chemicals can cause serious reproductive and developmental consequences, they may present a threat to drinking-water quality if exposure exceeds the threshold of the dose-dependent endocrine response. Designation of detected compounds as suspected endocrine disruptors was based on ratings presented by the Pesticide Action Network (PAN, 2012). This designation was made when any of several different sources of information lists the compound as suspected of endocrine disrupting activity. The various sources of information used by the PAN in this designation include the Illinois State Environmental Protection Agency, the Danish Environmental Protection Agency, the European Union Prioritization List, and three published references (Colborn and others, 1993; Benbrook, 1996; Keith, 1997).

Data to estimate pesticide use for different categories of land use were acquired to identify compounds expected to be present in the basin, as well as to focus and guide sampling times and locations for forestry sites; no attempt was made to quantify pesticide application rates or volumes. Reported pesticide-use data for urban lands were acquired from the Oregon Department of Agriculture, based on residential surveys conducted during 2007 (Sunny Jones, Oregon Department of Agriculture, written commun., May 17, 2010). These data were summarized for the three postal zip codes in Springfield, and represent the pounds of active ingredient reported to be used. Pesticide-use estimates for forestry were acquired from LCOG (David Richey, written commun., September 14, 2010), compiled from projected pesticide spray notifications provided to the Oregon Department of Forestry by commercial timber companies for specific sub-basins. These spray notifications generally include more compounds than are actually applied. Pesticide-use data for agriculture were estimated based on application data for specific crop types in the Willamette Valley from Anderson and others (1997), where those crops were characteristic of the McKenzie River basin; these estimates were verified with the Oregon State Extension agent for Lane County (Ross Penhallegon, oral commun., August 14, 2011).

\section{Water-Quality Sample Collection}

Pesticide samples were collected as a mix of composite and grab samples, depending on the location and flow rates. The emphasis on capturing extreme flow conditions during storm sampling in urban drains and small tributaries meant that water levels tended to rise and decline at most sites during a short period of time. Because of limited personnel to collect storm samples, the use of automatic samplers was determined to be appropriate. Approximate flow-weighted samples for stormwater drains and most tributary locations were composited manually from aliquots collected into 1-L glass bottles by Sigma ${ }^{\mathrm{TM}}$ automatic samplers; aliquots were composited based on stage data collected over the course of the storm (fig. 4). After evaluation of the distribution of aliquot collection over the sample hydrograph, each sample was identified with the region of the hydrograph where it was collected. Where stage data were not available, time-weighted composite samples were collected manually into 1-L amber glass bottles over a 30-minute period as equal-volume aliquots collected every 3 minutes by peristaltic pump. Grab samples were collected manually into 1-L amber glass bottles by peristaltic pump or via a sampling pole; samples from the EWEB intake were collected directly from a spigot. All flow- and time-weighted composite samples were composited and split using a Teflon ${ }^{\mathrm{TM}}$ churn splitter, and were processed in accordance with the USGS "National Field Manual for the Collection of Water-Quality Data” (U.S. Geological Survey, variously dated), and EWEB's "Lower McKenzie Watershed, Stormwater and Urban Runoff Monitoring Plan” (EWEB, written commun, 2004). To the greatest extent possible, the USGS parts-per-billion protocol was used in sample processing.

Several sets of special-topic ambient samples were collected early in the program from selected stormwater drains to evaluate specific questions related to timing and quality control of sample collection (table 4). Three sets of paired pre-storm and storm samples were collected to compare pesticide occurrence prior to the onset of storm conditions with occurrence during the peak of storm runoff. These were collected in fall 2002, and fall and spring 2004. Three sets of paired samples also were collected to examine the influence of sampling over different regions of the storm hydrograph on pesticide occurrence. These samples were collected both early and late in the storms sampled during fall 2002 and spring 2005. All these samples were composited and processed similar to ambient samples. 


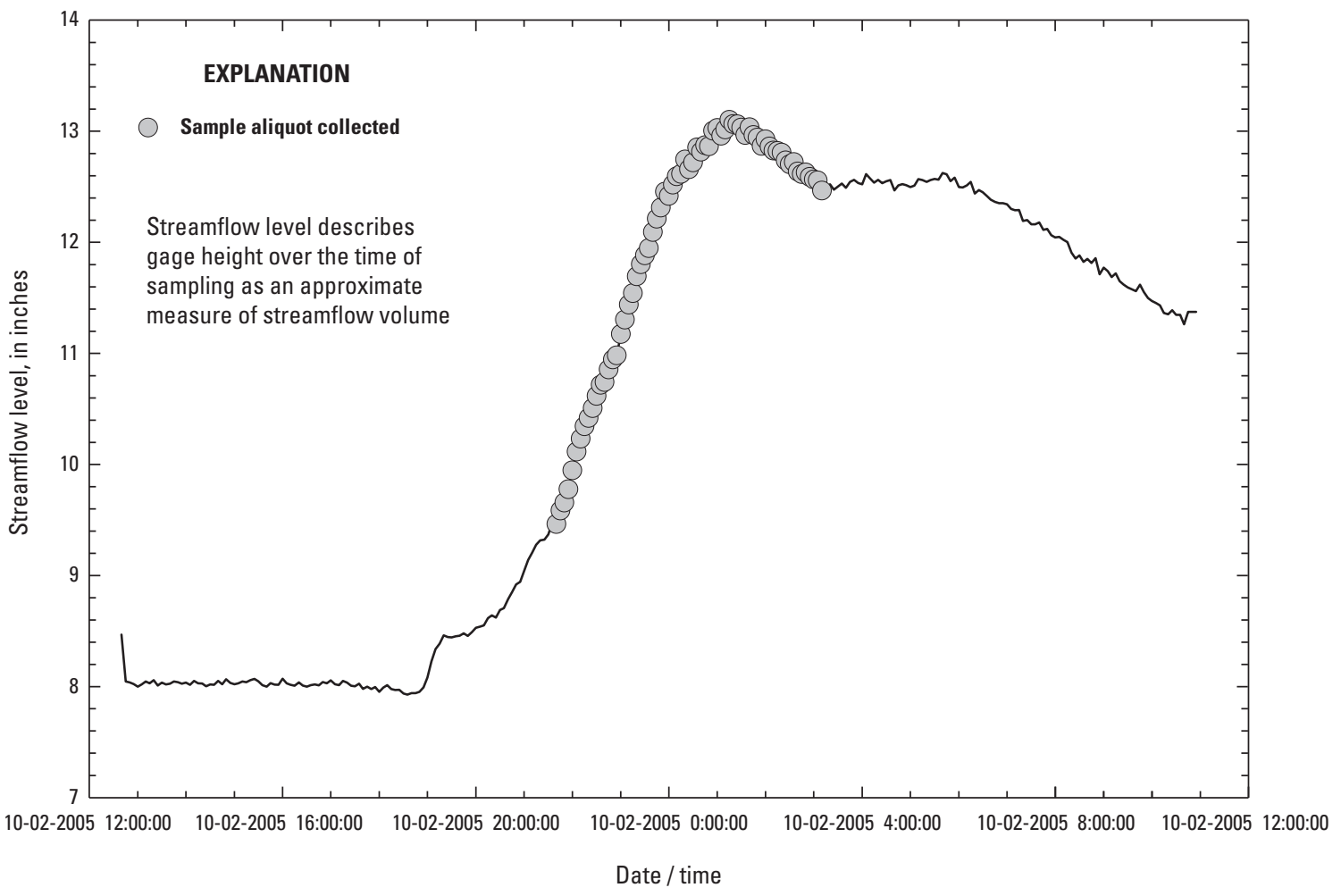

Figure 4. Streamflow stage and sample aliquot collection at Cogswell Creek, McKenzie River basin, Oregon, fall 2005.

Table 4. Description of special-topic sample types.

\begin{tabular}{cll}
\hline $\begin{array}{c}\text { Special-topic } \\
\text { sample type }\end{array}$ & Season and year & \multicolumn{1}{c}{ Sample sites } \\
\hline $\begin{array}{c}\text { Pre-storm and } \\
\text { storm sample }\end{array}$ & Fall 2002 & 64th Stormwater pipe \\
& Spring 2004 & 69th Stormwater channel \\
& Fall 2004 & 69th Stormwater channel \\
Sampling over & Fall 2002 & 69th Stormwater channel \\
storm hydrograph & Spring 2005 & 42nd Stormwater culvert \\
& & 64th Stormwater pipe \\
\hline
\end{tabular}


All samples were filtered within 8 hours of collection through $0.7-\mathrm{mm}$ baked glass-fiber (GF/F) filters into 1-L baked amber glass bottles, and shipped overnight on ice to the USGS National Water-Quality Laboratory (NWQL) in Denver, Colorado. Once samples reached the NWQL, they were analyzed using carbon-based and resin-based solid-phase extraction, capillary-column gas chromatography/ mass spectrometry (GC/MS—USGS schedule 2010/2033), and high-performance liquid chromatography/mass spectrometry (HPLC—USGS schedules 2060 and 2080). Additional filtered samples (125 mL amber glass bottles) were shipped to the USGS Organic Geochemistry Research Laboratory in Lawrence, Kansas, for high performance liquid chromatography/mass spectrometry (HPLC/MS) analysis of glyphosate compounds not included in the NWQL schedules (USGS analysis code LCGY). Analytical methods are documented in Werner and others (1996), Sandstrom and others (2001), Furlong and others (2001,2008), and Meyer and others (2009). The suite of compounds analyzed are listed in appendix A. Four compounds were measured by multiple USGS schedules under different parameter codes: carbaryl, carbofuran, linuron, and terbacil. Using guidance from the NWQL that ranks the quality control from mass spectrometry and gas chromatography methods higher than liquid chromatography, data for these compounds were included in the analysis for this report preferentially from schedule 2010/2033.

Two levels of reporting concentrations are used for all data: the long-term detection limit (LT-MDL) and the laboratory reporting level (LRL) (Childress and others, 1999). The LT-MDL is statistically defined as the smallest concentration that can be measured and reported with 99 percent confidence, and is calculated over an extended period of time (generally 6-12 months). At the LT-MDL concentration, the risk of a false positive detection is less than or equal to 1 percent; however, the risk of a false negative occurrence can be as much as 50 percent. To reduce this unacceptably high risk of reporting an analyte as not present when it actually is present, the LRL is defined by the laboratory as twice the LT-MDL.

All analytical results greater than the LRL in use at the date of laboratory analysis are reported as unqualified. Analytical results less than the relevant LRL but greater than the LT-MDL are reported only when the identity of the analyte is confirmed, indicating that the compound is present although there is uncertainty in the absolute value of the reported concentration. These results are reported with a qualifying E-code. If the analytical result is less than the LT-MDL, the concentration is reported as less than the LRL. Occasionally, concentrations are censored at values greater than the LRL because interference from the sample matrix introduces greater uncertainty. The range of LRLs for each compound during the period of this study are shown in appendix A.

\section{Quality Assurance}

A total of 39 quality-assurance (QA) samples, including equipment blanks, replicates, and laboratory spikes, were collected and represent about 24 percent of the total number of samples collected. The QA program was particularly intensive in the first years of sampling in order to ensure that methods used would provide reliable data at low detection levels without contamination. These samples were collected to identify the potential for bias as well as to assess the level of precision in the ambient data. Analyses of surrogate compounds added by the NWQL provide additional information on the accuracy and potential for bias of the analytical process. Finally, a special QA study was conducted to evaluate the potential for bias from sample collection using plastic tubing in the automatic samplers. This section summarizes all the QA results; figures are presented in appendix B.

Field equipment blanks were used to document the potential for contamination occurring during equipment cleaning, sample processing, shipment, and analysis at the laboratory. A total of nine blank samples were collected from 2002 to 2010 using certified organic-free water, and were submitted to the entire process of sample collection, compositing, filtering, shipment, and analysis. Only one detection was observed - caffeine $(0.010 \mu \mathrm{g} / \mathrm{L})$ in the first blank sample from the 42nd Street stormwater culvert (site 7) in September 2002. This sample was associated with an exceptionally high caffeine concentration $(11.4 \mu \mathrm{g} / \mathrm{L})$ that was subsequently traced to a coffee kiosk disposing gray water directly into the storm drain upstream of the sampling site. This blank concentration was considered to be relatively insignificant because it was approximately equal to the LRL $(0.0096 \mu \mathrm{g} / \mathrm{L})$ and represented a very small fraction $(<0.1$ percent) of the ambient concentration. No other detections, either unqualified or E-coded, were observed in any blank samples. These results indicate that contamination is not a concern for the ambient data.

A total of 18 pairs of replicate samples were collected to describe variability inherent in the sampling and analytical process. These samples were collected in several ways, encompassing all the sampling methods used for ambient data-11 pairs were collected with the same method (either grab or composite) and 7 pairs were collected with different methods (either split concurrent, collected over a different region of the hydrograph, or composite versus grab) (table 5). 
Table 5. Summary of replicate samples.

[Values in parentheses describe $\mathrm{N}$ for replicate pairs where RPD $>10$. A bbreviations: $</<$, both concentrations less than laboratory report level (LRL); $</ \mathrm{E}$, one concentration less than LRL, the other estimated between the minimum detection level (MDL) and LRL; </unqualified, one concentration less than LRL, the other not qualified; E/E, both values estimated between MDL and LRL; E/unqualified, one value estimated between MDL and LRL, the other value unqualified; unqualified/unqualified, both values unqualified]

\begin{tabular}{|c|c|c|c|c|c|c|c|c|}
\hline Replicate type & $\begin{array}{l}\text { Number of } \\
\text { samples }\end{array}$ & $\begin{array}{c}\text { Number of } \\
\text { compound } \\
\text { pairs }\end{array}$ & $</<$ & $</ E$ & $</$ unqualified & $E / E$ & E / unqualified & $\begin{array}{l}\text { Unqualified/ } \\
\text { unqualified }\end{array}$ \\
\hline Rise and fall / rise & 2 & 211 & 197 & 3 & 3 & $4(3)$ & $1(1)$ & $3(3)$ \\
\hline Rise / fall & 1 & 103 & 95 & 1 & 0 & $5(4)$ & 0 & $2(2)$ \\
\hline Composite / grab & 4 & 488 & 483 & 2 & 0 & 1 & $1(1)$ & $1(1)$ \\
\hline
\end{tabular}

Data from the replicate samples were evaluated in two ways: first, the concentrations in the pair of replicate samples were compared to determine the relative percent difference (RPD) as the difference between the two concentrations divided by the mean. RPD results were further examined to determine if there was a consistent effect of sample collection method. RPD values greater than 10 percent between the replicate pairs were considered to represent significant variability. Second, ratios of standard deviations from replicate samples were compared to those from routine samples to determine the relative importance of sampling variability to overall variability in the measurement process.

Most compound pairs (1,954, or 98 percent, of the 2,003 pairs of analyses) were associated with non-detections in both replicate samples. Of the remaining 49 pairs of analyses, 18 were associated with one value coded as less than LRL and either one E-coded or unqualified value; all E-coded or unqualified values were either less than $(n=10)$ or close to the threshold defined by the LRL ( $\mathrm{n}=8$, median difference $=0.02 \mu \mathrm{g} / \mathrm{L}$ ). These replicate pairs were not evaluated further because the values less than LRL were not quantified. For 16 of the other 31 replicate pairs, both replicate values were E-coded. Eight of these pairs were associated with an RPD greater than 10 percent, primarily associated with replicates collected over different regions of the hydrograph (appendix B, fig. B1-A); these compounds included carbaryl $(n=4)$, caffeine $(n=1)$, diuron $(n=1)$, malathion $(n=1)$, and prometon $(\mathrm{n}=1)$. Fifteen remaining compound pairs were associated with at least one unqualified value, and 12 of these showed a high level of variability between the two samples (RPD > 10 percent); affected compounds include 2,4-D ( $=4), 2,4-\mathrm{DB}(\mathrm{n}=2)$, caffeine $(\mathrm{n}=2)$, diazinon $(\mathrm{n}=1)$, diuron ( $\mathrm{n}=1)$, imidacloprid $(\mathrm{n}=1)$, and triclopyr $(\mathrm{n}=1)$ (appendix B, fig. B1-B and B1-C). Eight of the replicate pairs with RPD greater than 10 percent were associated with different sampling methods (six comparing composites collected over different regions of the hydrograph, and two comparing composite samples with grab samples); four pairs were collected as split concurrent replicates (appendix B, fig. B1-B and B1-C). These results demonstrate that sampling/ analytical variability can be important for a small number of compounds, especially where concentrations are E-coded, and that sampling method is implicated as a source of variability. Although the small number of samples with significant variability precludes determination of a clear pattern of bias in general, results indicate that sampling over different ranges of the hydrograph may be the most important source of variability.

In comparing the variability in replicate samples with variability in ambient data, the median standard deviation for replicate data (excluding pairs where at least one value was less than LRL or not quantified) was 0.007 overall compared to the median for ambient data (similarly excluding values not quantified) of 0.028. Analysis of variance among the different sources of variability in replicate samples showed a significant difference among the standard deviations associated with each replicate type ( $n=31, p<0.0001)$. Parsing out the different sources of sampling variability, the largest standard deviation was associated with samples collected over different regions of the hydrograph (median=0.019) compared to the variability due to sampling method (median=0.01), and the median standard deviation for split-concurrent samples (which essentially represents laboratory variability) was zero. These results indicate that variability generally can be ranked in the following order-laboratory variability $<$ variability due to different sampling methods $<$ variability due to sampling over changing field conditions $<$ variability inherent in sampling different storm conditions. The small number of samples with significant variability (greater than 10 percent RPD between replicate samples) prohibits more rigorous analysis, although results indicate that field variability of pesticide concentrations over the storm hydrograph is likely to be more important than variability introduced by the combined sampling and analytical methods for dissolved pesticides in these primarily small streams. 
Fourteen replicate laboratory spike samples were collected to measure the analytical recoveries for specific compounds, providing information on accuracy, precision, and potential bias in the analysis from effects of the sample matrix. Spike samples were environmental samples that were fortified with certified known concentrations of a group of analytes and paired with unspiked samples. Concentrations in the spike mixture represented an increase of about $0.1 \mu \mathrm{g} / \mathrm{L}$. Percent recoveries for the spiked sample were calculated as the ratio of the difference between the spiked and unspiked concentrations to the concentration of the added spike. Because some compounds were not detected in the ambient samples even though they were reported or estimated to be used in the basin, recoveries for these compounds were evaluated by laboratory reagent spike data. These reagent spike data cannot be considered equivalent to matrix spike data because they provide a measure of analytical recovery that is independent of the sample matrix.

Because of the small number of detections in the ambient data to compare to spike results, it generally was only possible to determine a small number of matrix spike recoveries where concentrations were quantified in the ambient samples. Of these, the GC/MS method provided higher recoveries (median $=77$ percent, $n=13$ ) than the HPLC method (median $=40$ percent, $n=4$ ) (appendix B, fig. B2). Recoveries for laboratory reagent spikes generally were higher than recoveries for matrix spikes, and again the GC/MS method (median $=97$ percent; $n=510$ ) performed better than the HPLC method (median $=89$ percent, $n=556$ ). Two of the 45 compounds that were detected in the ambient data (cis- and trans-propiconazole) were associated with median recoveries higher than 140 percent, and 5 compounds (2,4-D, triclopyr, 1-naphthol, dinoseb, and metsulfuron-methyl) were associated with median recoveries less than 60 percent. All these compounds except for 1-napthol were analyzed by the HPLC method. Of compounds reported to be used in the basin but never detected, three were associated with median recoveries less than 60 percent in laboratory reagent spike samples. These included cis-permethrin, bromoxynil, and oxamyl—-the latter two were analyzed by HPLC method. Because reports of pesticide use are estimated and are not reliable, these results do not reflect any certainty that these compounds should be expected to be detected, and were therefore not detected because of analytical bias. Nonetheless, the results clearly demonstrate that some compounds analyzed by HPLC method were more likely to be associated with low recoveries, which implies that measured concentrations for these compounds may be biased low.

Surrogate compounds, or deuterated versions of compounds included in the laboratory schedules that are never detected in environmental samples, were routinely added by the laboratory in known amounts to every sample. Because surrogates are similar in structure to selected target compound groups of interest, surrogates were analyzed to further monitor the potential for matrix effects that may affect compound recoveries. Surrogate recoveries were calculated in the same way as spike recoveries. Similar to the spike results, surrogate recoveries were most consistent using the GC/MS method, largely between 80 and 120 percent (appendix B, fig. B3). Surrogate recoveries using the HPLC method were more variable and tended to be lower, generally between 60 and 100 percent. More recoveries were less than 60 percent and greater than 140 percent for the HPLC method. These results are consistent with the spike results, showing that recoveries for the GC/MS method generally are less variable than recoveries for the HPLC method. Surrogate issues with the HPLC method have been documented by others and these results are consistent with the relatively poor performance of surrogate compounds with this method (Werner and others, 1996; Munday and Domagalski, 2003).

To evaluate the potential effect of plastic tubing in the autosamplers on pesticide concentrations, a special QA study was conducted in collaboration with a research chemist from the NWQL. This study involved collecting seven pairs of replicate grab samples from stormwater drains during 2002-04. The first sample in each replicate pair was collected through the autosampler tubing into clean glass bottles seated in the sampler, and then filtered into baked glass bottles without compositing. The second sample was grabbed directly into baked glass bottles. The results were evaluated by determination of RPD between the two sample collection types as well as comparison of standard deviations with those from other replicate samples and ambient data. Of 697 replicate pairs of analyses, both replicate concentrations were reported as less than the LRL for 634 pairs or about 91 percent. Of the other 63 pairs, 17 pairs were associated with one concentration qualified as less than the LRL and were not evaluated further because values less than the LRL were not quantified. Finally, 19 of the remaining 48 pairs of analyses were associated with an RPD greater than 10 . Most of these pairs with significant variability were from pairs either with both (10 of a total of 20) or one (4 of a total of 6) E-coded detections, with 5 pairs (from a total of 20) where both detections were unqualified. Of these, concentrations were relatively higher in 13 pairs in the samples collected directly into glass, while concentrations were relatively higher in 6 pairs in the samples collected through the plastic tubing (appendix B, fig. B4). Compounds with smaller concentrations in the tubing samples include 2,4-D $(\mathrm{n}=2)$, desulfinylfipronil $(\mathrm{n}=1)$, diazinon $(\mathrm{n}=2)$, diuron $(\mathrm{n}=3)$, metsulfuron-methyl $(\mathrm{n}=1)$, and sulfometuron-methyl $(\mathrm{n}=2)$.Compounds with higher concentrations in the tubing samples include bentazon $(\mathrm{n}=1)$, carbaryl $(\mathrm{n}=1)$, prometon $(\mathrm{n}=1)$, and triclopyr $(\mathrm{n}=1)$; caffeine showed no clear pattern with two pairs having smaller and two having higher concentrations. Although the number of detections was too low for statistical conclusions, these results indicate that concentrations for some compounds in samples collected by automatic sampler may be biased low due to interaction with the plastic tubing, especially for E-coded values that are subject to high analytical uncertainty. 
In order to evaluate the variability due to the use of plastic tubing within the context of other sources of sampling variability, standard deviations of replicate pairs (including only those pairs where both concentrations were greater than the LRL) from these special QA samples (median=0.018) were compared with those from the routine replicate samples describing variability from sampling method (median $=0.01$ ) and samples collected over different regions of the hydrograph (median $=0.019$ ). . These results indicate that the use of plastic tubing in the automatic samplers introduces variability to the sampling process that is comparable to the effect of sampling over different regions of the hydrograph.

This variability is most pronounced for E-coded concentrations, which by definition are low for most compounds. Although not insignificant, this variability was considered acceptable within the context of the reconnaissance or exploratory objectives of the project, which are focused on capturing storm runoff in order to identify important source areas for pesticides. It was decided that the logistics of event-based sampling of multiple stormwater drains and small streams, where flows tend to rise and decline relatively quickly over the course of a storm, meant that using automatic samplers provided a better means to collect a representative sample with the limited personnel resources that were available.

\section{Data Analysis}

Because of the non-fixed design of this reconnaissance study and the corresponding inconsistency in sampling timing and frequency, it was not possible to use standard statistical procedures to evaluate the data. The analysis presented in this report is essentially descriptive in nature, focusing on the distribution of detected compounds across seasons and landuse categories. The evaluation of storm conditions focuses on antecedent precipitation and sampled storm characteristics. Simple correlations are examined to evaluate relations between precipitation and/or discharge with occurrence of pesticides, as measured by number of detected compounds and the sum of all quantified or total concentrations in a single sample. Results from the various sampling surveys also are considered within the context of the physical-chemical characteristics of detected compounds, their potential for endocrine disrupting activity, and the various health-based criteria. Finally, results are synthesized with those from other studies to generate a conceptual model describing pesticide transport in the basin.

\section{Pesticide Occurrence}

A total of 135 environmental samples were collected among the 28 sites, including 18 replicates. All data are available from the USGS National Water Information System.
Each sample was analyzed for as many as 175 compounds, and a total of 43 compounds were detected at least once: 2 isomeric forms of 1 fungicide, 26 herbicides and 3 of their metabolites, 9 insecticides and 2 degradates, and caffeine as an indicator of human waste (table 6). The median number of detections per sample was 4, although some samples had no detections; the maximum number of compounds detected in a single sample was 11 (in the 69th stormwater channel at Thurston Road in Springfield, site 11, during May 2004). To support appropriate comparison of detections for compounds that are associated with a wide range of detection levels (appendix A), detection frequency was determined in two ways - first, using the number of quantified values (both E-coded and unqualified) simply as a function of the number of analyses for the specific compound (frequency); and second, using the number of quantified values as a function of number of analyses for the specific compound based on a common detection level (common frequency) (Gilliom and others, 2006). The common detection level was defined as $0.1 \mu \mathrm{g} / \mathrm{L}$, which represents the highest level at which most compounds (95 percent) were screened throughout the period of this study. Compounds are listed in table 6 in descending order of frequency within each compound class.

Most concentrations were low-the median value of maximum detected concentrations was $0.055 \mu \mathrm{g} / \mathrm{L}$. The highest concentrations generally were detected for herbicide compounds, which comprised six of the seven compounds with maximum concentrations greater than $1 \mu \mathrm{g} / \mathrm{L}$. The maximum detected concentration was $11.4 \mu \mathrm{g} / \mathrm{L}$ for caffeine, which was detected in a sample from downstream of a stormwater drain that was used for disposing gray water by a coffee kiosk in Springfield. This practice subsequently ceased, so this concentration should not be considered representative of current (2012) stormwater drain conditions.

Twenty-one of these compounds may be considered to represent a potential threat to drinking- water quality as they are regulated by a drinking-water standard $(\mathrm{n}=9)$ and/or suspected to be endrocrine-disrupting compounds $(n=20)$. Caffeine was the most frequently detected compound, detected in nearly one-third of all samples. The seven compounds with the highest detection frequency accounted for 191 detections, or about 46 percent of all detections. These included caffeine plus four herbicides (hexazinone, 2,4-D, atrazine, and glyphosate), and one herbicide metabolite (aminomethylphosphonic acid or AMPA, the primary metabolite for glyphosate), and one insecticide (carbaryl). When considering detections based the common reporting level, the analysis is focused on fewer (19) compounds because those with only low-level detections are omitted. All detections for hexazinone and atrazine are excluded when screened at this level, although caffeine, 2,4-D, and glyphosate remain among the most frequently detected compounds. With the addition of diuron, these four compounds combined represent more than 60 percent of all detections when measured by the common frequency of detection. 
Table 6. Maximum concentration and detection frequency for all compounds detected.

[Compounds are listed in descending order of frequency within each compound class. CAS Registry Number ${ }^{\circledR}$ is a registered trademark of the American Chemical Society. CAS recommends the verification of the CAS Registry Numbers through CAS Client Services ${ }^{\mathrm{SM}}$. Abbreviations: CAS, Chemical Abstracts Service; LRL, laboratory reporting level; $\mu \mathrm{g} / \mathrm{L}$, micrograms per liter]

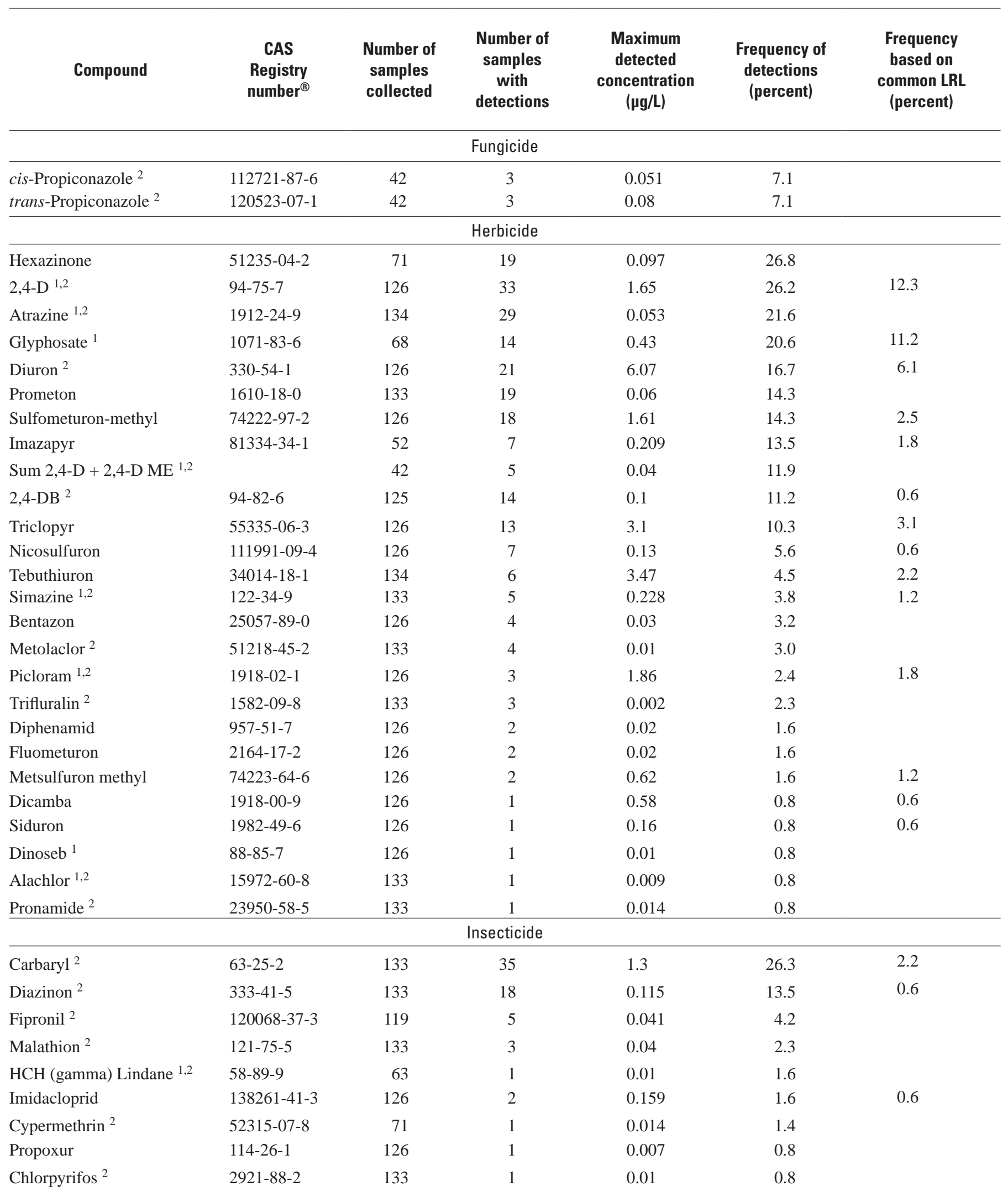


Table 6. Maximum concentration and detection frequency for all compounds detected.-Continued

[Compounds are listed in descending order of frequency within each compound class. CAS Registry Number ${ }^{\circledR}$ is a registered trademark of the American Chemical Society. CAS recommends the verification of the CAS Registry Numbers through CAS Client Services ${ }^{\mathrm{SM}}$. Abbreviations: CAS, Chemical Abstracts Service; LRL, laboratory reporting level; $\mu \mathrm{g} / \mathrm{L}$, micrograms per liter]

\begin{tabular}{|c|c|c|c|c|c|c|}
\hline \multicolumn{7}{|c|}{ Metabolite } \\
\hline AMPA & $1066-51-9$ & 68 & 21 & 0.95 & 30.9 & 3.8 \\
\hline OIET & 2163-68-0 & 126 & 11 & 0.042 & 8.7 & \\
\hline Desulfinylfipronil & & 119 & 9 & 0.006 & 7.6 & \\
\hline 1-Naphthol & $90-15-3$ & 71 & 1 & 0.01 & 1.4 & \\
\hline \multicolumn{7}{|c|}{ Human waste indicator } \\
\hline
\end{tabular}

\section{Physical-Chemical Characteristics and Reported Compound Use}

Physical-chemical characteristics and reported or estimated use by urban, forestry, or agricultural land use were summarized for all pesticides detected and/or reported to be used in the basin (table 7). Of the 35 pesticide compounds that were detected (excluding caffeine and metabolites that are not applied, and considering the two isomers of propiconazole and 2,4-D plus the sum of 2,4-D and 2,4-D ME each as single compounds), 12 were not reported to be used by any of the sources consulted in this analysis. Although the largest proportion of the remaining 23 detected compounds were reported as associated with urban or residential land use, no single land use dominated: 15 were reported as used in urban and residential settings (3 insecticides exclusively urban); 17 were estimated as used in agricultural settings ( 3 herbicides and 1 insecticide exclusively agricultural); and 9 were reported as used in forestry settings (1 herbicide exclusively forestry). Detected compounds generally were fairly hydrophilic ( $\log$ soil $\mathrm{Koc}<3$ ) with a moderate tendency to sorb to sediment particles (median log soil $\mathrm{Koc}=2.36$ ) and were only moderately ( $\mathrm{T}_{1 / 2}<100$ days) persistent in soil (median $\mathrm{T}_{1 / 2}=$ 47 days). In contrast, of the 25 compounds that were reported to be used in the basin but never detected, those associated with agricultural land use represented the largest proportion. Of the compounds never detected, a total of 22 compounds were estimated as used in agricultural settings (8 herbicides and 9 insecticides exclusively agricultural), although only 7 compounds were reported to be used in urban settings ( 1 fungicide, 1 herbicide, and 1 insecticide exclusively urban) and 2 were reported to be used in forestry (none exclusively forestry). These compounds were slightly more hydrophobic (median log soil $\mathrm{KoC}=2.7$ ), and less persistent in soil (median $\mathrm{T}_{1 / 2}=30$ days).

These results suggest several factors to consider in assessing pesticide occurrence relative to reported or estimated use in the basin. First, it must be emphasized that pesticide use is difficult to evaluate based on use reports because they are not definitive. Compounds may be used by farmers without their use being reported, especially in emergency situations (Oregon Department of Agriculture, 2001). Alternatively, pesticides may be reported as used by forestry managers simply as placeholders for potential use, and may not subsequently be applied as reported. Urban surveys also may not accurately represent the real use of pesticides by the respondents for various reasons, including simple refusal of response to the survey or incomplete information about pesticides that are used. Some compounds (for example, diazinon, carbaryl, malathion, and chlorpyrifos) have been banned for residential use in recent years but will still be in use if homeowners retain supply in their basement or garage. Notwithstanding the uncertainty in the reported and estimated use data, however, a critical factor in the non-detection of so many presumed agricultural compounds in this dataset is certainly the small number of samples collected in agricultural streams, especially during significant storm-runoff periods. Because the agricultural streams have not been sampled with comparable effort to the other land-use categories, the present data are insufficient to adequately assess the presence of agricultural pesticides in the McKenzie River basin. 
Table 7. Physical-chemical characteristics and categories of land use for detected compounds and compounds reported to be used but never detected.

[Reported land use: A, agricultural land use; F, forestry land use; U, urban land use; -, data not available]

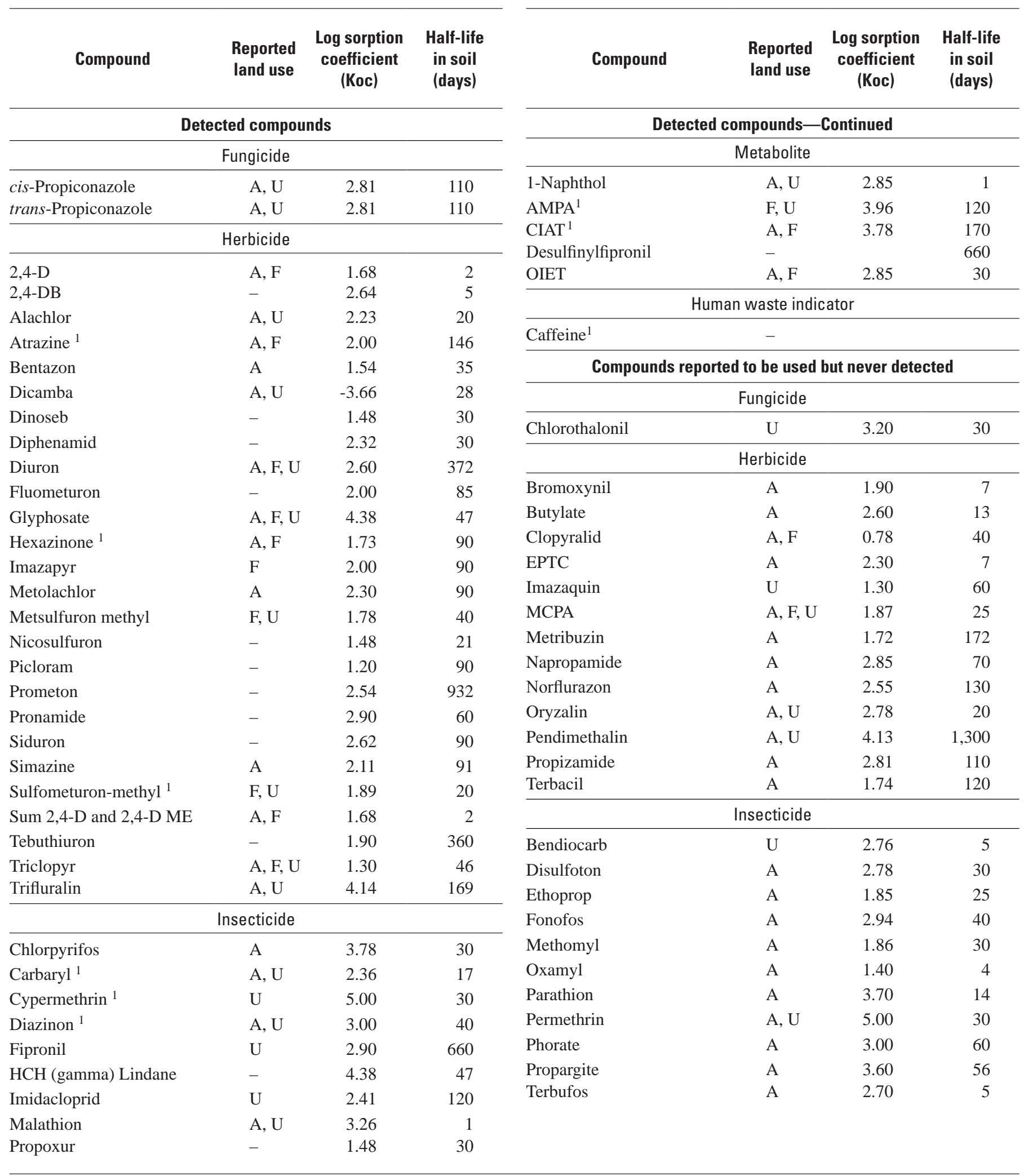

\footnotetext{
${ }^{1}$ Compounds detected at drinking water intake.
} 
Physical-chemical characteristics among detected compounds that are regulated by drinking- water standards or suspected of endocrine disruption (table 6) were compared to the remaining detected compounds to assess if potential differences in transport mechanisms might be inferred. No large differences were observed for regulated compounds compared to non-regulated compounds for log soil KoC (median=2.1 and 2.5, respectively), or $\mathrm{T}_{1 / 2}$ (median $=47$ and 53 days, respectively). Larger differences were observed for suspected endocrine disruptors for soil sorption potential, however, which suggests a different mode of transport behavior. Suspected endocrine disruptors were relatively more hydrophobic (median log soil $\mathrm{Koc}=2.8$ ) compared to non-endocrine disruptors (median log soil $\mathrm{Koc}=1.9$ ), although they tended to be only slightly more persistent in soil (median $\mathrm{T}_{1 / 2}=60$ days) than others (median $\mathrm{T}_{1 / 2}=46$ days). These results suggest that detected compounds suspected of endocrine disruption may be more prone to be transported in association with sediment particles than the other compounds that have been observed in the basin. Because these compounds were detected in filtered samples, the implication for drinking water source protection is that contaminated sediments may be serving as a source for these compounds in the basin.

The physical-chemical characteristics of the eight pesticide compounds (excluding caffeine) that were detected at the treatment-plant intake (table 7) span a large range, suggesting a coincident range of potential source and transport conditions. The three herbicides (atrazine, hexazinone, and sulfometuron-methyl) are relatively hydrophilic (log soil $\mathrm{Koc}=2.00,1.73$, and 1.89, respectively), while the three insecticides (carbaryl, cypermethrin, and diazinon) are more hydrophobic (log soil $\mathrm{Koc}=2.36,5.00$, and 3.00, respectively) as are the two metabolites (AMPA and CIAT, log soil $\mathrm{KoC}=3.96$ and 3.78, respectively). A similarly large range of persistence in soil occurs, with sulfometuron-methyl being relatively non-persistent $\left(\mathrm{T}_{1 / 2}=20\right.$ days), cypermethrin, diazinon, and hexazinone being moderately persistent $\left(\mathrm{T}_{1 / 2}=30,40\right.$, and 90 days, respectively), and atrazine being relatively persistent $\left(T_{1 / 2}=146\right.$ days).

Most compounds were reported to be used in multiple land-use applications, with only cypermethrin being associated with exclusively urban use. No single reported land use dominated among these compounds, suggesting that all categories of land use have an impact on the quality of water at the intake. Four compounds were either suspected of endocrine disruption (atrazine, carbaryl, cypermethrin, and diazinon), or additionally regulated by drinking-water criteria (atrazine).

To provide some context for the results from the treatment-plant intake, they were compared to pesticide data from the water-treatment plant on the lower Clackamas River in Oregon during 2002-05 (Carpenter and others, 2008). A higher frequency of pesticide detections was observed in the Clackamas River, with a total of 14 compounds detected in
9 samples collected over 2 years. Four of these compounds also were detected in the McKenzie River (atrazine and its metabolite CIAT, hexazinone, and diazinon), although most were not widely detected in this study. Drinking-water intake concentrations generally were comparable, although the maximum concentrations differed by an order of magnitude $(0.22 \mu \mathrm{g} / \mathrm{L}$ in the Clackamas River compared to $0.02 \mu \mathrm{g} / \mathrm{L}$ in the McKenzie River).

\section{Comparison to Water-Quality and Health-Based Standards}

Of the nine compounds that were detected at the EWEB treatment plant intake (table 8), most were frequently detected at other sites. The exception was cypermethrin, a pyrethroid insecticide that is strongly associated with urban land use, and that was never detected at any other site during this study. AMPA, carbaryl, and CIAT were detected twice at the intake, while diazinon, caffeine, hexazinone, atrazine, cypermethrin, and sulfometuron-methyl were each detected once, making a total of 12 detections overall over the 8-year course of this study. Of these 12 detections, 8 were E-coded values, indicating that the concentrations were less than the LRL. No concentrations exceeded the common reporting level of $0.1 \mu \mathrm{g} / \mathrm{L}$. MCL was defined for one compound, and human-health benchmarks were available for six of the nine compounds, excluding caffeine and the degradation products. One of those with no benchmark available, AMPA, is a metabolite of glyphosate and has a similar toxicological profile; both are associated with low levels of toxicity (World Health Organization, 2004). Where defined, MCL and Benchmark Quotients were consistently one to several orders of magnitude less than 0.1 , which is the suggested level for identification of compounds that warrant further monitoring to protect human health. Although these results indicate that adverse effects from pesticide concentrations at the drinkingwater intake are expected to be negligible at the present time, they also document the occasional low-level presence of compounds regulated by drinking-water criteria or suspected of endocrine-disrupting activity. Additionally, several samples, notably in spring 2009 and 2010, contained detectable concentrations for multiple compounds. Even though the total concentrations of pesticide in these samples was uniformly very low $(<0.1 \mu \mathrm{g} / \mathrm{L})$, the potential for additive or synergistic effects of pesticide mixtures on human health is not well understood, even at low concentrations.

\section{Seasonality, Hydrology, and Land Use}

The following sections evaluate the seasonal patterns of precipitation that were associated with the various land-use sampling surveys in the McKenzie River basin, and the corresponding patterns of pesticide occurrence across the range of sampled seasons and land use. 
Table 8. Benchmark quotients for compounds detected at source water for the Eugene Water and Electric Board drinking water facility.

[ $\mu \mathrm{g} / \mathrm{L}$, micrograms per liter; MCL, Maximum Contaminant Level; HBSL, Health-Based Screening Level; BQ, Benchmark Quotient (ratio of measured concentration to HBSL concentration); E, concentration estimated between minimum detection level and laboratory report limit]

\begin{tabular}{|c|c|c|c|c|c|c|}
\hline Compound & $\begin{array}{c}\text { Concentration } \\
(\mu \mathrm{g} / \mathrm{L})\end{array}$ & Sample date & $\begin{array}{c}\text { MCL } \\
\text { concentration } \\
(\mu \mathrm{g} / \mathrm{L})\end{array}$ & $\begin{array}{c}\text { HBSL } \\
\text { concentration } \\
(\mu \mathrm{g} / \mathrm{L})\end{array}$ & $\begin{array}{l}\text { BO } \\
\text { for } \\
\text { MCL }\end{array}$ & $\begin{array}{c}\text { BO } \\
\text { for } \\
\text { HBSL }\end{array}$ \\
\hline Diazinon & 0.009 & $12-24-03$ & - & 1 & - & 0.009 \\
\hline Caffeine & 0.012 & 09-17-04 & - & - & - & - \\
\hline AMPA & 0.02 & $10-04-08$ & - & - & - & - \\
\hline AMPA & 0.02 & 05-05-09 & - & - & - & - \\
\hline Carbaryl & E 0.005 & 05-05-09 & - & 40 & - & 0.0001 \\
\hline Hexazinone & Е 0.007 & 05-05-09 & - & 400 & - & 0.00002 \\
\hline Atrazine & E 0.006 & 05-06-09 & 3 & - & 0.0021 & - \\
\hline CIAT & E 0.004 & 05-06-09 & - & - & - & - \\
\hline Cypermethrin & E 0.014 & $10-24-09$ & - & 40 & - & 0.0004 \\
\hline CIAT & E 0.004 & 03-30-10 & - & - & - & - \\
\hline Carbaryl & E 0.01 & 03-30-10 & - & 40 & - & 0.0003 \\
\hline Sulfometuron-methyl & E 0.0064 & 03-30-10 & - & 2,000 & - & 0.000003 \\
\hline
\end{tabular}

\section{Seasonal Hydrologic Conditions}

Almost all sample surveys were conducted during storms, either spring $(\mathrm{n}=4)$ or fall $(\mathrm{n}=7)$, with two additional storm surveys conducted during winter (table 2). Three non-storm surveys also were conducted, two in spring and one in summer. The strategy for fall storm samples was simply to characterize the first major runoff-producing storm of the fall, while that for spring samples was to characterize the first major storm after spring pesticide application, generally considered to occur approximately in April. Spring sampling was not conducted during some years because of the frequently uneven nature of storms and runoff across the study area during that season, especially in non-urban environments where warmer temperatures and the presence of vegetation creates high evapotranspiration, which means more rain is needed to produce runoff.

Most pesticide detections occurred during spring or fall storm surveys, reflecting the large number of these seasonal storm samples, while relatively smaller numbers of compounds were detected during winter storms or during non-storm surveys (table 9; fig. 5). Concentrations were roughly similar for spring and fall storm samples (median concentration $=0.03 \mu \mathrm{g} / \mathrm{L}$ for spring samples and $0.023 \mu \mathrm{g} / \mathrm{L}$ for fall samples). Nonetheless, despite the small number of spring storm surveys, spring samples showed the largest number of detections determined by the laboratory (202 for spring samples compared to 169 for fall storm samples), as well as detections determined by a common reporting level (53 for spring samples and 38 for fall samples). Fewer compounds were detected in winter storm samples $(n=23$, or 4 based on a common reporting level), which
Table 9. Number of analyte/pesticide detections for different land use sites by season.

[Numbers in parentheses are based on a common reporting level of $0.1 \mu \mathrm{g} / \mathrm{L}$; - , no data]

\begin{tabular}{lcrcr}
\hline \multicolumn{1}{r}{ Season } & Urban & Forestry & Agriculture & Mixed \\
\hline Winter storm & $18(3)$ & $2(0)$ & - & $3(1)$ \\
Spring storm & $105(47)$ & $31(2)$ & $19(3)$ & $47(1)$ \\
Fall storm & $106(29)$ & $18(1)$ & - & $45(8)$ \\
Non-storm & $4(0)$ & - & - & $13(0)$ \\
\hline
\end{tabular}

were only collected at urban and mixed sites, reflecting that fewer pesticides are applied in the fall as well as suggesting that pesticide supply available for runoff from soil in urban areas may be depleted by the onset of the rainy season. Winter concentrations were low as well (median $=0.013 \mu \mathrm{g} / \mathrm{L}$ ), presumably indicating the additional influence of dilution with greater streamflow. A small number of detections also were associated with non-storm surveys ( $\mathrm{n}=17$, or zero when based on a common reporting level). These results are consistent with the general pattern that has been frequently observed (Anderson and others, 1996, 1997; Larson and others, 1997; Rinella and Janet, 1997; Wood, 2001; Gilliom and others, 2006), which is that the most significant pesticide transport occurs in nonirrigated areas during the spring and fall. Nonetheless, they also document that although pesticide transport was most pronounced in the spring, pesticides were detected in surface waters in the basin under a range of storm and non-storm conditions during the entire rainy season, especially at low concentrations. 


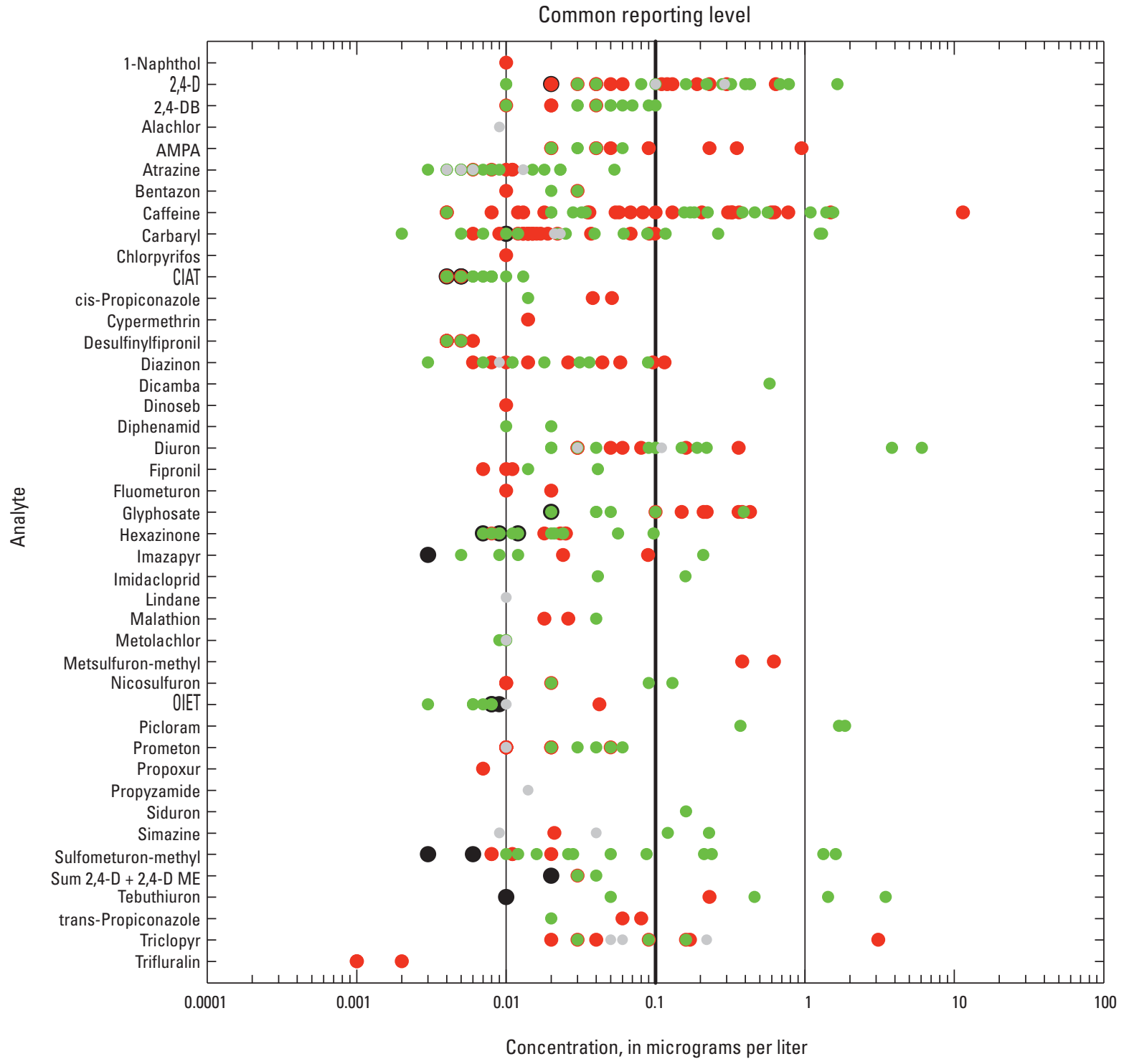

EXPLANATION

Non-storm samples

- Fall storm samples

- Spring storm samples

- Winter storm samples

Figure 5. Pesticide concentrations detected during seasonal surveys in the McKenzie River basin, Oregon, 2002-10. 
Focusing on the small number of compounds detected using a common reporting level of $0.1 \mu \mathrm{g} / \mathrm{L}$, the three compounds most frequently detected during the spring storms were 2,4-D ( $\mathrm{n}=11)$, caffeine $(\mathrm{n}=10)$, and diuron $(\mathrm{n}=7)$. Combined, these three compounds represented 53 percent of all detections during the spring storm surveys; all these detections were associated with urban sites, except one detection of diuron. Two of these compounds (caffeine, $\mathrm{n}=12$, and 2,4-D, $\mathrm{n}=7$ ) also were among the top three compounds detected during the fall storm surveys, which including glyphosate $(\mathrm{n}=7)$ represented 68 percent of all detections. Similarly, most of these detections were associated with urban sites (caffeine, $n=11 ; 2,4-D, n=6$; and glyphosate, $n=3$ ), and the remainder were associated with mixed sites (caffeine, $\mathrm{n}=1$; 2,4-D, $\mathrm{n}=1$; and glyphosate, $\mathrm{n}=4$ ).

Precipitation conditions during storm surveys were evaluated by summing instantaneous precipitation data over the course of a day to provide daily totals for data from two precipitation gages (fig. 1). The gage at Springfield City Hall (site 2) was presumed to roughly represent precipitation conditions for sites located in the downstream region of the basin near the river mouth, including the treatment plant intake, the urban stormwater sites, the agriculture sites, and the sites at the mouths of Camp Creek and Cedar Creek (sites 5-18). The gage at Trout Creek (site 4) was assumed to better represent precipitation conditions for sites farther upstream - the forestry sites and mainstem sites at Leaburg and Finn Rock (sites 19-32).

The four spring storm surveys were conducted in May or June, presumably following the period of spring pesticide application, and occurred in the midst of extended periods of precipitation approaching or exceeding $0.5 \mathrm{in}$. during the previous several months (fig. 6). The two winter storm surveys were conducted under similar conditions, following a series of large precipitation events exceeding 0.5 in. each. In contrast, the seven fall storm surveys were conducted in September or October during storms characterized by only one or two periods of antecedent precipitation approaching $0.5 \mathrm{in}$. during the previous week, with dry conditions prior to that for several months.

\section{Effect of Precipitation and Discharge}

Precipitation data were summed over the 7 days prior to sampling to examine the potential relation between total precipitation volume and pesticide occurrence (evaluated as the number of detections and the sum of all concentrations in a single sample or total concentration). Data from the two precipitation gages (at Springfield City Hall and Trout Creek) were associated with individual sampling sites as described above so that pesticide occcurrence could be evaluated in the context of estimated local precipitation. Simple correlations were determined between precipitation volume prior to sampling and pesticide occurrence for sites grouped by dominant land use, and separately for the drinking water intake (table 10). No significant correlation was observed between precipitation volume and total concentration for any site group. The strongest association was observed for the number of detections at forestry sites $(r=0.68, \mathrm{p}<0.0001$, $n=38$ ), indicating that larger precipitation events are associated with increasingly more detections at these sites. Likewise, detections at the drinking water intake also were directly correlated with increased precipitation $(r=0.55$, $\mathrm{p}=0.02, \mathrm{n}=17)$; agricultural sites showed no significant correlations $(\mathrm{p}<0.05)$, possibly due to the small sample size $(n=5)$. Urban sites showed a contrasting pattern, with a tendency toward fewer number of detections in response to increased precipitation $(r=-0.33, p=0.03, n=41)$. These results suggest that the source of pesticides in urban setting may be depleted by greater volumes of precipitation, implying that urban pesticides may be rapidly discharged to the storm channels with the first flush of precipitation following application.

Further analysis of conditions in Cedar Creek (site 9) focused on examining whether increased stormwater input as proportion of stream discharge was associated with a detectable impact on pesticide concentrations in the creek. The proportion of stormwater drain discharge was approximated by the ratio of a simple sum of mean discharge from the drains over the duration of each sample collection relative to the mean daily streamflow at Cedar Creek on the sample day. Despite the small sample size $(n=5)$, correlation analysis showed a positive, although statistically weak association between this proportion and total pesticide concentration over all seasons $(r=0.79, p=0.11)$. These results are consistent with the hypothesis that pesticide transport in Cedar Creek is at least partially dependent on discharge from stormwater drains.

Table 10. Correlation results for analysis of total concentration and number of pesticides detected (as proportion of analyses conducted) with precipitation sums from 7 days prior to sample collection.

[A bbreviaton: n.s., not statistically significant]

\begin{tabular}{lcccr}
\hline Site type & $\begin{array}{c}\text { Median } \\
\text { precipitation } \\
\text { (inches) }\end{array}$ & $\begin{array}{c}\text { Number of } \\
\text { samples }\end{array}$ & $\begin{array}{c}\text { Total } \\
\text { concentration }\end{array}$ & $\begin{array}{c}\text { Number of } \\
\text { pesticides } \\
\text { detected }\end{array}$ \\
\hline Agriculture & 3.88 & 5 & n.s. & n.s. \\
Forestry & 2.27 & 38 & n.s. & $0.68(\mathrm{p}<0.0001)$ \\
Urban & 0.62 & 41 & n.s. & $-0.33(\mathrm{p}=0.03)$ \\
EWEB intake & 1.36 & 17 & n.s. & $0.55(\mathrm{p}=0.02)$ \\
\hline
\end{tabular}


A.

Daily precipitation and urban survey sample collection

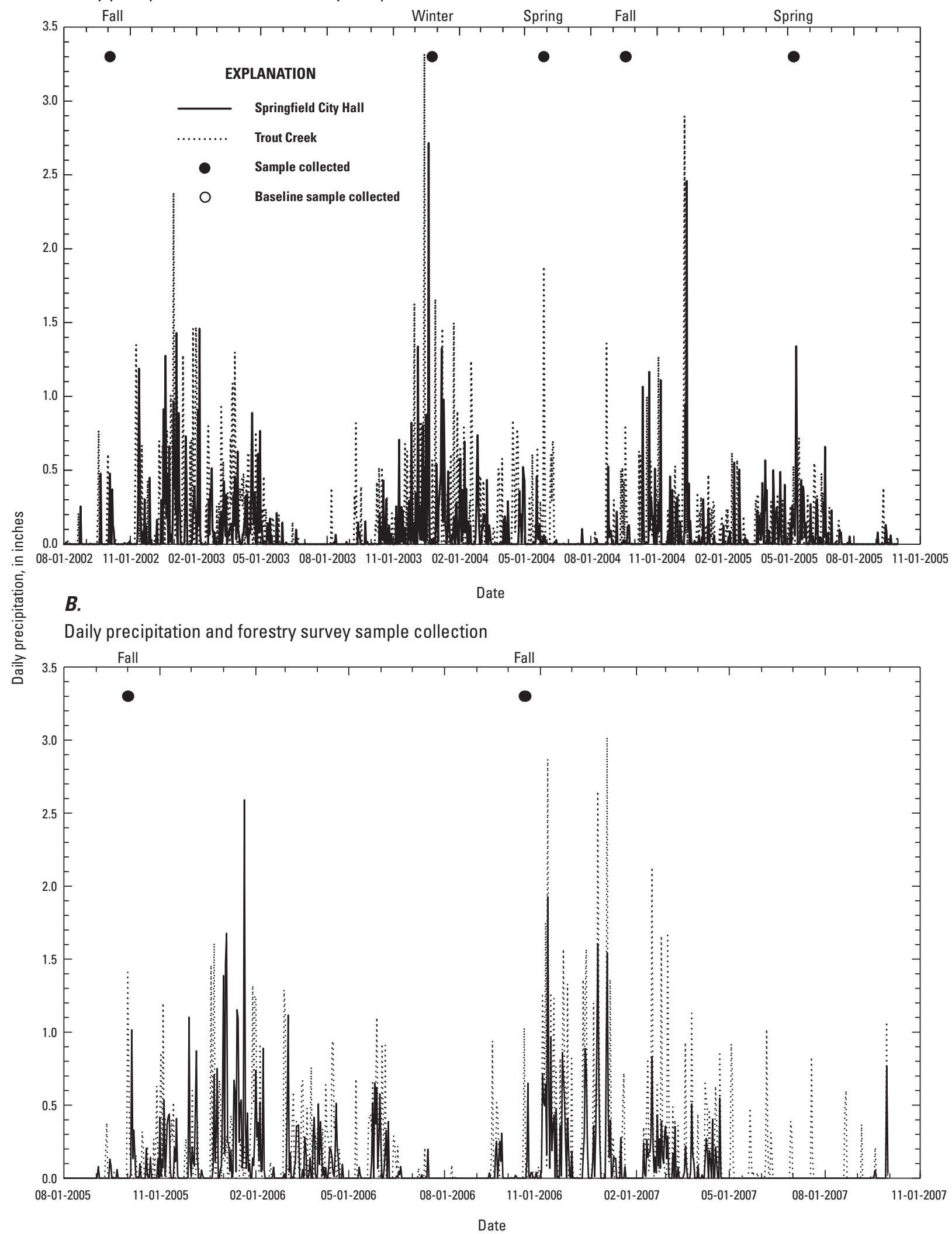

Figure 6. Daily precipitation and sample collection, McKenzie River basin, 2002-10. 
C.

Daily precipitation and mixed-site survey sample collection 2007-08

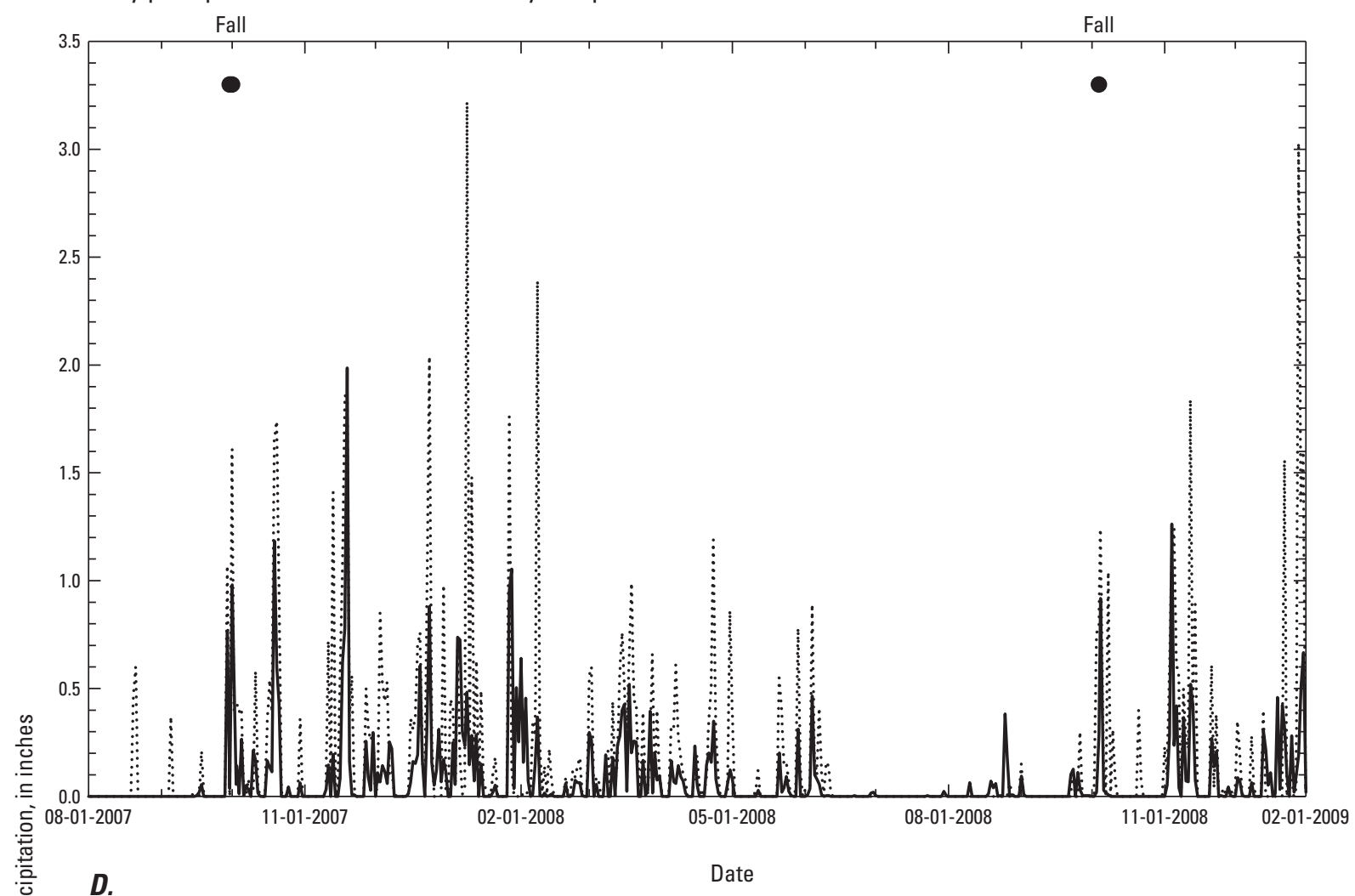

Daily precipitation and sample collection 2009-10

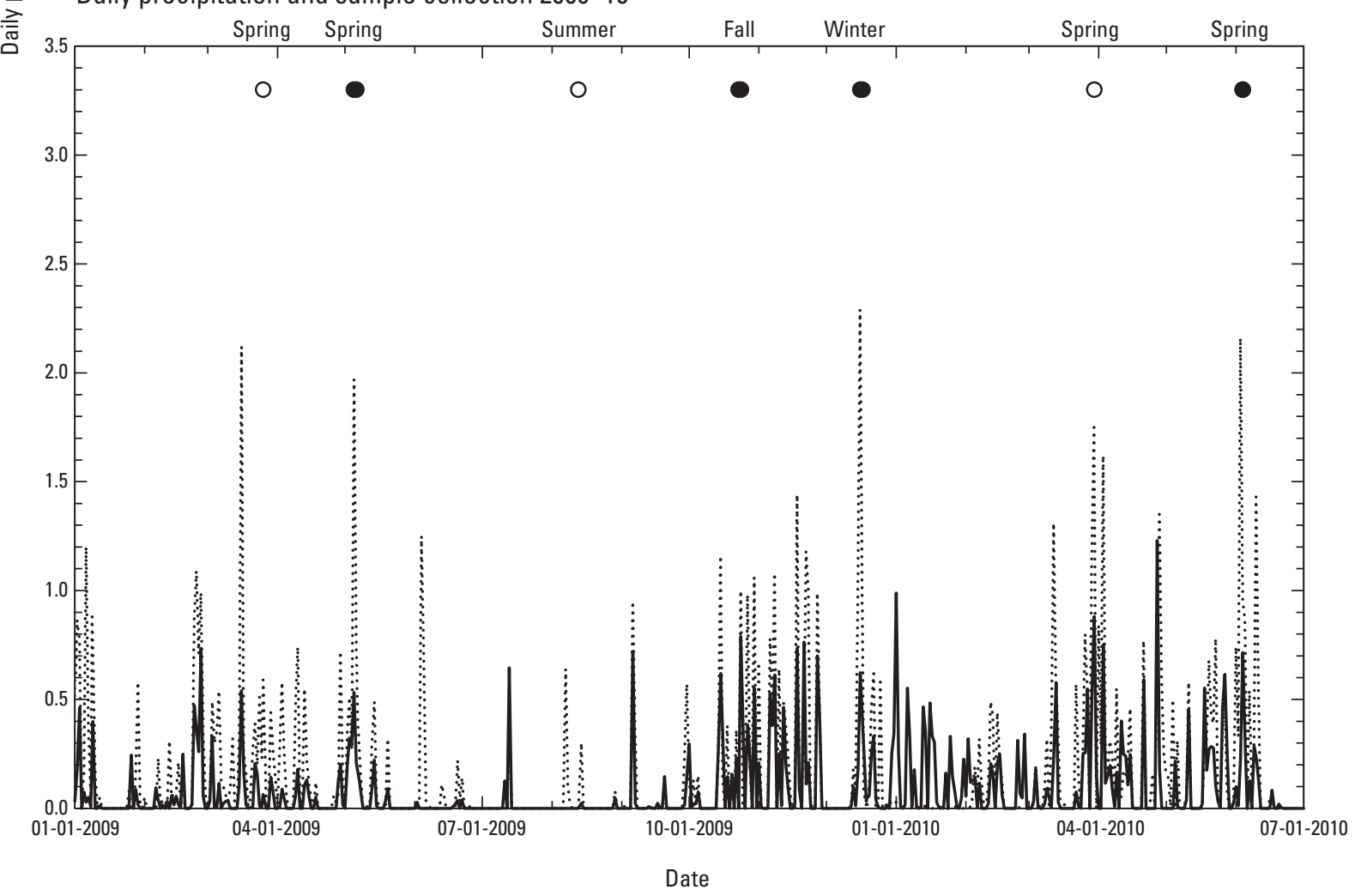

Figure 6.-Continued 


\section{Effect of Sample Timing}

Samples to contrast pre-storm and storm conditions were collected in stormwater drains during two fall storm surveys (2002 and 2004) and one spring survey (2004) (table 4). All sample pairs were associated with antecedent precipitation conditions at Springfield City Hall of approximately 0.5 in. within the previous 7 days (fig. 6). Presumably as a consequence of previous urban runoff, or possibly irrigation runoff from lawns and gardens, none of the pre-storm samples were devoid of pesticide compound, showing relatively high levels of detections although most were at low concentration (table 11). In fact, more than twice as many detections were observed in the pre-storm sample than in the storm sample during the fall 2004, although when screened at the common detection level of $0.1 \mu \mathrm{g} / \mathrm{L}$, all pre-storm detections were excluded for the fall samples. Storm samples consistently contained relatively higher total pesticide concentrations, although some individual compounds showed either no change in concentration (that is, prometon in fall 2002), or were relatively diluted in the storm sample (for example, 2,4-D and caffeine in spring 2004). These results indicate that urban rainy season conditions may be associated with ongoing presence of pesticides in stormwater drains, although generally at lower concentrations than occur under storm conditions.

The influence of sampling over different regions of the hydrograph was evaluated by three sets of paired samples collected at stormwater sites during the fall 2002 and spring 2005. The first sample set, comparing data from the rise and fall of the storm hydrograph, shows both a higher number of detections and nearly twice the total concentration for the sample collected over the rise compared to the fall (1.2 versus $0.70 \mu \mathrm{g} / \mathrm{L})$; this pattern was the same when concentrations were screened at the common reporting level (table 12). Similarly, the second two sets of samples collected early and later in the same storm while the hydrograph continued to rise, show a higher number of detections and larger total concentration for the samples collected nearer to the hydrograph peak (2.3 versus $5.0 \mu \mathrm{g} / \mathrm{L}$ and 0.49 versus $0.75 \mu \mathrm{g} / \mathrm{L}$, respectively). Caffeine and 2,4-D were most consistently measured in both sets of these samples based on the common reporting level (table 12). These results demonstrate the variability inherent in sampling changing stormwater conditions, which is largely occurring at low concentration
Table 11. Summary of results from pre-storm and storm samples.

[Number of samples: Number in parentheses represents detections based on common detection level of $0.1 \mu \mathrm{g} / \mathrm{L}$. A bbreviations: E, concentration estimated between the minimum detection level and the laboratory reporting limit; $\mu \mathrm{g} / \mathrm{L}$, microgram per liter]

\begin{tabular}{|c|c|c|c|c|}
\hline Season & $\begin{array}{c}\text { Sample } \\
\text { type }\end{array}$ & $\begin{array}{l}\text { Number of } \\
\text { samples }\end{array}$ & Compound & $\begin{array}{c}\text { Concentration } \\
(\mu \mathrm{g} / \mathrm{L})\end{array}$ \\
\hline \multicolumn{5}{|c|}{ 64th stormwater pipe } \\
\hline \multirow[t]{9}{*}{ Fall 2002} & Pre-storm & $4(0)$ & CIAT & E 0.005 \\
\hline & & & Caffeine & 0.036 \\
\hline & & & Carbaryl & Е 0.017 \\
\hline & & & Prometon & E 0.010 \\
\hline & Storm & $5(1)$ & Caffeine & 0.77 \\
\hline & & & Carbaryl & E 0.091 \\
\hline & & & Diazinon & 0.044 \\
\hline & & & Prometon & E 0.010 \\
\hline & & & Trifluralin & E 0.002 \\
\hline \multicolumn{5}{|c|}{ 69th stormwater channel } \\
\hline \multirow[t]{22}{*}{ Spring 2004} & Pre-storm & $11(7)$ & $2,4-\mathrm{D}$ & 0.68 \\
\hline & & & Atrazine & 0.023 \\
\hline & & & Caffeine & 0.46 \\
\hline & & & Carbaryl & E 1.26 \\
\hline & & & Diazinon & 0.089 \\
\hline & & & Dicamba & 0.58 \\
\hline & & & Diuron & Е 3.82 \\
\hline & & & Malathion & 0.04 \\
\hline & & & Metolachlor & E 0.01 \\
\hline & & & Siduron & 0.16 \\
\hline & & & Sulfometuron-methyl & E 1.61 \\
\hline & Storm & $11(7)$ & 2,4-D & 0.32 \\
\hline & & & Atrazine & 0.15 \\
\hline & & & Caffeine & 0.38 \\
\hline & & & Carbaryl & E 1.3 \\
\hline & & & Desulfinylfipronil & E 0.004 \\
\hline & & & Diazinon & 0.36 \\
\hline & & & Diuron & E 6.07 \\
\hline & & & Fipronil & E 0.014 \\
\hline & & & Metolachlor & E 0.009 \\
\hline & & & Prometon & E 0.05 \\
\hline & & & Sulfometuron-methyl & E 1.33 \\
\hline \multirow[t]{11}{*}{ Fall 2004} & Pre-storm & $8(0)$ & Atrazine & 0.011 \\
\hline & & & CIAT & E 0.004 \\
\hline & & & Caffeine & 0.068 \\
\hline & & & Carbaryl & Е 0.006 \\
\hline & & & Diuron & 0.08 \\
\hline & & & OIET & E 0.042 \\
\hline & & & Prometon & 0.02 \\
\hline & & & Sulfometuron-methyl & E 0.008 \\
\hline & Storm & $3(3)$ & $2,4-\mathrm{D}$ & 0.12 \\
\hline & & & Caffeine & E 0.31 \\
\hline & & & Diuron & Е 0.16 \\
\hline
\end{tabular}


Table 12. Summary of results from sampling over different regions of the storm hydrograph.

[Number of samples: Number in parentheses represents detections based on common detection level of $0.1 \mu \mathrm{g} / \mathrm{L}$. A bbreviations: E, concentration estimated between the minimum detection level and the laboratory reporting limit; $\mu \mathrm{g} / \mathrm{L}$, microgram per liter]

\begin{tabular}{|c|c|c|c|c|}
\hline Season & $\begin{array}{c}\text { Sample } \\
\text { type }\end{array}$ & $\begin{array}{l}\text { Number of } \\
\text { samples }\end{array}$ & Compound & $\begin{array}{c}\text { Concentration } \\
(\mu \mathrm{g} / \mathrm{L})\end{array}$ \\
\hline \multicolumn{5}{|c|}{ 69th Stormwater channel } \\
\hline \multirow[t]{15}{*}{ Fall 2002} & Rise & $8(3)$ & 2,4-D & 0.64 \\
\hline & & & Caffeine & Е 0.33 \\
\hline & & & Carbaryl & E 0.068 \\
\hline & & & Diazinon & 0.11 \\
\hline & & & Diuron & E 0.05 \\
\hline & & & Malathion & Е 0.018 \\
\hline & & & Prometon & Е 0.02 \\
\hline & & & Trifluralin & Е 0.001 \\
\hline & Fall & $7(2)$ & $2,4-\mathrm{D}$ & 0.19 \\
\hline & & & Carbaryl & Е 0.019 \\
\hline & & & Diazinon & 0.096 \\
\hline & & & Diuron & Е 0.36 \\
\hline & & & Malathion & Е 0.026 \\
\hline & & & Prometon & E 0.01 \\
\hline & & & Trifluralin & E 0.001 \\
\hline \multicolumn{5}{|c|}{ 42nd Stormwater culvert } \\
\hline \multirow[t]{13}{*}{ Spring 2005} & Early & $5(3)$ & $2,4-\mathrm{D}$ & 0.78 \\
\hline & & & 2,4-DB & 0.03 \\
\hline & & & Caffeine & E 1.39 \\
\hline & & & Carbaryl & Е 0.039 \\
\hline & & & Diuron & 0.10 \\
\hline & Peak & $8(5)$ & $2,4-\mathrm{D}$ & Е 0.4 \\
\hline & & & 2,4-DB & 0.04 \\
\hline & & & Caffeine & E 1.09 \\
\hline & & & Carbaryl & 0.022 \\
\hline & & & Diuron & 0.09 \\
\hline & & & Picloram & E 1.69 \\
\hline & & & $\begin{array}{l}\text { Sulfometuron- } \\
\text { methyl }\end{array}$ & 0.24 \\
\hline & & & Tebuthiuron & 1.43 \\
\hline \multicolumn{5}{|c|}{ 64th Stormwater pipe } \\
\hline \multirow[t]{12}{*}{ Spring 2005} & Early & $5(2)$ & $2,4-\mathrm{D}$ & 0.16 \\
\hline & & & 2,4-DB & 0.03 \\
\hline & & & Caffeine & 0.22 \\
\hline & & & Carbaryl & Е 0.061 \\
\hline & & & Diphenamid & 0.02 \\
\hline & Peak & $7(2)$ & 2,4-D & 0.32 \\
\hline & & & 2,4-DB & 0.05 \\
\hline & & & Caffeine & 0.18 \\
\hline & & & Carbaryl & Е 0.12 \\
\hline & & & Diazinon & 0.018 \\
\hline & & & Diuron & 0.02 \\
\hline & & & Prometon & 0.04 \\
\hline
\end{tabular}

$(<0.1 \mu \mathrm{g} / \mathrm{L})$. They reinforce the replicate analysis previously described, as well as the importance of documenting hydrograph conditions during sample collection. They also suggest that samples composited over the entire rise and fall of the storm hydrograph would tend to dampen this variability and thereby most comprehensively describe average conditions over the entire storm.

\section{Effect of Land Use}

The distribution of detected pesticide compounds across the range of land-use settings shows that the largest number of compounds was associated with urban land use (fig. 7). A total of 37 compounds were detected at urban sites at least once during this study, and 18 of these were uniquely detected at urban sites. In contrast, 14 compounds were detected at forestry sites and 8 compounds at agricultural sites, all of which were widely observed in a range of land-use settings, frequently associated with mixed land-use sites. Focusing on the smaller group of compounds detected using a common reporting level of $0.1 \mu \mathrm{g} / \mathrm{L}$, the pattern is roughly the same: 16 compounds were detected at urban sites (9 unique), 3 compounds were detected at forestry sites (2 unique) and 3 compounds were detected at agricultural sites (none unique). Of these commonly screened compounds, those unique to urban sites included 2,4-DB $(\mathrm{n}=1)$, carbaryl $(n=4)$, diazinon $(n=1)$, dicamba $(n=1)$, metsulfuron-methyl $(n=2)$, picloram $(n=3)$, simazine $(n=1)$, sulfometuron-methyl $(n=4)$, and tebuthiuron $(n=4)$; compounds unique to forestry sites included imazapyr $(\mathrm{n}=1)$ and nicosulfuron $(n=1)$.

Urban sites also were associated with the largest pesticide concentrations (fig. 7). Of the 17 detected concentrations that exceeded $1 \mu \mathrm{g} / \mathrm{L}$, all but 1 were detections from urban sites, specifically from stormwater drains. These urban compounds included 2,4-D ( $\mathrm{n}=1)$, caffeine $(\mathrm{n}=5)$, carbaryl $(n=2)$, diuron $(n=2)$, picloram $(n=2)$, sulfometuron-methyl $(\mathrm{n}=2)$, and tebuthiuron $(n=2)$. The remaining concentration exceeding $1 \mu \mathrm{g} / \mathrm{L}$ was for triclopyr, and was detected at Ward Creek, a forestry site (site 26). This extreme value does not reflect forestry application exclusively, however, because it was subsequently associated with recent homeowner application near the stream. 


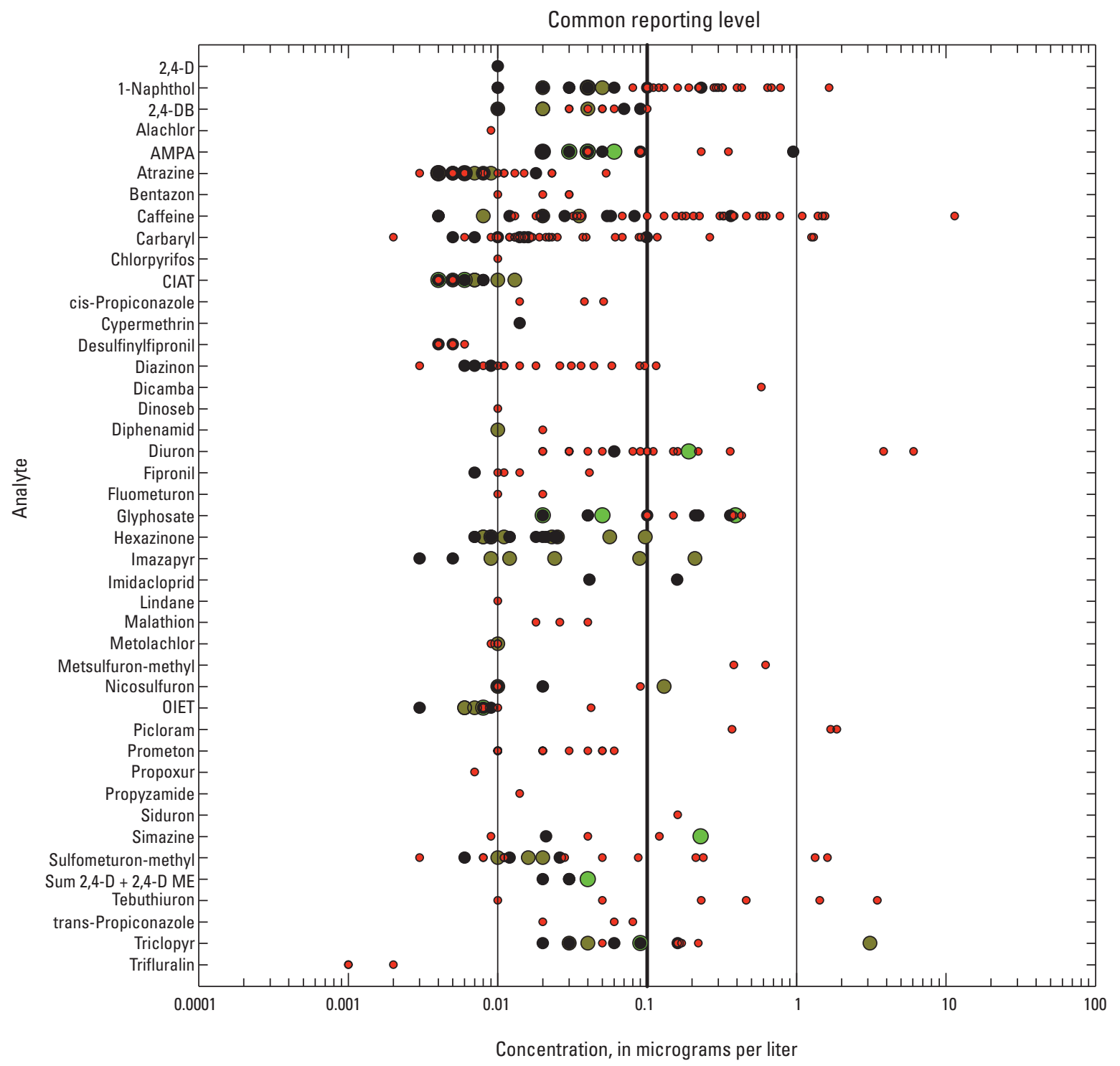

$\begin{array}{ll}\text { EXPLANATION } \\ \begin{array}{ll}\text { Agricultural land use } \\ \text { - }\end{array} \text { Forestry land use } \\ \text { - } & \text { Mixed land use } \\ \text { - Urban land use }\end{array}$

Figure 7. Pesticide concentrations by major land-use category, McKenzie River basin, Oregon. 
Total concentrations were highest for urban sites (median $=0.70 \mu \mathrm{g} / \mathrm{L}, \mathrm{n}=37$ ), and total concentrations generally were lowest for agricultural sites (median $=0.11 \mu \mathrm{g} / \mathrm{L}, \mathrm{n}=4$ ) (fig. 8). Total concentrations generally were lower for forestry (median = 0.042, $\mathrm{n}=20$ ) and mixed (median =0.072 $\mu \mathrm{g} / \mathrm{L}$, $\mathrm{n}=33$ ) sites than for urban sites. A strong seasonal pattern was observed overall, with fall (median $=0.14 \mu \mathrm{g} / \mathrm{L}, \mathrm{n}=42$ ) and spring (median $=0.14 \mu \mathrm{g} / \mathrm{L}, \mathrm{n}=40$ ) storm samples from all sites combined associated with the largest total concentrations compared to winter storm samples (median $=0.055, \mathrm{n}=8$ ) and non-storm samples (median $=0.026, n=5$ ). The distribution of total concentrations across seasons and land use indicates that only urban sites showed a contrast among seasons that ranged across several orders of magnitude. Total concentrations were higher in spring storm samples (median=1.4 $\mu \mathrm{g} / \mathrm{L}$, $\mathrm{n}=13$ ) than in fall storm samples (median $=0.70 \mu \mathrm{g} / \mathrm{L}$, $\mathrm{n}=18$ ). Total concentrations were more similar across seasons for forestry sites (median for fall $=0.047 \mu \mathrm{g} / \mathrm{L}$, $\mathrm{n}=10$; for spring $=0.04 \mu \mathrm{g} / \mathrm{L}, \mathrm{n}=9$ ). Total concentrations for the mixed sites were higher in the autumn storm samples (median $=0.098 \mu \mathrm{g} / \mathrm{L}, \mathrm{n}=14$ ) than the spring storm samples (median $=0.057 \mu \mathrm{g} / \mathrm{L}, \mathrm{n}=13$ ). Total concentrations at agricultural sites, only sampled during spring storms, were relatively high but less than concentrations detected in urban sites (median $=0.11 \mu \mathrm{g} / \mathrm{L}, \mathrm{n}=5$ ). Total concentrations for winter storm samples were uniformly low across all land-use sites (for urban sites, median $=0.065 \mu \mathrm{g} / \mathrm{L}, \mathrm{n}=5$; for mixed sites, median $=0.084 \mu \mathrm{g} / \mathrm{L}, \mathrm{n}=2$; and for forestry sites a single value of $0.014 \mu \mathrm{g} / \mathrm{L})$.

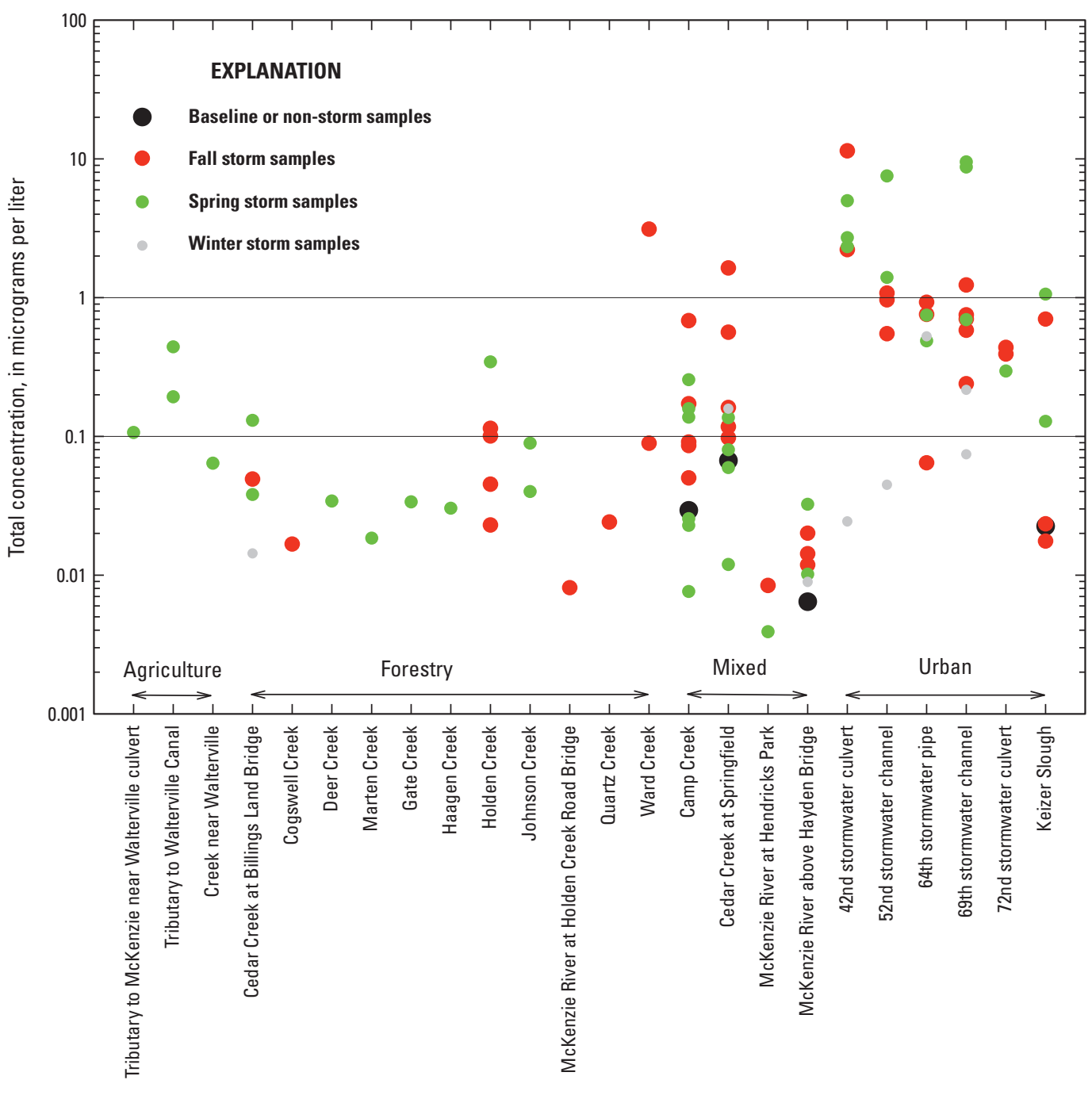

Sample site

Figure 8. Total concentrations for detected pesticide compounds by season and land use, McKenzie River basin, Oregon. 


\section{Land-Use Signatures}

The potential to detect specific land-use signatures at sites characterized by a mixture of land-use activity was limited because the uncertainties in pesticide use reporting as well as the overlap in use among different land- use categories made it difficult to identify compounds that can serve to reliably identify specific land-use applications. Nonetheless, the data indicate that urban/rural residential and agricultural pesticides are important components of pesticide transport in tributary drainage basins with a mix of land use, despite the relatively small proportion of drainage basin area associated with these uses. In the lower basin, the Cedar Creek drainage is predominantly forested (about 62 percent), but with a significant component of urban and rural residential land use (about 24 percent) and a smaller proportion of agricultural land use (about 11 percent). A total of 17 compounds were detected in12 samples at the mouth of Cedar Creek (site 9) (total $n$ for detections=44) (table 13). Most of these compounds also were associated with the range of reported agricultural, forestry, and urban applications, although two compounds (fipronil and its metabolite desulfinylfipronil) were exclusively associated with reported urban use. Detections based on a common reporting level were associated with four compounds-2,4-D, caffeine, glyphosate and its metabolite AMPA, which also represent a mix of reported agricultural, forestry, and urban applications.

Table 13. Detected compounds at Cedar and Camp Creeks, McKenzie River basin, Oregon.

[Location of sites is shown in figure 1. Values in parenthesis are based on common reporting level of 0.1 microgram per liter. -, not detected]

\begin{tabular}{|c|c|c|}
\hline \multirow[b]{2}{*}{ Compound } & \multicolumn{2}{|c|}{ Number of detected compounds } \\
\hline & $\begin{array}{l}\text { Cedar Creek } \\
\text { (site 14) }\end{array}$ & $\begin{array}{c}\text { Camp Creek } \\
\text { (site 9) }\end{array}$ \\
\hline 1-Naphthol & 1 & - \\
\hline $2,4-\mathrm{D}$ & $6(1)$ & $4(1)$ \\
\hline 2,4-DB & 1 & 2 \\
\hline AMPA & $5(1)$ & 3 \\
\hline Atrazine & 1 & 5 \\
\hline CIAT & 1 & 8 \\
\hline Caffeine & $4(1)$ & 2 \\
\hline Carbaryl & 5 & - \\
\hline Desulfinylfipronil & 2 & - \\
\hline Diazinon & 2 & - \\
\hline Diuron & - & 1 \\
\hline Fipronil & 1 & \\
\hline Glyphosate & $6(3)$ & $1(1)$ \\
\hline Hexazinone & 2 & 7 \\
\hline Imazapyr & - & 2 \\
\hline Imidacloprid & - & $2(1)$ \\
\hline Nicosulfuron & 2 & 1 \\
\hline OIET & 1 & 3 \\
\hline Simazine & - & 1 \\
\hline Sulfometuron-methyl & 2 & - \\
\hline Triclopyr & 2 & $3(1)$ \\
\hline
\end{tabular}


Camp Creek (site 14) also is largely forested (about 85 percent), with less agricultural activity (about 8 percent) and a small component of rural residential land use (about 2 percent). Most of the 15 compounds that were detected in 10 samples from Camp Creek were reported to be widely used across all land uses (total $n$ for detections $=45$ (table 13). Two compounds were reported as exclusively urban (imidacloprid) or agricultural (simazine). Detections based on the common reporting level were associated with four compounds-2,4-D, glyphosate, imidacloprid, and triclopyr. Imidacloprid is an insecticide associated with urban use, and the other three compounds are associated with a mix of reported uses.

A comparable pattern of compounds from across the range of land-use applications was observed at the treatmentplant intake (McKenzie River above Hayden Bridge, site 5), as previously discussed (table 8). In 17 samples, a total of 9 compounds (total $\mathrm{n}$ for detections $=12$ ) were detected, reflecting reported land-use application that included all categories of land use even though urban and agricultural lands comprise a small component of the drainage basin (about 4 and 2 percent, respectively). None of the concentrations in samples from the intake exceeded the common reporting level of $0.1 \mu \mathrm{g} / \mathrm{L}$. Farther upstream, effects of forestry or agricultural pesticide use were not observed in mainstem sites, possibly due to the small number of samples. Caffeine was the only compound observed at these upstream sites, with three detections in five samples from the McKenzie River at Hendricks Park Boat Ramp (site 16) and one detection in two samples from the McKenzie River at Holden Creek Road Bridge farther upstream (site 19). All these concentrations exceeded the common reporting level of $0.1 \mu \mathrm{g} / \mathrm{L}$. Both of these sites are associated with forestry land use with varying degrees of limited residential or agricultural land use. However, even though the data are limited, these results indicate that effects of forestry pesticide use are negligible at these locations in the river system, and effects of agricultural pesticide use are similarly not detectable.

\section{Physical Characteristics and Land Use}

Evaluating physical characteristics of all detections (excluding double counting of summed forms and degradates that are not applied to the landscape) across the range of land use, most were of compounds that were not highly hydrophobic (log soil $\mathrm{Koc}<3$ ), as measured by their tendency to sorb to soil particles (median log soil Koc $=2.3, n=310$ ) (fig. 9A). Those detections with the most hydrophobic character primarily were associated with urban and agricultural land use (fig. 9). Many of these also are suspected of endocrine disruption (table 6). Similarly, data for persistence indicates that most detections were not associated with highly persistent compounds $\left(\mathrm{T}_{1 / 2}<100\right.$ days) (median $\mathrm{T}_{1 / 2}=46$ days, $\mathrm{n}=310$ ), although the most persistent compounds were associated with urban and agricultural sites (fig. 9B). Strongly hydrophobic and persistent compounds were also observed at mixed sites (especially Cedar Creek at Springfield (site 9), which is subject to significant urban influence. No strong seasonal pattern for physical characteristics was observed, although a slight increasing gradient in hydrophobic character was indicated from the nonstorm samples through spring, winter, and fall (median log soil $\mathrm{KoC}=1.9,2.0,2.2$, and 2.4, respectively). 

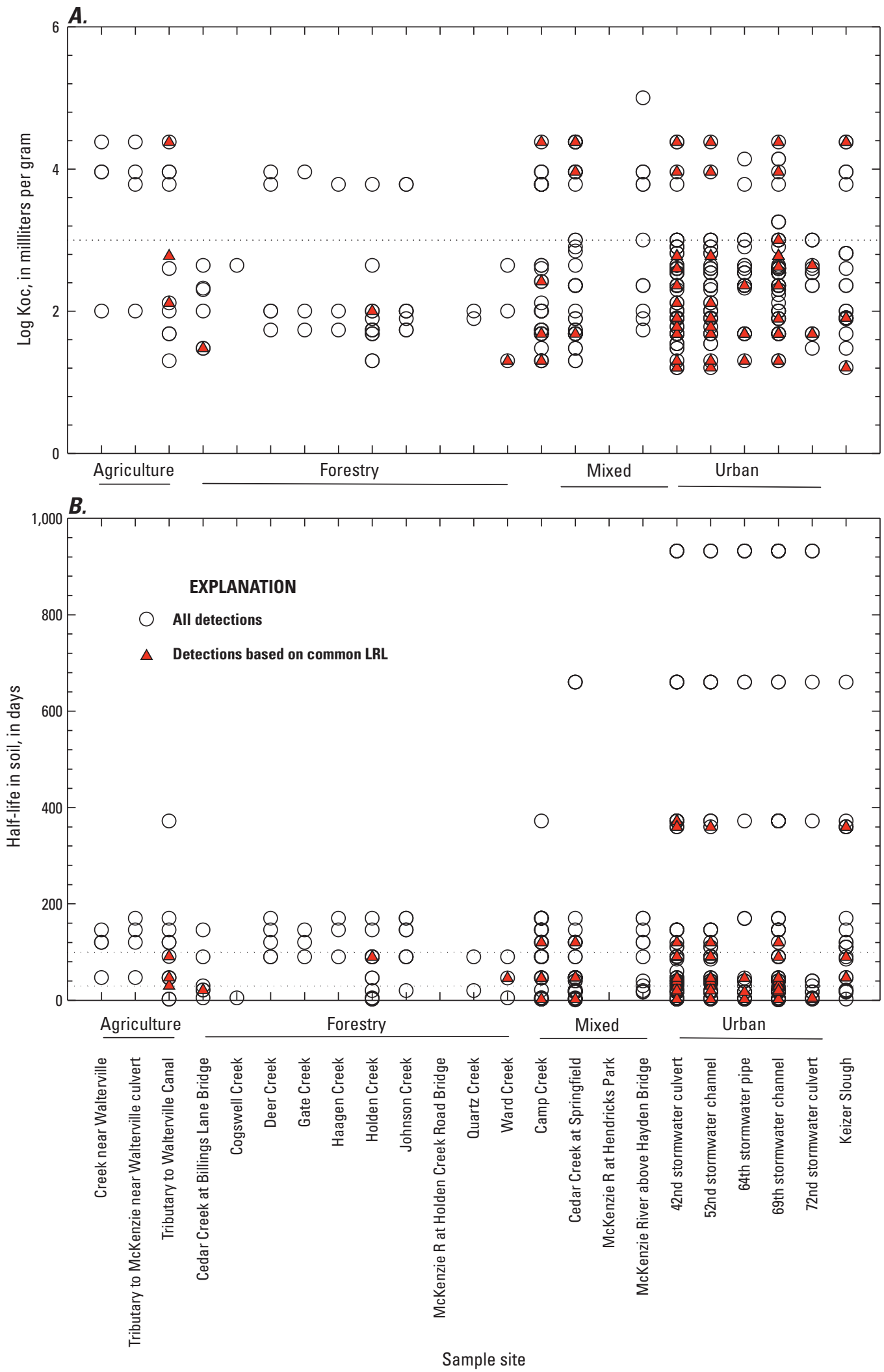

Figure 9. Physical characteristics for pesticide compounds detected at specific sample sites, McKenzie River basin, Oregon. 


\section{Conclusions}

In 135 environmental samples collected at 28 sites in the McKenzie River basin during 2002-10 that were analyzed for as many as 175 compounds, a total of 43 compounds were detected at least once. Concentrations tended to be low ( $<0.1 \mu \mathrm{g} / \mathrm{L}$ ) (median for maximum concentration for each compound $=0.055 \mu \mathrm{g} / \mathrm{L})$. Most samples contained compound mixtures (median number of detections per sample $=4$ ), although some samples had no detections. Caffeine was the most frequently detected compound, and with hexazinone, 2,4-D, atrazine, glyphosate and its metabolite AMPA, and carbaryl, accounted for approximately 46 percent of all detections. When detections were measured using a common LRL $(0.1 \mu \mathrm{g} / \mathrm{L})$, the number of compounds was reduced to 19 , reflecting the occurrence of many compounds only at low concentration. When screened at the common LRL, no detections were observed for two of the most frequently detected compounds (hexazinone and atrazine), although caffeine, 2,4-D, and glyphosate (with the addition of diuron) remained among the most frequently detected compounds. Twenty-one compounds (nine when based on the common LRL) are either regulated by a drinking-water standard ( $n=9$ versus $n=4$ for common LRL) and/or suspected to be endocrine-disrupting compounds ( $n=20$ versus $n=6$ for common LRL).

Nine compounds were detected at the treatment-plant intake (none when screened at the common LRL), most of which were frequently detected at other sites. Concentrations were uniformly quite low, most of them E-coded as "estimates" or less than the LRL. Human-health benchmarks were available for six of these compounds and were several orders of magnitude higher than measured concentrations, indicating that pesticide concentrations at the drinking-water intake present a negligible threat to human health.

Nonetheless, multiple compounds were occasionally detected in a single sample, and the potential for synergistic effects of occasional low-level presence $(<0.1 \mu \mathrm{g} / \mathrm{L}$ total concentration) of compound mixtures is not well understood.

The largest number of pesticide detections occurred during spring storm surveys, primarily associated with urban stormwater drains. Urban sites also were associated with the highest concentrations, occasionally exceeding $1 \mu \mathrm{g} / \mathrm{L}$. Many of the compounds detected at urban sites were relatively hydrophobic (log soil Koc $>3$ ), persistent $\left(T_{1 / 2}>100\right)$, and suspected of endocrine disruption; these patterns held for both total detections and for detections screened at the common LRL. When screened by the common LRL, caffeine and 2,4-D were most frequently detected in spring and fall storms; additionally, diuron was an important compound detected during the spring and glyphosate was among the most frequently detected during the fall.
Even though pesticides were detected across the range of sites under both storm and non-storm conditions, not all categories of sites responded in the same way to increased precipitation. No simple relation was observed for any category of sites between total (summed) pesticide concentration and precipitation volume, although larger precipitation events were significantly correlated $(\mathrm{p}<0.05)$ with more detections at forestry sites and the drinking-water intake. In contrast, increasing precipitation volume was associated with fewer detections at urban sites. These results suggest that pesticides show a different pattern of runoff and transport in the urban environment compared to less impervious environments associated with forested lands.

The data show a tendency for increasing total pesticide concentration in Cedar Creek with increasing proportion of flow from stormwater drains, suggesting that stormwater is an important influence on pesticide transport in that tributary. Additional data from stormwater drains show that pesticides can be detected even under non-storm conditions, although total concentrations were relatively reduced compared to storm concentrations. Considerable variability in total pesticide concentration was observed in samples collected from stormwater drains over the range of a storm hydrograph.

Definitive land-use signatures impacting conditions at the drinking-water intake were difficult to establish because of the potential for many observed chemicals to be used across a range of land uses, as well as the uncertainty in pesticide use estimates. Nonetheless, the occurrence of pesticide detections across all categories of sites indicates that all land-use applications contribute to pesticide runoff. This pattern was observed for all detections as well as the subset of detections screened at the common LRL. No significant detections based on the common LRL of any pesticide compounds were observed at the drinking-water intake or any mainstem river site, indicating that concentrations in the McKenzie River itself were consistently low. Although forest land use is predominant in the basin, and forestry pesticide use can be detected in small tributaries draining forested lands following application, these compounds rarely were detectable in the McKenzie River. Forestry pesticide use, therefore, probably is not a potential threat to drinking-water quality at the present time. Agricultural pesticide runoff is not well characterized by the limited data available. Nonetheless, agricultural pesticide use is likely to pose a greater potential threat because of the large number of relatively hydrophobic agricultural compounds reported to be used in the basin (most of which were never detected, presumably because of limited sampling of agricultural streams) and the moderately high concentrations that were observed in small tributaries draining agricultural lands. More complete understanding of agricultural chemicals in runoff in the McKenzie River basin requires further investigation. In contrast, results of this analysis are sufficient to strongly suggest that urban pesticide use is an important source for pesticides of concern 
for drinking water in runoff, not limited exclusively to storm conditions. A large number of compounds and high concentrations ( $>0.1 \mu \mathrm{g} / \mathrm{L}$ ) were observed in stormwater drains, many of them relatively hydrophobic ( $\log \mathrm{Koc}>3$ ) and persistent $\left(\mathrm{T}_{1 / 2}>100\right.$ days).

\section{Conceptual Model}

Because this was a reconnaissance study, the data were not intended to provide a consistent framework for comprehensive and rigorous analysis. Nonetheless, the results from this study and others in Oregon represent a useful foundation for generating a hypothetical conceptual model describing pesticide contamination and transport in the McKenzie River basin. This conceptual model depends on and is consistent with current scientific thinking about pesticides in surface waters (Larson and others, 1997). Nonetheless, because limited data currently exist to fully characterize pesticide occurrence and transport in the McKenzie River basin, this model can be understood essentially as a set of hypotheses that are proposed to serve as the foundation for future monitoring in the basin.

The McKenzie River basin is dominated by forested land in the High and Western Cascade physiographic provinces with a large groundwater component, and consequently by mainstem streamflow that is clean and relatively stable during base flow. As such, it serves as a valuable source for drinking water of superior quality for the City of Eugene. The relatively small number of pesticide detections and low concentrations detected at the treatment plant intake indicate that this high quality of water is not seriously compromised at this time. Nonetheless, pesticides can be detected in stormwater channels and streams that drain a range of land use in the basin including urban/residential settings, agricultural applications, and forestry management.

A large number of compounds are reported or estimated to be used within the context of these land-use activities. Some fraction of the many pesticides applied across the mixture of land-use settings in the basin is transported from the site of application to surface waters in the basin, presumably primarily through surface runoff, so that all land-use activities in the basin generate measurable pesticide runoff. Because most pesticide applications occur in the middle and lower regions of the basin, where precipitation generally occurs as rain, pesticide transport is pronounced during storm conditions in the spring and fall. Pesticide compounds also may be present at low levels in surface waters throughout the year, suggesting ongoing supply from some sources and/or some degree of groundwater input in addition to surface-water runoff.

A large number of pesticides are used in urban settings, some of them estimated to be unique to urban use. Pesticides are applied in urban areas according to a fairly continuous pattern throughout the spring, summer, and fall (Larson and others, 1997). Once precipitation begins to fall, the larger proportion of impervious area in urban environments means that runoff is generated quickly. Virtually all pesticides that reach impervious areas are transported to stormwater drains, where concentrations can become quite high. As a result, pesticides may be detected in urban stormwater drains whenever significant runoff occurs. The summed or total pesticide concentrations in storm drains vary considerably over the course of individual storm events, often being highest near the peak of the hydrograph; at the same time, urban pesticide sources also may be depleted or diluted relatively quickly by increasing volume of precipitation. Urban runoff via stormwater drains during storms is an important source of discharge to Cedar Creek, and a lesser source to Keizer Slough, both of which flow into the McKenzie River close to the treatment-plant intake.

The occurrence of agricultural pesticides in streams in the McKenzie River basin is not well documented, although it is assumed to accord with patterns observed in other Oregon streams (Anderson and others, 1996, 1997; Rinella and Janet, 1997; Wood, 2001). These patterns include runoff of agricultural pesticides during large spring storms following application, with reduction in runoff occurring during the low-flow period in the summer. Another peak in concentration is anticipated in agricultural streams during the first major precipitation event in the fall.

Most compounds that are used for forestry applications in the McKenzie River basin are widely used for other applications in the basin, although a small number are unique to forestry use. Because forestry applications are relatively limited in both time and space, forestry pesticide use is less of a concern than urban or agricultural use. Pesticides, predominantly herbicides, are utilized in forestry management primarily for site preparation before planting and reduction of competition from non-target vegetation. This pattern of application means herbicides are applied only once or twice in the period of two to five decades between planting and timber harvest (Larson and others, 1997). As a result, in any given year pesticides are applied to a small number of forested watersheds, which are also relatively small in size. Furthermore, depending on the compound and mode of application, pesticide runoff from forestry use occurs fairly quickly during the first few storms following application (Neary and others, 1993). Forestry pesticides are therefore transported in surface waters only briefly, occurring in shortlived pulses that are quickly reduced by dilution downstream (Larson and others, 1997). As a result, the seasonal pattern in forestry pesticide transport is relatively ephemeral and site specific, with pesticides showing a strong response to precipitation and primarily mobilized within the first few months after they are applied (Neary and others, 1993).

Most compounds that are detected in water by conventional laboratory analysis tend to be relatively hydrophilic and are therefore transported primarily in the dissolved phase. Additional compounds have been reported or estimated to be used in the basin, especially for agricultural 
applications, but have not yet been observed in surface water. Laboratory analysis has been conducted exclusively on filtered samples, so chemicals that are more hydrophobic in character and occurring primarily in association with sediment particles are not likely to be detected. Data from a study of sediment released from Cougar Reservoir in the South Fork McKenzie River during a construction project in 2002-05 document that metabolites of DDT were detected in fine sediments deposited downstream, including below the confluence with the mainstem McKenzie River (Anderson, 2007). DDT was widely used in a forestry application in the upper McKenzie Basin during the 1950s. No species of DDT or its metabolites were detected in water during that study, although they have been detected in very low concentrations, well below reporting limits for conventional analysis, in extracts from passive samplers deployed in the lower basin (USGS, unpublished data). These data suggest that contaminated sediment may be serving as a persistent and low-level source for these types of compounds in the basin.

Potential threats to drinking water quality are specifically identified in this report by the occurrence of pesticide compounds that are regulated for drinking water or suspected of endocrine disruption. Observed concentrations of pesticides at the drinking water intake, while uniformly low $(<0.1 \mu \mathrm{g} / \mathrm{L})$, include one regulated compound and four suspected endocrine disruptors, making the reduction of sources for these compounds a high priority for EWEB. These compounds were estimated to be either associated with exclusive urban (cypermethrin) or predominantly agricultural (atrazine and diazinon) land use, or both urban and agricultural applications (carbaryl). Furthermore, while little data exist to characterize agricultural pesticide runoff, a large proportion (40 percent) of compounds detected in agricultural streams is currently regulated by drinking water criteria. Similarly, a large number (50 percent) of compounds detected in urban runoff are known or suspected endocrine disrupting compounds. In contrast, fewer compounds detected in forestry streams are associated with either category ( $<30$ percent). Accordingly, while pesticide sources include all land use activities occurring in the basin, those compounds presenting the greatest recognized potential threat to drinking water quality in the McKenzie River are largely related to urban and agricultural pesticide applications.

\section{Implications for Monitoring}

A scientifically-based monitoring program is one with clear objectives and a sampling strategy that builds on current data to refine understanding and provide new insights. In terms of drinking water source protection, appropriate objectives are directly related to identifying and reducing perceived potential threats to drinking water quality. The data presented here, and the proposed conceptual model describing pesticide transport in the McKenzie River Basin, indicate that pesticide runoff occurs across the range of land use activities in the basin. Nonetheless, the majority of compounds that present a documented threat to drinking water quality, in terms of water-quality regulations or suspected endocrine disruption, are associated with agricultural and urban land use applications rather than forestry. These data suggest that agricultural and urban land use areas are the most important to target for future monitoring efforts, and eventually for developing management strategies to reduce pesticide runoff.

Conventional monitoring approaches for drinking water source protection are focused on identifying conditions that result in mobilization of contaminants, especially those with documented adverse health consequences. These programs are typically based on discrete samples that characterize storm runoff across a range of land use sources, similar to the approach taken in this reconnaissance study. In terms of identifying potential threats to drinking water quality, it is clearly important to quantify acute concentrations of toxic chemicals during peak periods of runoff and to identify possible sources for those chemicals. An important issue for further consideration, however, is that pesticides and other relatively hydrophobic chemicals may be present at very low concentrations (below the detection level for conventional analytical techniques), especially in compound mixtures with unknown synergistic effects. This is especially true for many of the compounds associated with urban and agricultural use in the basin. Since health-based criteria are based on longterm exposure, an important component of the potential threat from the most hydrophobic of these chemicals may be not be acute or short-term concentrations, which are not likely to be detected with discrete samples in any case. Passive sampling methods that sequester relatively insoluble compounds over a period of weeks may be more suitable for documenting the low-level presence of many of these compounds, and are increasingly being used for current use pesticides and other organic compounds of interest (Alvarez and others, 2008). Furthermore, utilization of the passive sampling approach provides an alternative perspective that expands the temporal scale of observation to incorporate more chronic conditions, thereby expanding our understanding of pesticide occurrence.

A separate concern relative to assessing threats to drinking water is that MCL criteria and human-health benchmarks that identify the potential for toxicity are defined for compounds in isolation, without accounting for exposure to compound mixtures. These criteria and guidelines do not represent the actual exposure risk of chemical mixtures that are typically observed in the stream environment. The use of metabolic assays that target specific biological responses to chemical mixtures provides a means to quantify specific toxic behavior resulting from the synergistic effect of multiple chemicals, some of which may not be measured or even detectable with conventional analysis (Routledge and Sumpter, 1996). 
In summary, there are several components to consider relative to monitoring a complex system like the McKenzie River: the elements of the system, which include the individual chemicals and their sources; the interconnections within the system, which can be conceived as the land use and climate factors that interact to mobilize and transport chemicals; and the function or behavior of the system, which includes the detrimental effect of chemical mixtures on human health. The conventional approach to water quality monitoring generally is to document the first two components, at least at the scale of discrete point-in-time conditions. An important next step in developing our understanding of pesticide occurrence is expanding the temporal scale of pesticide measurement beyond the specific conditions that occur during storm runoff to characterize more persistent exposure, especially for relatively hydrophobic and toxic chemicals that occur in very low concentrations in water (Alvarez and others, 2008). Furthermore, including some measure of system behavior in the form of synergistic effects of compound mixtures creates a more effective monitoring program capable of providing new understanding about existing threats to drinking water.

\section{References Cited}

Alsea Geospatial, Inc., Hardin-David, Inc., Pacific Wildlife Research, Inc., WaterWork Consulting, 2000, McKenzie River subbasin assessment:, Bonneville Power Administation and U.S. Forest Service, Summary Report, 64 p., accessed January 31, 2012, at http://www. mckenziewc.org/assessment.pdf.

Alvarez, D.A., Cranor, W.L., Perkins, S.D., Clark, R.C., and Smith, S.B., 2008: Chemical and toxicological assessment of organic contaminants in surface water using passive samplers: Journal of Environmental Quality, v. 37, p. 1,0241,033 .

Anderson, C.W., Rinella, F.A., and Rounds, S.A., 1996, Occurrence of selected trace elements and organic compounds and their relation to land use in the Willamette River Basin, Oregon, 1992-94: U.S. Geological Survey Water-Resources Investigations Report 96-4234, 68 p. (Also available at http://pubs.usgs.gov/wri/1996/4234/report.pdf.)

Anderson, C.W., Wood, T.M., and Morace, J.L., 1997, Distribution of dissolved pesticides and other water quality constituents in small streams, and their relation to land use, in the Willamette River Basin, Oregon, 1996: U.S. Geological Survey Water-Resources Investigations Report 97-4268, 87 p. (Also available at http://pubs.usgs. gov/wri/1997/4268/report.pdf.)
Anderson, C.W., 2007, Influence of Cougar Reservoir drawdown on sediment and DDT transport and deposition in the McKenzie River Basin, Oregon, water years 200204: U.S. Geological Survey Scientific Investigations Report 2007-5164, 42 p. (Also available at http://pubs.usgs. gov/sir/2007/5164/pdf/sir20075164.pdf)

Benbrook, C.M., 1996, Growing doubt-A primer on pesticides identified as endocrine disruptors and/ or reproductive toxicants: Washington D.C., National Campaign for Pesticide Policy Reform, 88 p.

Blair, S., 2000, Drinking water source protection planSource protection monitoring: Eugene Water and Electric Board, 32p.

Carpenter, K.D., Sobieszczyk, S., Arnesberg, A.J, and Rinella, F.A., 2008, Pesticide occurrence and distribution in the Lower Lackamas River basin, Oregon, 2000-05: U.S. Geological Survey Scientific Investigations Report 20085027. (Also available at http://pubs.usgs.gov/sir/2008/5027/ index.html.)

Childress, C.J.O., Foreman, W.R., Connor, B.F., and Maloney, T.J., 1999, New reporting procedures based on long-term method detection levels and some considerations for interpretations of water-quality data provided by the U.S. Geological Survey National Water Quality Laboratory: U.S. Geological Survey Open-File Report 99-193, 19 p., accessed January 31, 2012 at http://water.usgs.gov/owq/ OFR 99-193/index.html.

Colburn, T., Vom Sall, F.S., and Soto, A.M., 1993, Developmental effects of endocrine-disrupting chemicals in wildlife and humans: Environmental health perspectives, v. 101, p. 378-384.

Coupe, R.H., and Blomquist, J.D., 2004, Water-soluble pesticides in finished water of community water supplies: Journal of the American Water Works Association, v. 96, no. 10 , p. $56-68$.

Field, J.A., Reed, F.L., Sawyer, T.E., Griffith, S.M., and Wigington, J.J., Jr., 2003, Diuron occurrence and distribution in soil and surface and ground water associated with grass seed production: Journal of Environmental Quality, v. 32, p. 171-179.

Furlong, E.T., Anderson, B.D., Werner, S.L., Soliven, P.P., Coffey, L.J., and Burkhardt, M.R., 2001, Methods of analysis by the U.S. Geological Survey National Water Quality Laboratory_-Determination of pesticides in water by graphitized carbon-based solid-phase extraction and high-performance liquid chromatography/mass spectrometry: U.S. Geological Survey Water-Resources Investigations Report 01-4134, 73 p. (Also available at http://nwql.usgs.gov/Public/pubs/WRIR01-4134.pdf.) 
Furlong, E.T., Werner, S.L., Anderson, B.D., and Cahill, J.D., 2008, Determination of human-health pharmaceuticals in filtered water by chemically modified styrenedivinylbenzene resin-based solid-phase extraction and highperformance liquid chromatography/mass spectrometry: U.S. Geological Survey Techniques and Methods, book 5, sec. B, chap. 5, 56 p. (Also available at http://pubs.usgs. gov/tm/tm5b5/.)

Gilliom, R.J., Barbash, J.E., Crawford, C.G., Hamilton, P.A., Martin, J.D., N. Nakagaki, Nowell, L.H., Scott, J.C., Stackelberg, P.E., Thelin, G.P., and Wolock, D.M., 2006, The quality of our nation's waters-Pesticides in the Nation's streams and ground water, 1992-2001: U.S. Geological Survey Circular 1291, 172 p. (Also available at http://pubs.usgs.gov/circ/2005/1291/.)

Gustafson, D.I., 1989, Groundwater ubiquity score—A simple method for assessing pesticide leachability: Environmental Toxicology and Chemistry, v. 8, no. 4, p. 339-357.

Keith, L.H., 1997, Environmental endocrine disruptors-A handbook of property data: New York, Wiley Interscience, $1,232 \mathrm{p}$.

Homer, Collin, Huang, Chengquan, Yang, Limin, Wylie, Bruce, and Coan, Michael, 2004, Development of a 2001 national landcover database for the United States: Photogrammetric enginerring and remote sensing, p. 829840.

Larson, S.R., Capel, P.D., and Majewski, M.S., 1997, Pesticides in surface waters-distribution, trends, and governing factors: Chelsea, Mich., Ann Arbor Press, Pesticides in the hydrologic system, v. 3, 400 p.

Mackay, Donald, Shiu, W.Y., Ma, K.C., 1997, Illustrated handbook of physical-chemical properties and environmental fate for organic chemicals-Volume V: Pesticide chemicals. Lewis Publishers.

Meyer, M.T., Loftin, K.A., Lee, E.A., Hinshaw, G.H., Dietze, J.E., Scribner, E.A., 2009, Determination of Glyphosate, its degradation product aminomethylphosphonic acid, and glufosinate in water by isotope dilution and online solidphase extraction and liquid chromatography/tandem mass spectrometry: U.S. Geological Survey Techniques and Methods, book 5, chap. A10, 32 p. (Also available at http:// pubs.usgs.gov/tm/tm5a10/.)

Morgenstern, K.A., 2006, Nonpoint source pollution assessment and evaluation results for the McKenzie River Watershed, Oregon: Eugene Water \& Electric Board, 191 p.
Munday, Cathy, and Domagalski, J.L., 2003, Qualitycontrol results for ground-water and surface-water data, Sacramento River Basin, California, National Water-Quality Assessment, 1996-1998: U.S. Geological Survey WaterResources Investigations Report 02-4201, 45 p. (Also available at http://pubs.usgs.gov/wri/wrir024201/.)

Neary, D.G., Bush, P.B., and Michael, J.L., 1993, Fate, dissipation and environmental effects of pesticides in southern forests - a review of a decade of research progress: Environmental Toxicology and Chemistry, v. 12, p. 411-428.

Oregon Department of Agriculture, 2001, Guidelines for pesticide emergency exemptions: Oregon Department of Agriculture, 19 p., accessed January 31, 2012, at http:// www.oregon.gov/ODA/PEST/docs/pdf/sec18gui.pdf.

Oregon Department of Agriculture, 2008, 2007 Annual Report: Pesticide Use Reporting System, accessed July 2010, http:// www.oregon.gov/ODA/PEST/purs index.shtml.

Oregon Department of Agriculture, 2009, 2008 Annual Report: Pesticide Use Reporting System, accessed May 15, 2010 at http://www.oregon.gov/ODA/PEST/purs index. shtml.

Pesitice Action Network, 2012, Pesticide Database: Pesticide Action Network, accessed February 3, 2012 at http://www. pesticideinfo.org.

Rinella, F.A. and Janet, M.L., 1997, Seasonal and spatial variability of nutrients and pesticides in streams of the Willamette Basin, Oregon, 1993-95: U.S. Geological Survey Water-Resources Investigations Report 97-4082-C, 59 p. (Also available at http://or.water.usgs.gov/pubs dir/ Pdf/97-4082c.pdf.)

Risley, John, Wallick, J.R., Waite, Ian, and Stonewall, A., 2010, Development of an environmental flow framework for the McKenzie River Basin, Oregon: U.S. Geological Survey Scientific Investigations Report 2010-5016, 94 p. (Also available at http://pubs.usgs.gov/sir/2010/5016/.)

Routledge, E.J., and Sumpter, J.P., 1996, Estrogenic activity of surfactants and some of the their degradation products assessed using a recombinant yeast screen: Environmental Toxicology and Chemistry, v. 15, no. 3, p. 241-248.

Rupp, D.E., R.E. Peachey, K.L. Warren, and Selker, J.S., 2006, Diuron in surface runoff and tile drainage from two grass-seed fields: Journal of Environmental Quality, v. 35, p. 303-311. 
Sandstrom, M.W., Stroppel, M.E., Foreman, W.T., and Schroeder, M.P., 2001, Methods of analysis by the U.S. Geological Survey National Water Quality LaboratoryDetermination of moderate-use pesticides and selected degradates in water by C-18 solid-phase extraction and gas chromatography/mass spectrometry: U.S. Geological Survey Water-Resources Investigations Report 01-4098, 70 p. (Also available at http://nwql.usgs.gov/Public/pubs/ WRIR/WRIR-01-4098.pdf.)

Sherrod, D.R. and Smith, J. G., 2000, Geologic map of upper Eocene to Holocene volcanic and related rocks of the Cascade Range, Oregon: U.S. Geological Survey Geologic Investigations Series Map I-2569, 2 sheets, scale 1:500,000. (Also available at http://pubs.usgs.gov/imap/i-2569/.)

Stackelberg, P.E., Furlong, E.T., Meyer, M.T., Zaugg, S.D., Henderson, A.K., and Reissman, D.B., 2004, Persistence of pharmaceutical compounds and other organic wastewater contaminants in a conventional drinking-water treatment plant: Science of the Total Environment, v. 329, no. 1-3, p. 99-113.

Tague, Christina, and Grant, G.E., 2004, A geological framework for interpreting the low flow regimes of Cascade streams, Willamette River basin, Oregon: Water Resources Research, v. 40, W04303, 9 p., DOI:10D1029/2003WR002629, accessed January 31, 2012 at http://www.agu.org/pubs/crossref/2004/2003WR002629. $\underline{\text { shtml. }}$

Toccalino, P. L., 2007, Development and application of healthbased screening levels for use in water-quality assessments: U.S. Geological Survey Water-Resources Investigations Report 2007-5106, 12 p. (Also available at http://pubs.usgs. gov/sir/2007/5106/index.html.)

Toccalino, P.L., Nowell, L.H., Wilber, W.G., Zogorski, J.S., Donohue, J.M., Eiden, C.A., Krietzman, S.J., and Post, G.B., 2003, Development of health-based screening levels for use in state- or local-scale water-quality assessments: U.S. Geological Survey Water-Resources Investigations Report 03-4054, 22 p. (Also available at http://pubs.usgs. gov/wri/wri034054/.)
Turnipseed, D.P., and Sauer, V.B., 2010, Discharge measurements at gaging stations: U.S. Geological Survey Techniques and Methods book 3, chap. A8, 87 p. (Also available at http://pubs.usgs.gov/tm/tm3-a8/.)

U.S. Geological Survey, variously dated, National field manual for the collection of water-quality data: U.S. Geological Survey Techniques of Water-Resources Investigations, book 9, chaps. A1-A9, (Also available at http://pubs.water. usgs.gov/twri9A.)

Vogue, P.A., Kerle, E.A., and Jenkins, J.J., 1994, OSU Extension pesticide properties database: National Pesticide Information Center, accessed January 31, 2012, at http:// npic.orst.edu/ingred/ppdmove.htm.

Waite, Ian, Sobieswzczyk, Stephen, Carpenter, K.D., Arnsberg, A.J., Johnson, H. M., Hughwes, C.A., Sarantou, M.J., and Rinella, F.A., 2006, Effects of urbanization on stream ecosystems in the Willamette River Basin and surrounding area, Oregon and Washington: U.S. Geological Survey Scientific Investigations Report 2006-5101-D, 62 p. (Also available at http://pubs.usgs.gov/sir/2006/5101-D/.)

Werner, S.L., Burkhardt, M.R., and DeRusseau, S.N., 1996, Methods of analysis by the U.S. Geological Survey National Water Quality Laboratory—Determination of pesticides in water by Carbopak-B solid-phase extraction and highperformance liquid chromatography: U.S. Geological Survey Open-File Report 96-216, 42 p.

Western Regional Climate Center, 2010, Western U.S. Climate Historical Summaries: Western Regional Climate Center, National Climatic Data Center 1961-1990 Normals, accessed 5-27-2010 at http://www.wrcc.dri.edu/Climsum. $\underline{\mathrm{html}}$.

World Health Organization, 2004, Guidelines for drinkingwater quality (3d ed.): Geneva, World Health Organization, World Health Organization Drinking-water Quality Series, $494 \mathrm{p}$.

Wood, T.M., 2001, Herbicide use in the management of roadside vegetation, western Oregon, 1999-2000_Effects on the water quality of nearby streams: U.S. Geological Survey Water-resources Investigations Report 01-4065, 27 p. (Also available at http://or.water.usgs.gov/pubs/ Abstracts/01-4065.html.) 


\section{Appendix A. Description of Pesticide Compounds Analyzed}

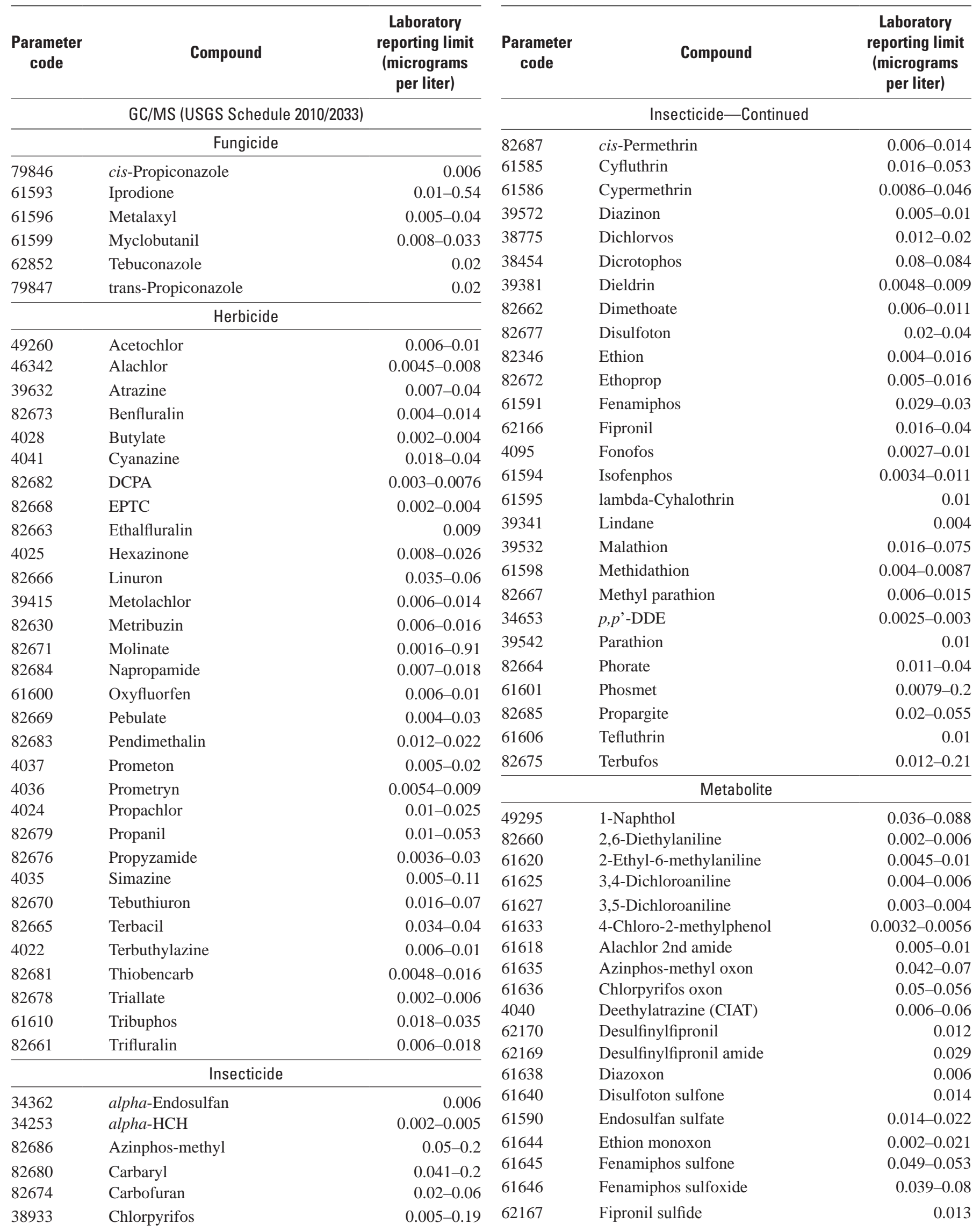




\section{Appendix A. Description of Pesticide Compounds Analyzed-Continued}

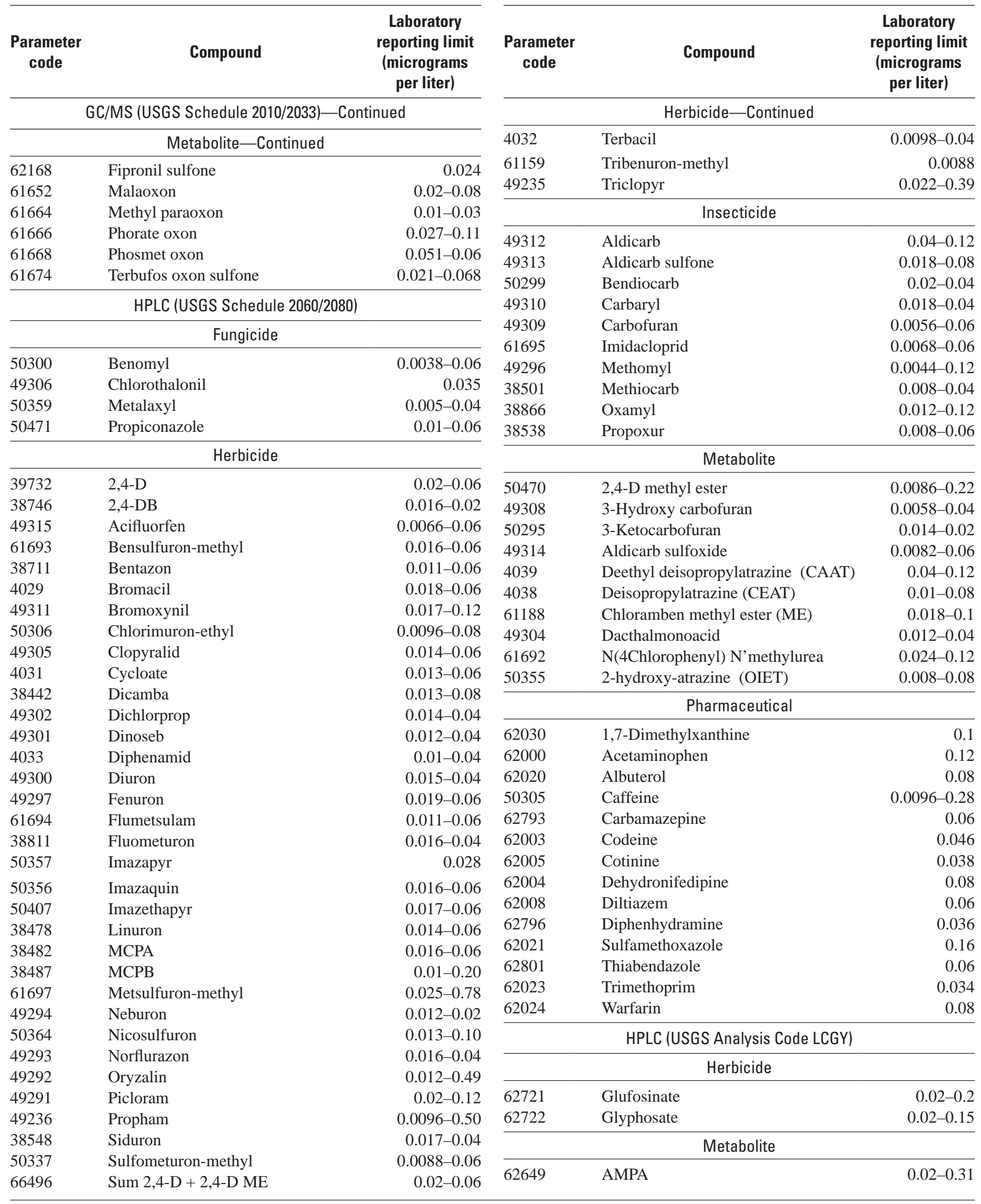




\section{Appendix B. Quality Assurance Results}
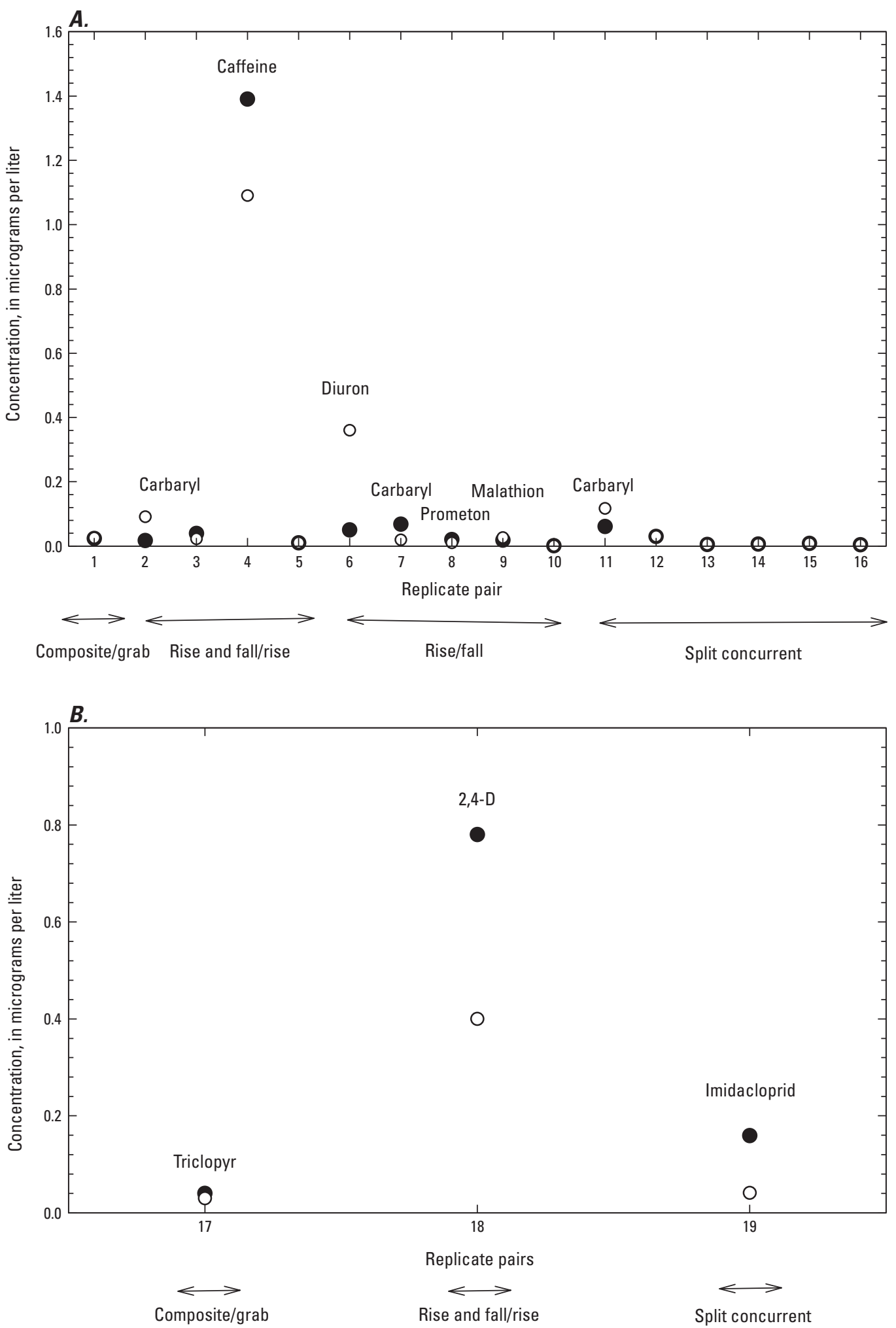

Figure B1. Concentration data for replicate pairs. $(A)$ Where both values are E-coded; $(B)$ where one value is $\mathrm{E}$-coded and the other is unqualified; $(C)$ where both values are unqualified (compounds identified where RPD > 10) [RPD = relative percent difference; see text for further information] 


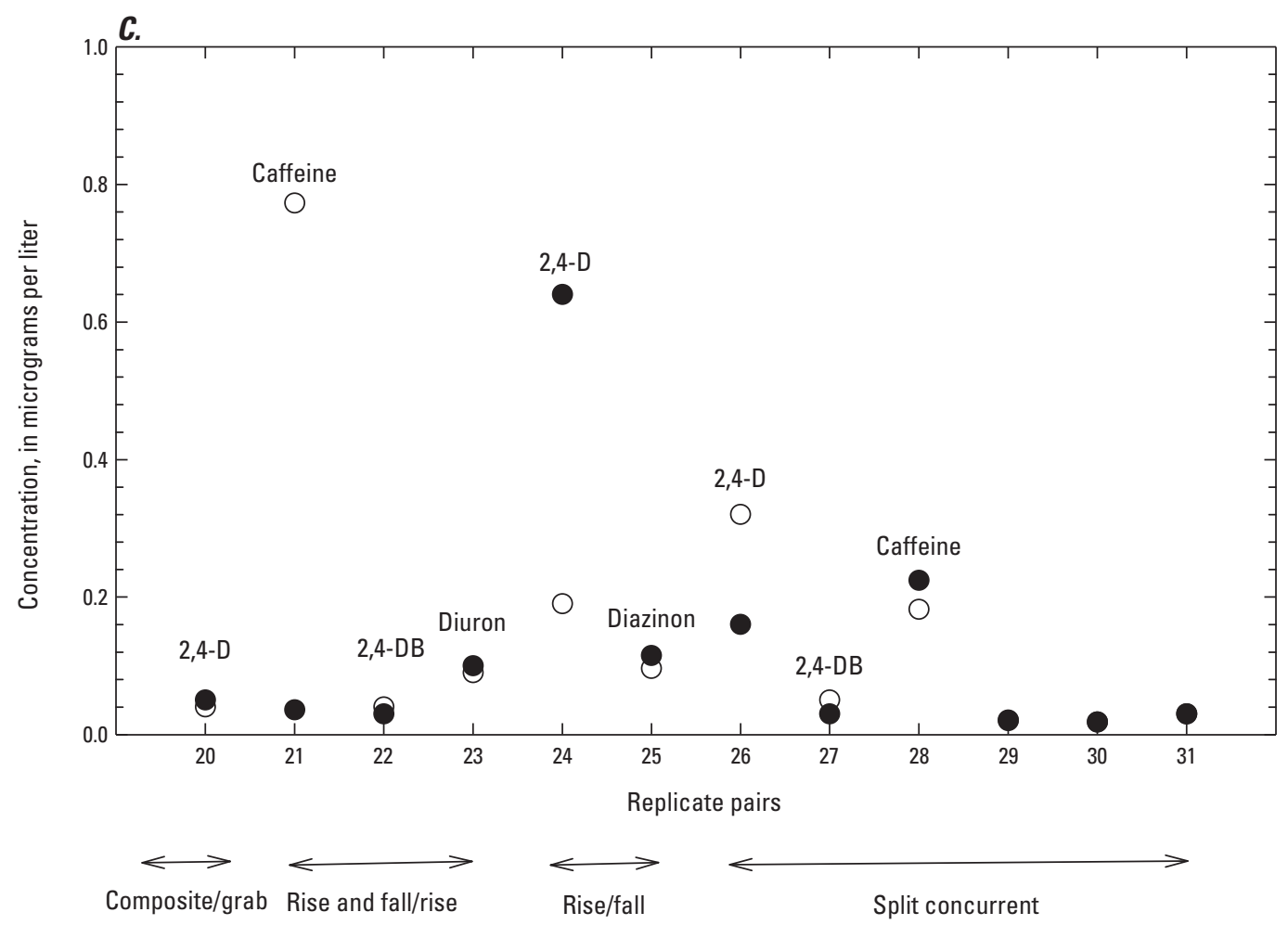

Figure B1.-Continued 


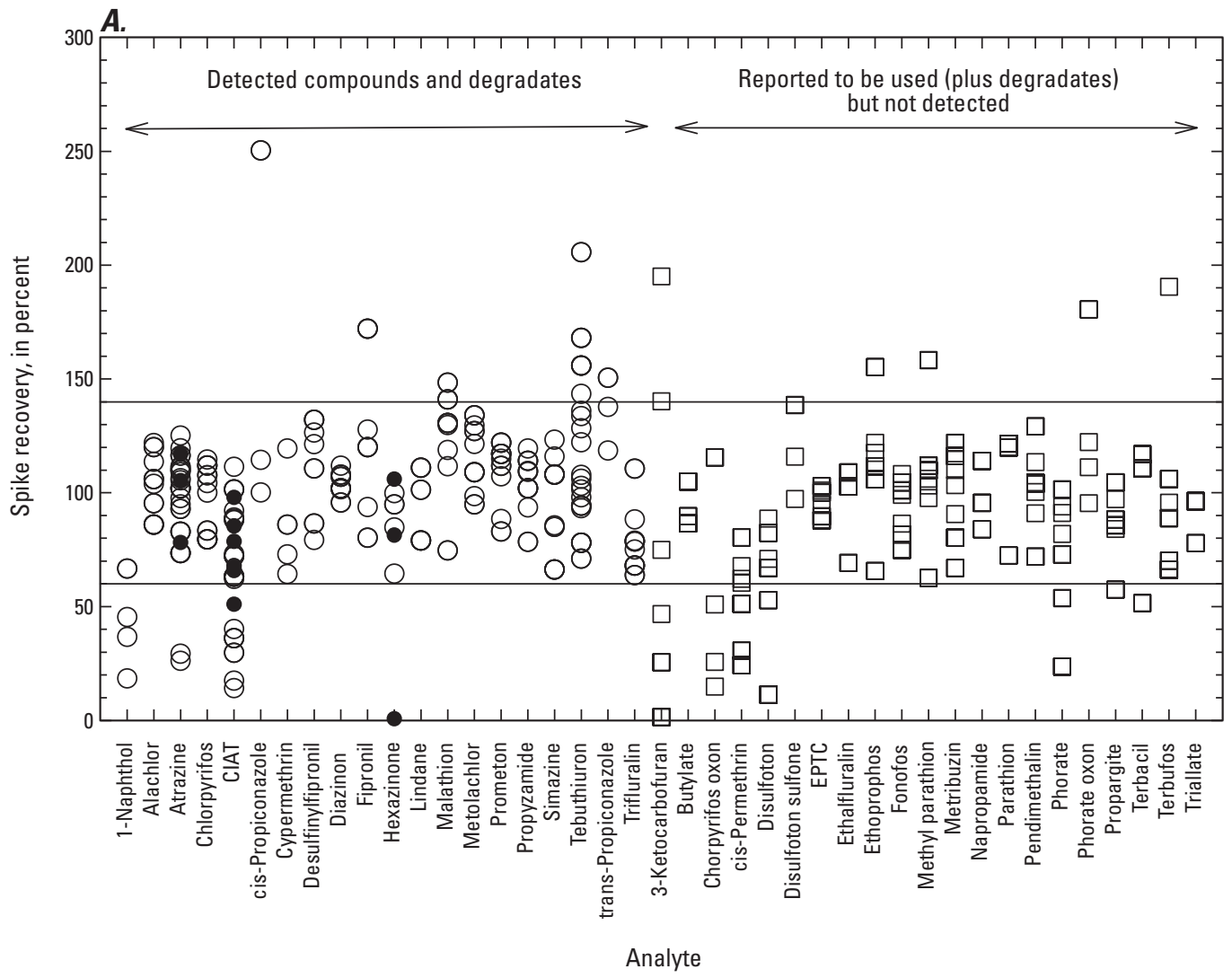

EXPLANATION

Detected compounds, reagent spikes

- Detected compounds, matrix spikes

$\square \quad$ Reported used, not detected, reagent spikes

Figure B2. Spike recoveries $(A)$ for compounds analyzed by GC/MS; $(B)$ for compounds analyzed by HPLC. 


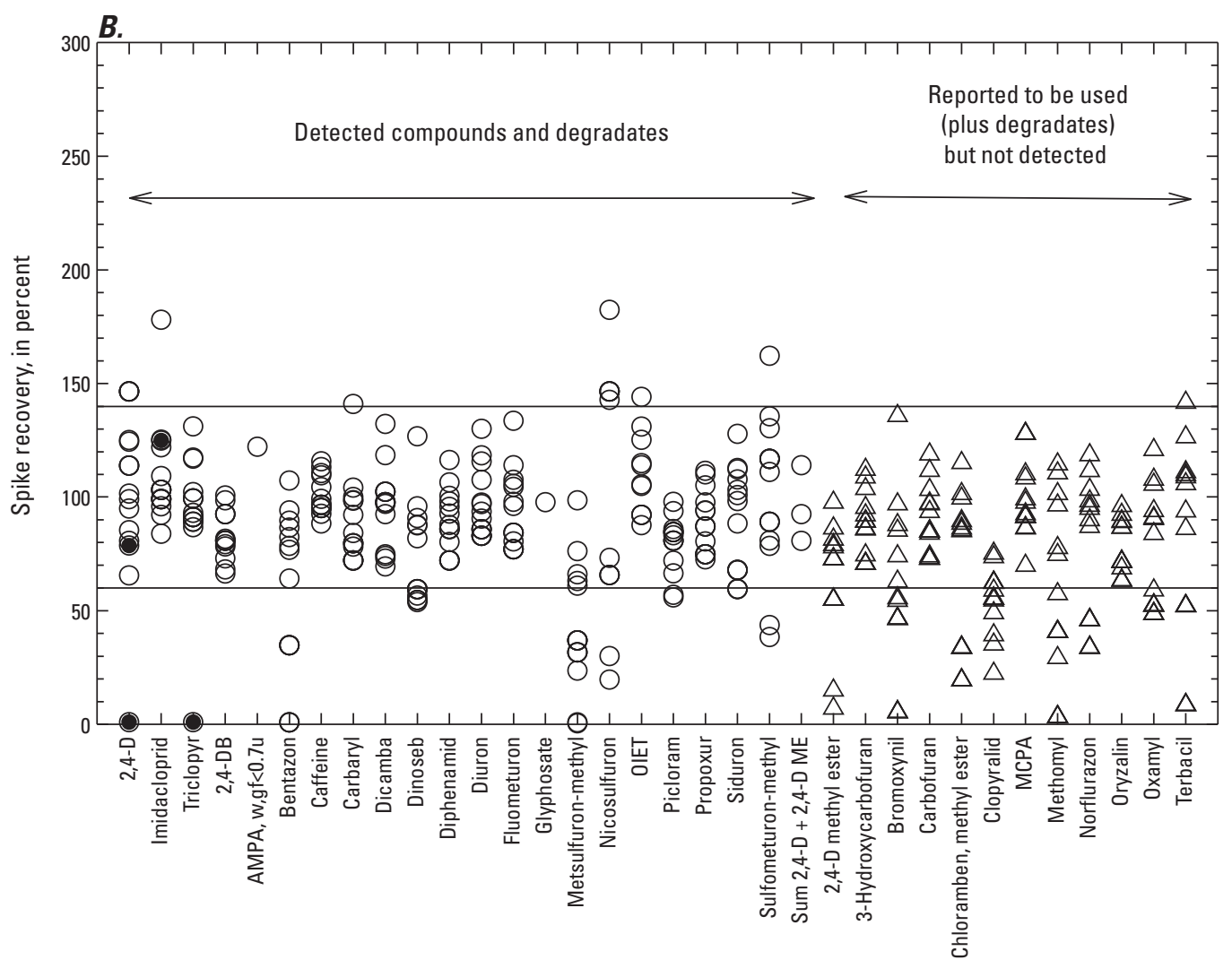

Analyte

EXPLANATION

Detected compounds, reagent spikes

- Reported used, not detected, reagent spikes

$\triangle$ Reported used, not detected, reagent spikes

Figure B2.-Continued 


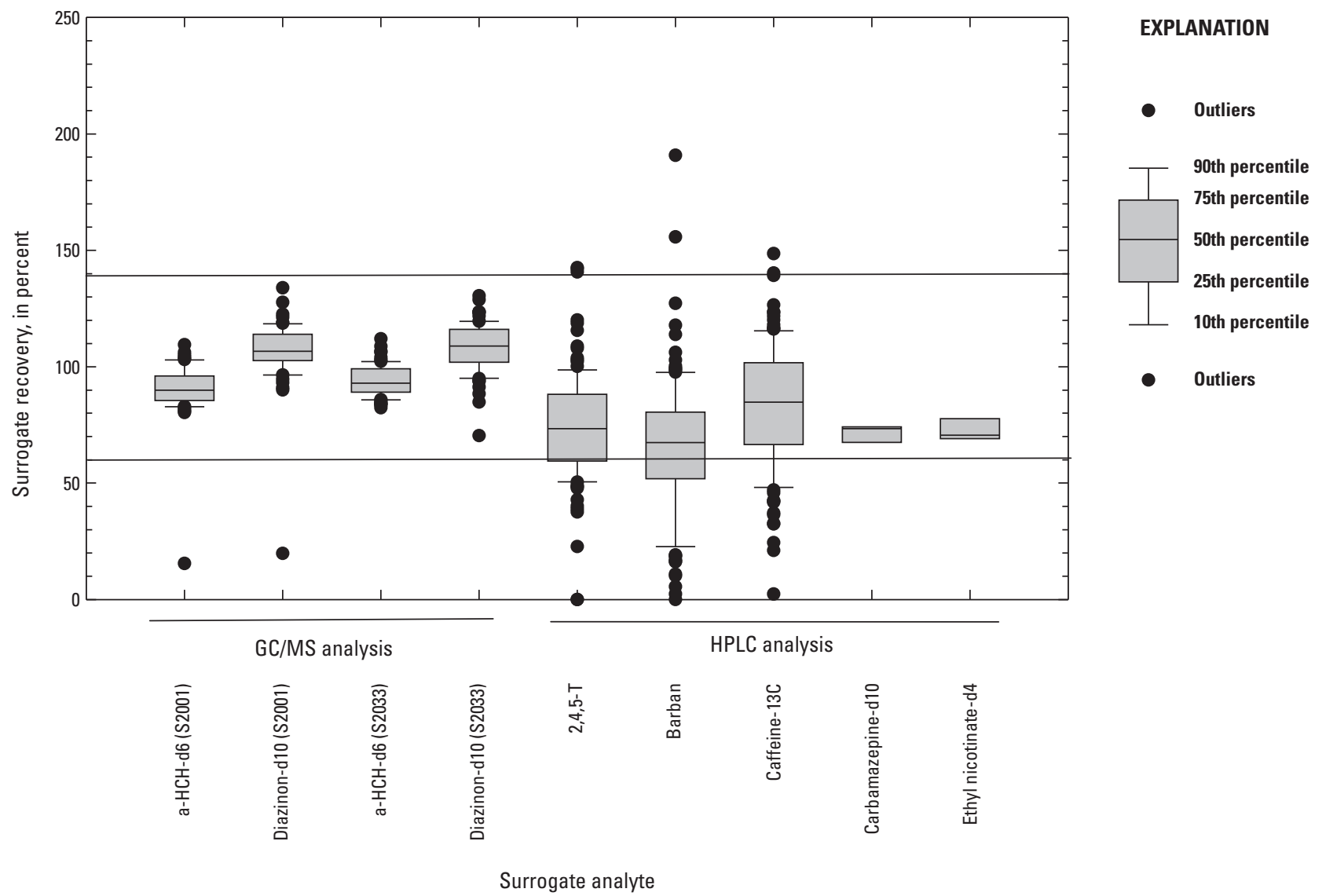

Figure B3. Surrogate recoveries. 


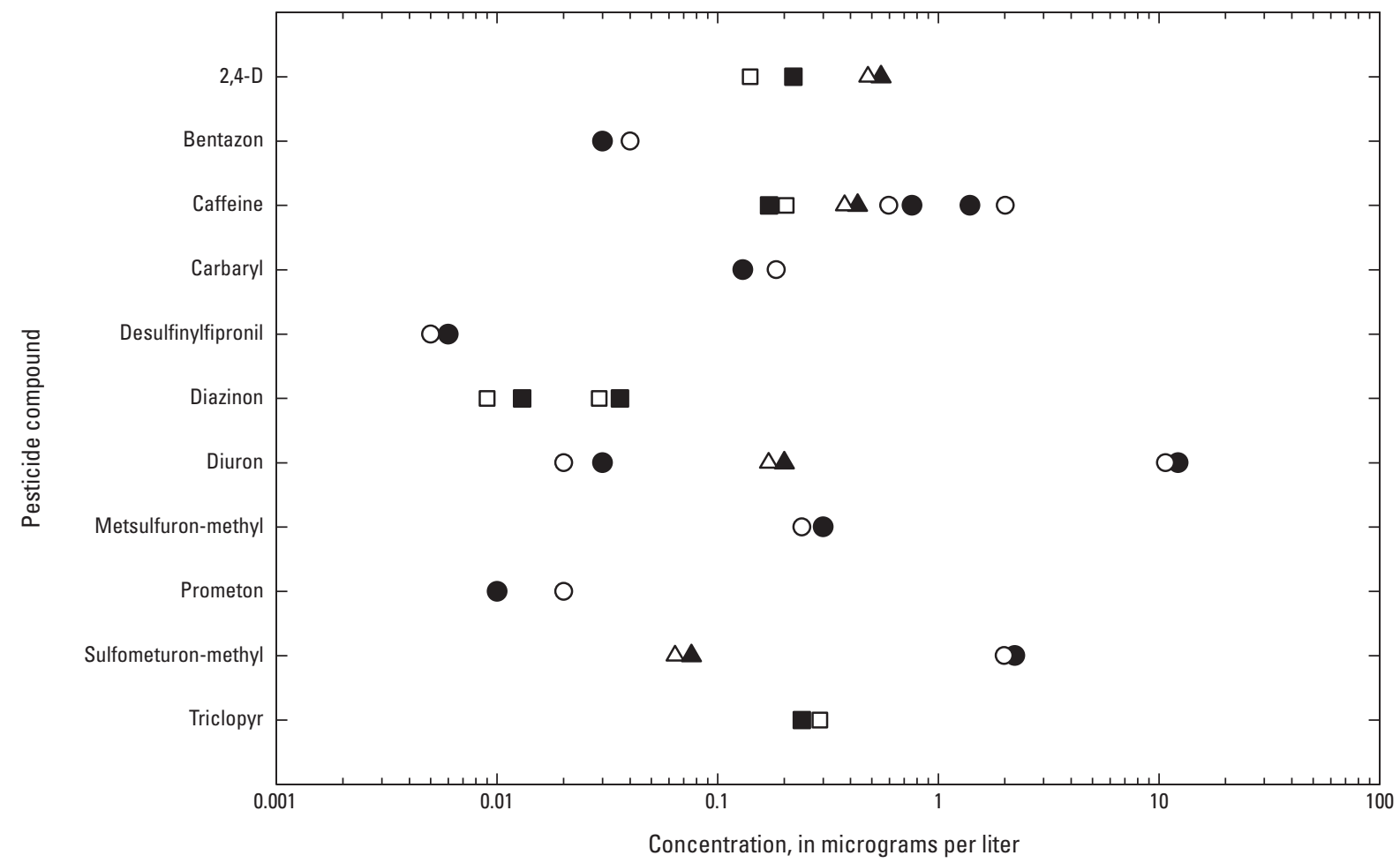

EXPLANATION

Direct sample where both values E-coded

- Direct sample where one value E-coded and the 0

Direct sample where both values unqualified

Tubing sample where both values E-coded

$\Delta \quad$ Tubing sample where one value E-coded and other

$\square \quad$ Tubing sample where both values unqualified

Figure B4. Results from special QA study to evaluate effect of plastic tubing, where RPD $>10$ and both values quantified. [RPD = relative percent difference; see text for further informati 
Publishing support provided by the U.S. Geological Survey

Publishing Network, Tacoma Publishing Service Center

For more information concerning the research in this report, contact the Director, Oregon Water Science Center

U.S. Geological Survey

2130 SW 5th Avenue

Portland, Oregon 97201

http://or.water.usgs.gov 
产

D

ㅎ․․

\% 